UNIVERSIDADE DE SÃO PAULO

ESCOLA DE ENFERMAGEM

GIOVANNA MARIAH ORLANDI

MEDIDAS DE APOIO AO TRATAMENTO DA TUBERCULOSE:

PERCEPÇÃO DE PROFISSIONAIS DE SAÚDE DA ATENÇÃO

BÁSICA DO MUNICÍPIO DE SÃO PAULO

São Paulo

2015 
GIOVANNA MARIAH ORLANDI

\title{
MEDIDAS DE APOIO AO TRATAMENTO DA TUBERCULOSE: PERCEPÇÃO DE PROFISSIONAIS DE SAÚDE DA ATENÇÃO BÁSICA DO MUNICÍPIO DE SÃO PAULO
}

\author{
Dissertação apresentada ao Programa de \\ Pós-Graduação em Enfermagem da \\ Escola de Enfermagem da Universidade \\ de São Paulo para obtenção do título de \\ Mestra em Ciências
}

Área de concentração: Cuidado em Saúde

Orientadora: Prof. ${ }^{a}$ Dr. ${ }^{a}$ Maria Rita Bertolozzi 
AUTORIZO A REPRODUÇÃO E DIVULGAÇÃO TOTAL OU PARCIAL DESTE TRABALHO, POR QUALQUER MEIO CONVENCIONAL OU ELETRÔNICO, PARA FINS DE ESTUDO E PESQUISA, DESDE QUE CITADA A FONTE.

Assinatura:

Data:

\section{Catalogação na Publicação (CIP)}

Biblioteca "Wanda de Aguiar Horta"

Escola de Enfermagem da Universidade de São Paulo

Orlandi, Giovanna Mariah

Medidas de apoio ao tratamento da tuberculose: percepção de profissionais de saúde da Atenção Básica do município de São Paulo / Giovanna Mariah Orlandi. São Paulo, 2015.

$130 \mathrm{p}$.

Dissertação (Mestrado) - Escola de Enfermagem da Universidade de São Paulo.

Orientadora: Prof. ${ }^{a}$ Dr. ${ }^{a}$ Maria Rita Bertolozzi

Área de concentração: Cuidados em Saúde

1. Tuberculose. 2. Adesão à medicação. 3. Política social. 4. Enfermagem. I. Título. 
Nome: $\quad$ Giovanna Mariah Orlandi

Titulo: Medidas de apoio ao tratamento da tuberculose: percepção de profissionais de saúde da Atenção Básica do município de São Paulo

Dissertação apresentada ao Programa de Pós-Graduação em Enfermagem da Escola de Enfermagem da Universidade de São Paulo para obtenção do título de Mestra em Ciências.

Aprovado em:

\section{BANCA EXAMINADORA}

Prof. Dr.

Instituição:

Julgamento:

Assinatura:

Prof. Dr.

Instituição:

Julgamento:

Assinatura:

Prof. Dr.

Instituição:

Julgamento:

Assinatura:

Prof. Dr.

Instituição:

Julgamento:

Assinatura:

Prof. Dr.

Instituição:

Julgamento:

Assinatura: 


\section{AGRADECIMENTOS}

A caminhada em busca do conhecimento não é fácil e, tampouco, breve. Minha jornada a esta busca não está finalizada e, possivelmente, nunca estará, pois sempre estarei em busca de novos conhecimentos. Neste pequeno trajeto percorrido foram muitas as pessoas que me acompanharam, guiaram e contribuíram para realização deste trabalho. Deixo, portanto, meus agradecimentos a todas estas pessoas que acompanharam meu crescimento em meio a esta caminhada.

À Deus, que me abençoou em todos os caminhos que percorri e que me deu forças quando pensei que não as teria mais.

A minha querida orientadora, Prof. ${ }^{a}$ Dr. ${ }^{a}$ Maria Rita Bertolozzi, que me acolheu $e$ acreditou em meu potencial, pelo carinho, apoio, confiança e todo conhecimento compartilhado. Sua participação foi fundamental para a realização deste trabalho. Não posso deixar de mencionar que sua trajetória profissional, humildade e competência são inspiradoras!

Aos meus avós, Aymar, Dovoani e Sônia, pelo amor incondicional e palavras de conforto e carinho.

À minha prima Ana, seu marido Mark e filho John, por me acolherem em sua casa no início desta jornada.

Ao meu amado Hugo pelo apoio e compreensão deste momento em minha vida.

A todos os meus familiares pelo carinho e compreensão.

Aos membros do grupo de pesquisa GPTB, pelo conhecimento compartilhado e, em especial, Érica, Mariana, Rosângela e Kuitéria, pelo carinho, amizade e por toda ajuda provida.

Aos membros do grupo de pesquisa "Vulnerabilidade, adesão e necessidades em saúde coletiva" pelos momentos de discussão e reflexão.

Às professoras Dr. ${ }^{a}$ Renata Ferreira Takahashi e Dr. Tânia Maria Ribeiro Monteiro de Figueiredo pelas valiosas contribuições no Exame de Qualificação. 
Á Dr. ${ }^{a}$ Paula Hino pelo carinho e pelas contribuições a este trabalho.

A todos os meus colegas da pós-graduação por deixarem mais agradáveis os dias de estudos intensos.

À Ana Lúcia, Camilla, Linara, Luciane, Mariana, Jéssica, Jaqueline e Rafaela, pela valiosa amizade de longa data e apoio nos momentos difíceis.

À Aline, Karen e Letícia pela amizade, presença e carinho.

Às funcionárias do Departamento de Enfermagem em Saúde Coletiva, Maria do Socorro, Valéria, Terezinha e Evelyn, pelo carinho e prontidão.

Às especialistas, Karen, Eloá e Vânia, por todo carinho e conhecimento compartilhado durante o estágio no Programa de Aperfeiçoamento de Ensino (PAE) e em outros momentos no decorrer do Mestrado.

Aos funcionários da biblioteca Wanda de Aguiar Horta, pela competência e prontidão.

Aos funcionários da Secretaria de Pós-Graduação pelas orientações, prontidão e competência.

À enfermeira Amanda pela ajuda na coleta de dados.

Ao estatístico Bernardo pela prontidão e competência.

À Sr. ${ }^{a}$ Rejane Calixto Gonçalves, Coordenadora da Atenção Básica do Município de São Paulo, e ao $\mathrm{Sr}^{\circ}{ }^{\circ}$ Edson pelas orientações, autorização e viabilização deste trabalho.

Aos supervisores das Supervisões Técnicas de Saúde Campo Limpo, Butantã e Penha pela autorização.

Aos gerentes e profissionais das unidades básicas de saúde que constituíram o local deste estudo pela contribuição e colaboração.

Aos profissionais da Coordenação de Vigilância em Saúde e aos profissionais do Programa Municipal de Controle da Tuberculose pela colaboração e, em especial, à Sr. ${ }^{a}$ Sumie Matai de Figueiredo, pelos esclarecimentos sobre o banco de dados no TBWEB. 
Às minhas professoras da graduação Sílvia, Cláudia e Lurdinha, por me auxiliarem nos primeiros passos do caminho à pesquisa científica e, em especial, ao tema tuberculose. Às minhas também professoras da graduação Marilene, Rose e Gislaine, pelos conselhos, carinho e contribuição à minha paixão pela Saúde Coletiva.

À enfermeira Aurides, pela inspiração.

Ao Conselho Nacional de Desenvolvimento Científico e Tecnológico (CNPq) pelo suporte financeiro deste trabalho (Processo no 134346/2014-9).

Meus sinceros agradecimentos a todos vocês! 
“O que vale na vida não é o ponto de partida e sim a caminhada. Caminhando e semeando, no fim terás o que colher". 
Orlandi GM. Medidas de apoio ao tratamento da tuberculose: percepção de profissionais de saúde da Atenção Básica do município de São Paulo [dissertação]. São Paulo: Escola de Enfermagem, Universidade de São Paulo; 2015.

\section{RESUMO}

Introdução: Um dos aspectos primordiais para o controle da tuberculose é a adesão ao tratamento. Tendo em vista as condições precárias de vida que os doentes em geral apresentam, incentivos relacionados ao suporte social e destinados ao alcance da cura têm sido recomendados e instituídos por órgãos governamentais. Neste sentido, este estudo teve o objetivo de analisar como profissionais de saúde da atenção básica percebem a influência de tais medidas na adesão ao tratamento da tuberculose em algumas Coordenadorias de Saúde do Município de São Paulo. Materiais e Métodos: Estudo exploratório e descritivo, com corte transversal e de abordagem qualiquantitativa. Amostra representativa de enfermeiros e médicos da Atenção Primária à Saúde de três Supervisões de Vigilância em Saúde do Município de São Paulo foi entrevistada, por meio de questionário semiestruturado, no período de maio a julho de 2015. O referencial teórico do estudo está posto na concepção da Determinação Social do Processo Saúde-Doença e em um dado conceito de adesão. Os dados quantitativos foram armazenados em banco de dados e os qualitativos (depoimentos dos profissionais) foram submetidos à técnica de análise de discurso. Os procedimentos éticos foram resguardados. Resultados: Entrevistou-se 86 profissionais, 60,5\% enfermeiros e o restante eram médicos. A maior parcela $(88,4 \%)$ afirmou conhecer as políticas de saúde municipais voltadas à para TB; 91,8\% sabiam sobre a oferta de incentivos pelo Município; 90,7\% referiram que o Tratamento Diretamente Observado contribui para a adesão ao tratamento; 65,1\% apontaram não ter participado de capacitação sobre a doença; e apenas $39,5 \%$ souberam informar sobre indicadores relacionados à TB. Identificou-se, nos depoimentos, que incentivos como cesta básica e vale-transporte são muito relevantes para a cura do paciente quando associados ao vínculo com a equipe, principalmente porque os pacientes geralmente apresentam difíceis condições de vida. Porém, os incentivos não influenciam a adesão no caso de usuários de drogas ilícitas ou álcool, moradores de rua, pacientes com maior poder aquisitivo e aqueles que deixam de cuidar da própria saúde. Conclusão: Os incentivos constituem medida que ajuda na adesão ao tratamento da TB, principalmente quando associados ao vínculo entre a equipe de saúde e os pacientes. Considera-se que tais incentivos contribuem para o enfrentamento do tratamento, podem ser utilizados como estratégia paliativa, mas as intervenções dos profissionais de saúde e dos gestores devem ser orientadas a transformar a situação da TB, o que significa apoiar os processos que ajudem a mudar as condições de vida dos pacientes.

Palavras-Chave: Tuberculose. Adesão à medicação. Política social. Enfermagem. 
Orlandi GM. Support measures for tuberculosis treatment: perceptions of Primary Health Care workers in Sao Paulo city [dissertation]. São Paulo: Escola de Enfermagem, Universidade de São Paulo; 2015.

\begin{abstract}
Introduction: One of the main aspects for the tuberculosis control is the adherence to the treatment. Usually TB patients come from a poor living conditions background and in general, incentives related to the social support to achieve the cure have been recommended and instituted by government agencies. Thus, this study aimed to analyze how primary health care professionals perceive the influence of such measures on adherence to the tuberculosis treatment in some of the Health Coordinations in São Paulo City. Materials and Methods: This is an exploratory and descriptive study, cross-sectional and quali-quantitative approach. Representative sample of nurses and physicians of Primary Health Care from three Surveillance Health Division of São Paulo city were interviewed through semi-structured questionnaire from May to July 2015. The Social Determination of the Health-Disease Process and an adherence concept were used as a theoretical framework. Quantitative data were filed in the database and qualitative (professionals speeches) were submitted to a discourse analysis technique. Ethical procedures were respected. Results: We interviewed 86 professionals, $60.5 \%$ nurses and the others were physicians. The majority $(88.4 \%)$ knew about the municipal health policies for TB; $91.8 \%$ about the provision of incentives by the municipality; $90.7 \%$ reported that the Directly Observed Treatment contributes to the treatment adherence; $65.1 \%$ indicated not having participated in training about the disease; and only $39.5 \%$ were able to report on TB-related indicators. From the speeches it was identified that incentives such as food package and transportation are very relevant to the patient's healing when combined with the bond to the team, especially because patients usually have difficult living conditions. However, the incentives do not influence the adherence in the case of users of illicit drugs or alcohol, the homeless, patients with higher purchasing power and those who fail to take care of their own health. Conclusion: The incentives contribute to the TB treatment adherence, especially when associated with the link between health staff and patients. Those incentives help to face treatment, they can be used as a palliative strategy, but the interventions of health professionals and managers should be instructed to transform TB situation, what means to give support to the processes to change the patients life conditions.
\end{abstract}

KEYWORDS: $\quad$ Tuberculosis. Medication Adherence. Public Policy. Nursing. 


\section{LISTA DE FIGURAS}

Figura 1 - Coordenadorias Regionais de Saúde do Município de São Paulo. 2015 .

Figura 2 - $\quad$ Associação entre a taxa de cura da tuberculose e a aquisição de cestas básicas pelo Município. São Paulo-SP, 2015.

\section{LISTA DE GRÁFICOS}

Gráfico 1 - Taxa de incidência da tuberculose por Supervisão Técnica de Vigilância em Saúde. São Paulo, 2015.

Gráfico 2 - $\quad$ Taxa de cura e abandono de casos novos de tuberculose por

Supervisão de Vigilância em Saúde de residência. São Paulo, 2015.

Gráfico 3 - Taxa de cura de casos novos de tuberculose por ano de início de tratamento da doença. São Paulo, 2015. 63

\section{LISTA DE QUADROS}

Quadro 1 - Significados que emergiram da análise dos depoimentos dos profissionais de saúde. São Paulo, 2015. 


\section{LISTA DE TABELAS}

Tabela 1 - Características pessoais dos sujeitos. São Paulo, 2015

Tabela 2 - $\quad$ Distribuição dos sujeitos segundo Supervisão Técnica de Saúde (STS) e modalidade de Unidade. São Paulo, 2015.

Tabela 3 - $\quad$ Distribuição dos sujeitos em relação ao conhecimento sobre financiamento para o controle da tuberculose. São Paulo, 2015.

Tabela 4 - Distribuição dos sujeitos segundo conhecimento sobre os incentivos para a tuberculose sua regularidade. São Paulo, 2015.

Tabela 5 - Distribuição dos sujeitos do estudo segundo conhecimento sobre os incentivos ofertados pelo Município. São Paulo, 2015.

Tabela 6 - $\quad$ Distribuição dos sujeitos segundo frequência semanal do Tratamento Diretamente Observado e categoria profissional que realiza a supervisão. São Paulo, 2015.

Tabela 7 - Distribuição dos sujeitos segundo menção ao período de tempo para recebimento do resultado de exames para diagnóstico da tuberculose.

São Paulo, 2015 48

Tabela 8 - $\quad$ Cestas básicas e vales-transportes adquiridos pelo Município. São Paulo, 2015. 64 


\section{LISTA DE SIGLAS}

ACS - Agente Comunitário de Saúde

AMA - Unidade de Assistência Médica Ambulatorial

BPC ～- Benefício de Prestação Continuada

BVJ - Benefício Variável Vinculado ao Jovem

BVS - Biblioteca Virtual em Saúde

CadÚnico - Cadastro Único

CF $\quad-\quad$ Constituição Federal

COVISA - Coordenação de Vigilância em Saúde

CRS - Coordenadoria Regional de Saúde

DOTS - Tratamento Diretamente Observado de Curta Duração

EEUSP - Escola de Enfermagem da Universidade de São Paulo

FNS - $\quad$ Fundo Nacional de Saúde

HIV - Vírus da Imunodeficiência Humana

IBGE - Instituto Brasileiro de Geografia e Estatística

ILTB - Infecção Latente da Tuberculose

INSS - - Instituto Nacional do Seguro Social

LOAS ～- Lei Orgânica da Assistência Social

MDM - Metas de Desenvolvimento do Milênio

MDR - Multidrogarresistente

MDS - Ministério do Desenvolvimento Social e Combate à Fome

MSP ～- Município de São Paulo

ODS - - Objetivos de Desenvolvimento Sustentável

OMS ～- Organização Mundial da Saúde

PBF $\quad$ - Programa Bolsa Família

PCT - Programa de Controle da Tuberculose

PNAS - Programa Nacional de Assistência Social 
PNCT - Programa Nacional de Controle da Tuberculose

PNUD - Programa das Nações Unidas para o Desenvolvimento

PPD - Derivado Proteico Purificado

PTRC - Programa de Transferência de Renda Condicionada

SINAN - Sistema de Informação de Agravos de Notificação

STS - - Supervisão Técnica de Saúde

SUS - - Sistema Único de Saúde

SUVIS - Supervisão de Vigilância em Saúde

TB - $\quad$ Tuberculose

TBWEB - Sistema de Notificação e Acompanhamento dos Casos de Tuberculose

TCLE - $\quad$ Termo de Consentimento Livre e Esclarecido

TDO - Tratamento Diretamente Observado

TRM - Teste Rápido Molecular

UBS - - Unidade Básica de Saúde

UNESCO - Organização das Nações Unidas para a Educação, a Ciência e a Cultura 


\section{SUMÁRIO}

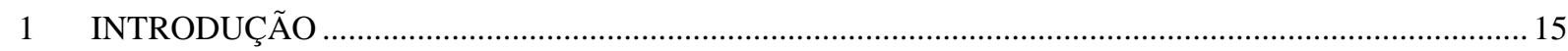

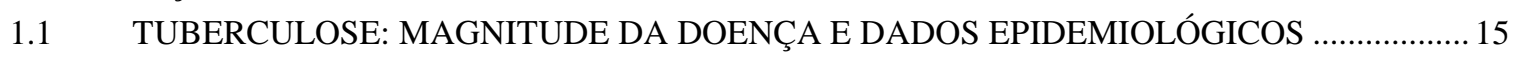

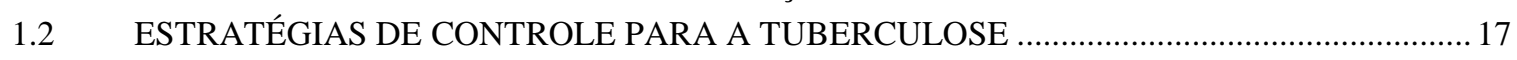

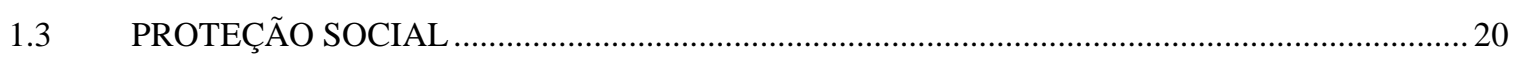

1.3.1 Trajetória da Proteção Social .......................................................................................... 23

1.4 A ADESÃO À TERAPIA MEDICAMENTOSA E INCENTIVOS PARA O

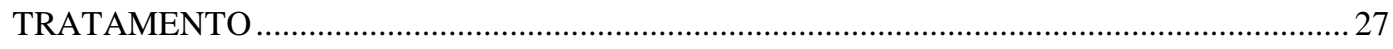

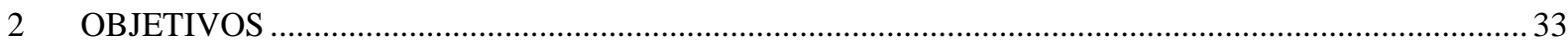

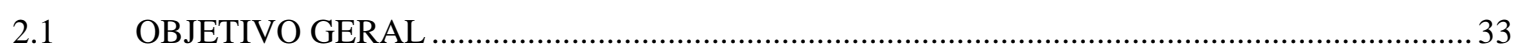

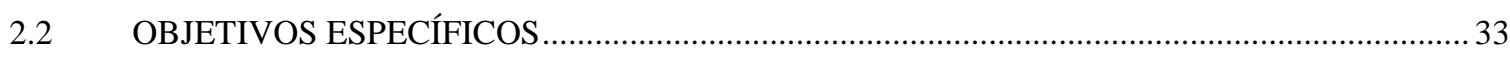

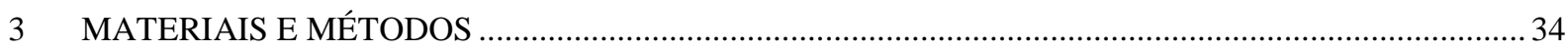

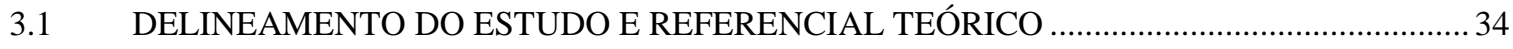

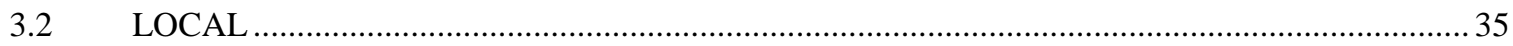

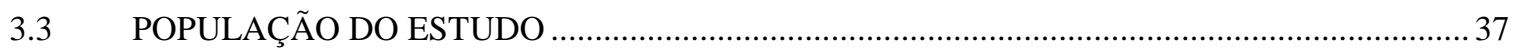

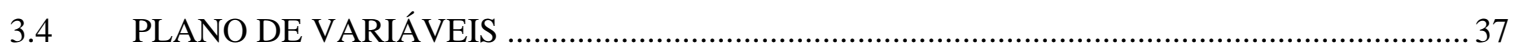

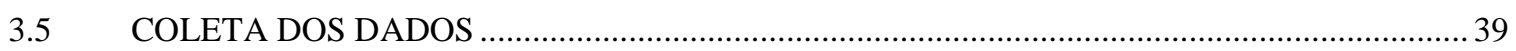

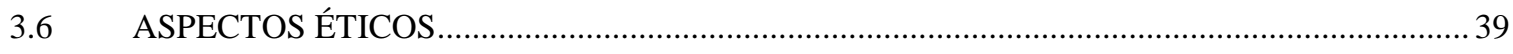

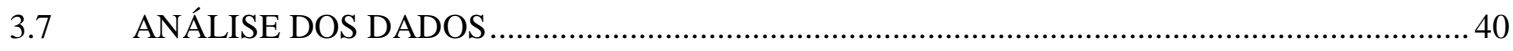

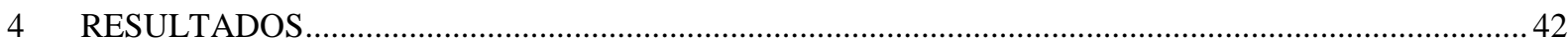

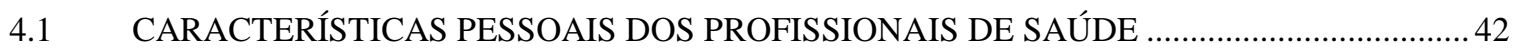

4.2 CONHECIMENTO DOS PROFISSIONAIS DE SAÚDE SOBRE A TB NO MUNICÍPIO.......... 43

4.3 ORGANIZAÇÃO DO SERVIÇO DE SAÚDE PARA O ATENDIMENTO DO

4.4 SIGNIFICADOS CONTIDOS NA ANÁLISE DOS DEPOIMENTOS DOS

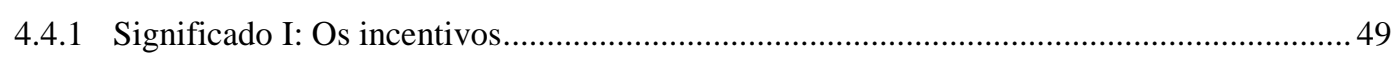

4.4.2 II: Condições de vida das pessoas acometidas pela tuberculose ...........................................53

4.4.3 Significado III: Vínculo formado entre a equipe de saúde e o paciente durante o tratamento

4.5 A SITUAÇÃO EPIDEMIOLÓGICA DA TB NO MUNICÍPIO DE SÃO PAULO E O

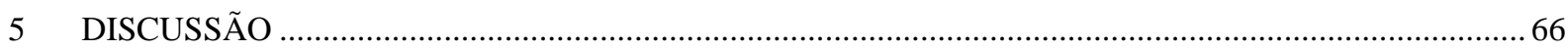

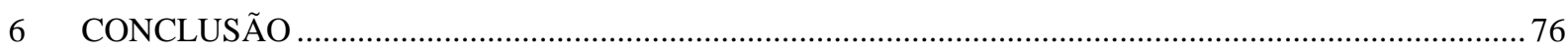

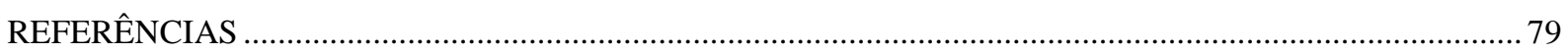

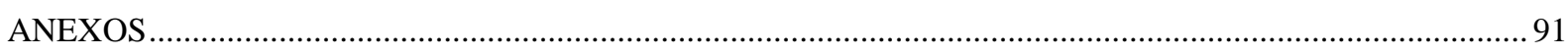

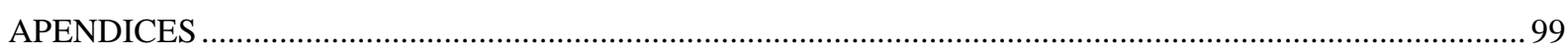




\section{INTRODUÇÃO}

\subsection{TUBERCULOSE: MAGNITUDE DA DOENÇA E DADOS EPIDEMIOLÓGICOS}

A tuberculose (TB) permanece como importante problema mundial de saúde pública, ultrapassando o vírus da imunodeficiência humana (HIV) como doença que causa o maior número de mortes no mundo (World Health Organization, 2015). As más condições de vida e habitação, inadequações nos sistemas de saúde, que comprometem o acesso às ações de saúde, a escassa informação sobre a doença, as migrações populacionais (principalmente em decorrência de conflitos étnicos e raciais) e o aumento da resistência medicamentosa são associados às dificuldades no controle da doença e ao abandono do tratamento (Rodrigues et al., 2010; Brasil, 2012). A situação entre os países na atualidade evidencia que os conflitos de ordem bélica também têm introduzido novos elementos no cenário das migrações e, em consequência, das condições de vida e de trabalho que podem repercutir negativamente na situação epidemiológica da TB.

Todos os aspectos apontados anteriormente devem ser analisados na perspectiva da determinação social da doença. A enfermidade é consagradamente relacionada às condições sociais e às desigualdades sociais. Assim, também está presente em certos países que apresentam alta e média renda, onde, de igual forma, podem apresentar grupos vulneráveis, como imigrantes ilegais, moradores de rua, dependentes químicos, alcoolistas, populações reclusas em instituições prisionais, além de outros, que compõem a população na qual estão as maiores taxas de incidência da enfermidade (Garden et al., 2013). Processos que excluem as pessoas do acesso à vida com dignidade repercutem diretamente na incidência da doença (Bertolozzi, 2005).

De acordo com a Organização Mundial da Saúde (OMS), estima-se que, em 2014, ocorreram 9,6 milhões de casos novos da doença, com coeficiente de incidência de 122/100.000 habitantes, prevalência de 133/100.000 habitantes e 1,5 milhões de mortes (World Health Organization, 2015). 
O Brasil está entre os 22 países com maior carga de TB. Atualmente, ocupa a $22^{a}$ posição na classificação mundial de incidência da doença, seguido da China e Federação Russa, respectivamente. Além disso, está entre os seis países que não conseguiram atingir a meta de $85 \%$ de cura no tratamento, chegando a apenas 72\%. Em 2014, a OMS estimou o coeficiente de incidência da doença em relação ao Brasil, de 44/100.000 habitantes (90 mil casos), o coeficiente de prevalência de 52/100.000 habitantes (110 mil casos) e a taxa de mortalidade de 2,6/100.000 habitantes (5,3 mil mortes) (World Health Organization, 2015).

O Estado de São Paulo é responsável por um quinto das notificações de TB no País, apresentando a maior concentração de casos da doença. Dados mais recentes e disponibilizados por ocasião da elaboração deste presente estudo indicam que, em 2010, o Estado apresentou coeficiente de incidência de 39/100.000 habitantes. Por outro lado, é o segundo Estado com maior proporção de cura de casos novos bacilíferos $(80,6 \%)$, perdendo apenas para o Acre. Em relação à proporção de encerramento de casos novos, o Estado de São Paulo encontra-se entre os três com maiores taxas (97,9\%). Já em relação ao indicador de proporção de Tratamento Diretamente Observado (TDO), realizado entre os casos novos bacilíferos, o Estado não apresenta boas taxas, ocupando a sexta posição no País entre as Unidades Federadas que menos o realizam $(43,8 \%)$. No mesmo ano, foram constatados 922 óbitos e 11\% de abandono (Brasil, 2012, 2015a).

Em relação ao Município de São Paulo, em 2009, ano cujos últimos dados oficiais estavam disponibilizados, apresentou coeficiente de incidência de 53,2/100.000 habitantes, 314 óbitos, 73,2\% de cura e 14,6\% de abandono do tratamento. A Coordenadoria Regional de Saúde (CRS) Centro-Oeste apresentou a maior taxa de abandono $(16,8 \%)$ e a CRS Sul a menor $(8,8 \%)$. Quanto à faixa etária, a partir de 2008, houve aumento dos pacientes que apresentavam a doença entre 20 a 29 anos, sobrepondo-se à faixa etária de 40 a 49 anos, antes prevalente. Segundo a Secretaria de Saúde do Estado de São Paulo, essa mudança pode decorrer de situações que vem, progressivamente, aumentando no Município de São Paulo e se referem ao aumento da dependência química e à vinda de imigrantes jovens da América do Sul, principalmente da Bolívia, à procura de oportunidades de emprego e de melhores condições de vida (Brasil, 2011a).

Posta a magnitude da doença, tanto no âmbito mundial quanto no âmbito nacional e regional, apresentam-se alguns aspectos relevantes em relação às estratégias de controle da 
doença, estabelecidas por organizações mundiais, e que vem orientando a política nacional de controle da tuberculose.

\subsection{ESTRATÉgIAS DE CONTROLE PARA A TUBERCULOSE}

Como já é bastante conhecido, em 1882, Robert Koch descobriu o bacilo causador da doença, o Mycobacterium tuberculosis. A descoberta da estreptomicina, em 1944, possibilitou o desenvolvimento de fármacos para o tratamento da TB, fazendo com que a carga da doença no mundo diminuísse e que fossem focalizadas as ações de combate à enfermidade (Ortblad et al., 2015). No decorrer do século XX, novos métodos para diagnósticos foram desenvolvidos, como a abreugrafia (combinação entre a radiografia de tórax e a fotografia), e novos esquemas de tratamento foram adotados em decorrência da evolução dos fármacos, otimizando o tratamento de 24 meses para seis meses, reiterando-se a focalização de ações no âmbito médico e da saúde (Hijjar, 2007; Maciel et al., 2012).

Em 1993, a OMS declarou a TB em situação de emergência mundial, em virtude de sua importante incidência e, desde então, vem recomendando o Directly Observed Treatment Short-Course (DOTS), em português: Tratamento Diretamente Observado de Curta Duração. O DOTS apresenta cinco componentes, orientados para a condução de boas práticas para o controle da doença: a) compromisso político para garantir recursos humanos e financeiros, e elaboração de planos de ação e mobilização social; b) tratamento diretamente observado (TDO) com ingestão diária da medicação ou, no mínimo, três vezes por semana, na presença de um profissional de saúde; c) realização de baciloscopia de escarro e entrega do resultado do exame; d) fornecimento e gestão eficaz dos medicamentos; e, e) organização dos registros e informações sobre o tratamento (Hijjar et al., 2007; World Health Organization, 2009). Além disso, apoio ao paciente, internação (quando necessária) e serviços de referência e contrarreferência devem ser garantidos pelo DOTS. Essa estratégia busca, como uma das metas, atingir a taxa de $70 \%$ de detecção de casos de TB e taxa de $85 \%$ de cura (Brasil, 2011b, 2011c). A estratégia é recomendada para diminuir o abandono do tratamento, ao propiciar formação de vínculo com o paciente e permitir que a equipe conheça as singularidades e o contexto social em que a pessoa em tratamento vive (Brasil, 2011b). Em síntese, o DOTS tem como objetivos: aumentar a taxa de adesão e de cura, reduzir a taxa de abandono, interromper a cadeia de transmissão da doença, reduzir a mortalidade, diminuir a 
resistência ao medicamento, reduzir o sofrimento humano e efetivar ações de educação em saúde (Brasil, 2011c).

No ano 2000, a estratégia Stop TB Partnership foi estabelecida pela Assembleia Mundial da Saúde, seguida da Conferência Ministerial sobre Tuberculose e Desenvolvimento Sustentável em Amsterdã, na Holanda. Consiste em um movimento global para acelerar as ações sociais e políticas, com o objetivo de deter a propagação da TB em todo o mundo e, desta forma, eliminar a doença como problema de saúde pública. Desde sua criação, essa estratégia tem crescido, tendo triplicado o número de organizações que trabalham em conjunto para reduzir o número de vítimas da doença em todo o mundo. No momento, inclui mais de 1.200 organizações orientadas para alcançar um mundo livre de TB (World Health Organization, 2010).

No sentido de ampliar a implementação do DOTS, em 2006, a Stop TB Partnership, em conjunto com as Metas de Desenvolvimento do Milênio (MDM) estabelecidas pela ONU, lançou o Plano Global do Stop TB 2006-2015, com meta de reduzir em 50\% os coeficientes de prevalência e de mortalidade por tuberculose até 2015, em comparação às taxas apresentadas em 1990 (World Health Organization, 2010). Dos 22 países com maior carga mundial da doença, 16 países, inclusive o Brasil, alcançaram estas metas. A partir de 2016, o objetivo é acabar com a epidemia mundial de TB por implementação da End TB Strategy 2016-2030, com metas relacionadas aos Objetivos de Desenvolvimento Sustentável (ODS), os quais substituem as MDM para reduzir o número de mortes por tuberculose em $90 \%$ até 2030 (em comparação aos índices de 2015), eliminar 80\% dos casos novos e garantir que nenhuma família seja sobrecarregada com altos custos devido à enfermidade (World Health Organization, 2015).

O End TB Strategy possui quatro princípios: a) Responsabilidade e administração governamental em relação ao acompanhamento e avaliação das ações; b) Forte parceria com organizações e comunidades da sociedade civil; c) Proteção e promoção dos direitos humanos, ética e equidade; e d) Adaptação da estratégia e dos objetivos no âmbito nacional, com colaboração global (World Health Organization, 2015).

No Brasil, as ações de combate e prevenção da TB podem ser verificadas desde, aproximadamente, 1899, com a fundação da Liga Brasileira contra a Tuberculose e da Liga Paulista contra a Tuberculose, ambas de caráter filantrópico. Essas Ligas seguiam o método 
médico-social europeu, o qual propunha a implantação de campanhas de educação sanitária, sanatórios e dispensários, assistência focada na população desfavorecida economicamente, e o reconhecimento da participação do poder público; entre outras ações. Entretanto, foi apenas em 1920 que o poder público se envolveu em ações contra a doença, com a Inspetoria de Profilaxia da Tuberculose pelo Departamento Nacional de Saúde Pública. Em 1946 foi criada a Campanha Nacional de Controle da Tuberculose, com o propósito de ampliar a intervenção do Estado frente às políticas sociais e promover a normatização e a padronização da assistência ao paciente com TB. A divulgação de estudos comprovando a eficácia do tratamento de curta duração, na década de 1970, impulsionou o pioneirismo brasileiro em padronizar o novo esquema de seis meses de tratamento, anteriormente realizado em 12 meses, e oferecer os medicamentos por via oral em toda a rede pública de saúde (Bertolozzi, 1998; Hijjar et al., 2007).

Em meados da década de 1980 foi estabelecida a coordenação das ações pelo Ministério da Saúde. A partir deste momento, houve a revisão das normas técnicas, a descentralização do Programa Nacional de Controle da Tuberculose (PNCT) e, posteriormente, a instauração do tratamento supervisionado de forma integrada ao Sistema Único de Saúde (SUS). Em decorrência, o Programa garante, atualmente, a distribuição gratuita de medicamentos e insumos, além de ações preventivas e de controle do agravo (Brasil, 1999, 2006; Hijjar et al., 2007).

O PNCT visa o controle da TB junto à Atenção Básica, de forma integrada a outros programas como, por exemplo, ao Programa de Agentes Comunitários de Saúde e à Estratégia de Saúde da Família, com a finalidade de garantir a ampliação do acesso ao diagnóstico e ao tratamento. Além disto, preconiza o envolvimento de organizações não governamentais e de parcerias com organismos nacionais (universidades, Sociedade Brasileira de Pneumologia e Tisiologia) e internacionais de combate à TB (Stop TB, União Internacional Contra a Tuberculose e Enfermidades Respiratórias, Agência Americana para o Desenvolvimento Internacional, OMS, Organização Pan-americana da Saúde, entre outras). O Plano Estratégico para 2007-2015, apresentado pelo PNCT, possui como meta, alcançar todos os componentes propostos pelo DOTS e a Stop TB Partnership, anteriormente mencionados (Brasil, 2006a).

Desde 2003, a tuberculose é considerada prioridade para o Governo Federal e, admitindo-se que a doença é socialmente determinada, o PNCT tem se aproximado do Ministério do Desenvolvimento Social e Combate à Fome (MDS), com o objetivo de 
estabelecer ações conjuntas no enfrentamento da TB na população em situação de pobreza (Brasil, 2013). Uma das ações dessa parceria foi a análise das bases de dados do Sistema de Informação de Agravos de Notificação (SINAN) por TB e do Cadastro Único para Programas Sociais do Governo Federal (CadÚnico). Este último permite identificar e caracterizar as famílias de baixa renda e é utilizado para selecioná-las como candidatas aos programas sociais promovidos pelo Governo Federal. Em decorrência, foram identificados 17.427 (23,9\%) casos novos de TB diagnosticados em 2010 incluídos no CadÚnico (Brasil, 2014a).

Além desta parceria, em 2012, criou-se a Frente Parlamentar de Luta contra a Tuberculose no Congresso Nacional, que se destaca como importante estratégia para a inserção da temática na agenda parlamentar. Tal iniciativa parece contribuir para a sustentabilidade do movimento social e implantação de possíveis benefícios às pessoas afetadas pela doença, tais como a inclusão dos pacientes em programas de transferência de renda e gratuidade no transporte público para aqueles que estão em tratamento. É importante ressaltar que, dada a ampla experiência com o SUS e as propostas na área de proteção social para o enfrentamento da TB, o Brasil foi o proponente da nova estratégia global de controle da TB na Assembleia Mundial de Saúde de 2014 (Brasil, 2014a).

Tais medidas parecem promover a manutenção do tratamento e mitigar o sofrimento das pessoas acometidas pela TB, ao atenuar os gastos com transporte e alimentação, por exemplo, e a perda do rendimento durante o longo tratamento da enfermidade. Este suporte, aliado a outras intervenções, possibilita a melhora da adesão ao tratamento e a diminuição das taxas de incidência e mortalidade da doença (Lönnroth et al., 2014; Ortblad et al., 2015).

Nessa perspectiva, em continuação, apresentam-se alguns elementos relacionados à proteção social: como se configura e a quem busca atender.

\subsection{PROTEÇÃO SOCIAL}

Admite-se, em geral, que medidas de proteção social contribuem, ainda que de forma muito pontual, a melhorar o estado de saúde do indivíduo que as recebe e, consequentemente, daqueles que com ele convivem. 
Com base em revisão bibliográfica extensa, encontrou-se, no Brasil, um documento produzido pelo Ministério do Desenvolvimento Social e Combate à Fome (MDS) e pela Organização das Nações Unidas para a Educação, a Ciência e a Cultura (UNESCO), que define proteção social como "um conjunto de iniciativas públicas ou estatalmente reguladas para a provisão de serviços e benefícios sociais visando enfrentar situações de risco social ou privações sociais" (Brasil, 2009, p. 58). Tal definição é corroborada por Canesqui (2012), que coloca a proteção social como proposta complementar às políticas públicas de proteção à população e que, portanto, contribui para atenuar as desigualdades sociais.

A ideia de proteção contém um caráter de preservação, apoio e amparo. A Política Nacional de Assistência Social (PNAS) de 2004 atua na proteção social em três situações: proteção às fragilidades dos ciclos de vida; proteção às fragilidades da convivência familiar; e proteção à dignidade humana. Desta forma, visa garantir a defesa da vida, independentemente de quaisquer características do sujeito, considerando-se que a vida não está adstrita ao sentido biológico, mas amplia-se ao sentido social e ético (Brasil, 2009a).

Na ausência de um Estado de Bem Estar Social e na medida em que, lamentavelmente, depara-se com desigualdades sociais, a proteção social é advogada como necessária para aqueles que se encontram à margem do sistema de produção e que apresentam vulnerabilidades sociais. No documento do MDS e UNESCO, citado anteriormente, o conhecimento sobre as vulnerabilidades dos grupos sociais é de grande importância para a aplicação de medidas de proteção social necessárias para a defesa da vida. Muitas dessas estão relacionadas ao trabalho, à habitação, à educação, à saúde, ao transporte, entre outros (Brasil, 2009).

Mas, para Jaccoud (2009), o sistema de proteção social vai além dos benefícios fornecidos aos indivíduos em situação de pobreza. Está pautado, também, na prevenção, e tem permitido o enfrentamento da insegurança e das precariedades relacionadas às vulnerabilidades da população, na medida em que suas condições de trabalho estiverem comprometidas pela idade, doença, invalidez ou desemprego. Além disso, defende o acesso igualitário aos recursos coletivos e a instituição de valores comuns que possam unir os indivíduos, transcendendo suas diferenças. A este respeito, há menções na literatura de que o desenvolvimento econômico, a equidade e a democracia reforçam o papel dos sistemas de proteção (Vaitsman et al., 2009; Ferreira et al., 2011) 
Especificamente em relação à TB, um evento realizado em Londres, em 2012, pela organização não governamental Chatham House, e patrocinado pela OMS, Fundação Bill \& Melinda Gates, Programa das Nações Unidas para o Desenvolvimento (PNUD), Agência de Proteção à Saúde do Reino Unido, entre outros, teve como objetivo explorar as medidas de proteção social como apoio à prevenção, cuidados e controle da TB. Este evento reuniu mais de 40 especialistas em tuberculose, economistas, analistas de proteção social, representantes da sociedade civil, e outros, de diversos países, como Peru, Paquistão, Zâmbia, África do Sul, Brasil, Índia e países da Europa Oriental (países pertencentes e não pertencentes à União Europeia - em especial a Rússia - e países da Ásia Central) (Chatham House, 2012). Os participantes foram alocados em grupos a fim de elencar as medidas de proteção existentes para os pacientes com TB em cada país. Entre os países que não possuem um programa nacional de controle da doença estruturado tem-se o Paquistão e a Zâmbia. O primeiro apresenta programas de proteção social isolados, como é o caso do projeto piloto realizado em um hospital, que fornece alimentos, auxílio moradia, auxílio para transporte e apoio psicológico para pacientes multidrogarresistentes (MDR). O segundo apresenta um projeto piloto de transferência de renda, destinado a famílias carentes afetadas pelo HIV e que tem promovido impacto na redução da incidência de doenças, incluindo a TB. A África do Sul possui um programa de TB relativamente bem estruturado, com o projeto piloto de um regime nacional de seguro de saúde universal e um novo processo de reestruturação dos cuidados de saúde primários, inspirados na experiência do Brasil. Os países da Europa Oriental possuem algumas medidas de proteção social, como o sistema de pensões, para grupos vulneráveis à doença, porém, foi apontada a falta de empenho público na aplicação de medidas de proteção.

Entre os países considerados com bons programas de controle da doença figuram o Peru e o Brasil. O primeiro apresenta algumas políticas sociais como, por exemplo, o fornecimento de alimentos, porém há falhas na distribuição desses recursos. O segundo foi considerado como ideal em termos de recursos humanos e econômicos e disponibilidade de dados, com destaque aos programas de transferência de renda, como o Programa Bolsa Família (PBF), que abrange os pacientes em tratamento da doença (Chatham House, 2012; Das, 2012). Estes são considerados como programas de proteção social. 


\subsubsection{Trajetória da Proteção Social}

A proteção social começou a ser organizada nos países ocidentais a partir do século XIX e instituiu, além de benefícios e serviços públicos, a obrigatoriedade jurídica aos direitos sociais. Na Europa, o campo da política social surgiu em meio aos debates políticos e culturais que emergiam na época. Na Inglaterra, por exemplo, ocorriam debates sobre a possibilidade de intervenção nas condições de pobreza. Já na Alemanha, iniciava-se o desenvolvimento de uma teoria de igualdade de direito e distribuição igualitária de benefícios (Viana et al., 2005).

No século XX, no período de reconstrução pós-guerra (1948-1973), desenvolveu-se na Europa o Welfare State que assegurou, segundo Viana et al. (2005, p. 21):

\footnotetext{
Um conjunto de benefícios, considerados fundamentais, à totalidade da população, e não apenas aos necessitados [...] compreendendo pensões, assistência sanitária, indenizações por acidente de trabalho ou desemprego, auxílio à família e à pobreza, e outras formas de assistência social pública.
}

No Brasil, entre os séculos XVI a XIX, ainda que lamentavelmente presentes o genocídio indígena, o trabalho escravo e a colonização, as questões sociais não eram analisadas como um problema a ser enfrentado e solucionado. Entretanto, com a Abolição da Escravatura (1888), a implantação do regime político republicano (1889), a industrialização e a urbanização crescente, e o decorrente crescimento das vulnerabilidades sociais determinaram a emergência da necessidade de institucionalização de um sistema de proteção social público para amparar a sociedade contra enfermidades, velhice, invalidez, desemprego e exclusão (por classe, gênero, geração, etnia e cultura). Antes disso, a proteção social era realizada por meio de ações sociais de base familiar, comunitária ou filantrópica. Percebe-se, então, a necessidade do Estado, frente aos problemas sociais, atuar na proteção social, por meio de mecanismos que possibilitassem a garantia de renda quando da impossibilidade de acesso e, posteriormente, garantindo uma oferta de serviços e benefícios associados (Pochmann, 2004; Viana et al., 2005; Brasil, 2009a).

Até a década de 1930, o empregador industrial absorvia praticamente a totalidade do custo de reprodução do trabalhador, sendo responsável, na maioria das situações, pela manutenção do salário, moradia, educação, saúde, previdência e assistência, entre outros provimentos. O modo de proteção social no Brasil ganhou expressão a partir de então, quando 
se estabeleceu o projeto de industrialização e grande parte do custo da reprodução da força de trabalho foi retirado da estrutura interna de produção da empresa. Assim, foi definido o salário mínimo (1940) e o financiamento das políticas públicas de educação, saúde, previdência e assistência. Porém, este sistema de proteção era voltado somente aos trabalhadores com registro em carteira de trabalho (Pochmann, 2004; Arretche, 2005).

A década de 1960 foi marcada com iniquidades sociais, desigual distribuição de renda e números expressivos de excluídos e miseráveis tanto na área rural quanto na área urbana. Para combater tal situação, seria necessária uma política de redistribuição de renda por meio de políticas sociais. Entretanto, com o autoritarismo da Ditadura Militar (1964-1985), não se cogitava em medidas para a superação dessas necessidades. É marca desse período, o grande retrocesso na área de políticas públicas no País, sendo as contribuições sociais, advindas da folha de salário dos trabalhadores formais e não rurais, as principais fontes de financiamento do gasto social. Apresenta-se, assim, a proteção social, apenas como direito desta pequena parcela da população (Fagnani, 2005).

O processo de reação política da sociedade civil por meio de manifestações, movimento sindical, organização de novos movimentos políticos de oposição, entre outros, foi intensificado a partir de meados dos anos 1970. Na primeira metade dos anos 1980, já era possível identificar a projeção de uma reforma nacional. Com o término da Ditadura Militar, evidencia-se a necessidade de introduzir o princípio da "seguridade social" e de alterar o modelo de proteção social apenas para o trabalhador contribuinte, para um sistema amplo de bem-estar social que assegurasse direitos sociais, independentemente da contribuição individual para o financiamento dessas ações (Fagnani, 2005).

Assim, em ambiente de importante mobilização popular, também em reação à situação das desigualdades sociais, em 1988, foi aprovada a nova Constituição Federal (CF), a qual garante os direitos humanos e sociais como responsabilidade pública e estatal. Além disso, introduziu a Seguridade Social no interior de três políticas de proteção social: a Saúde, a Previdência e a Assistência Social. Desta forma, ampliou qualitativamente a concepção da proteção social, indo adiante da vinculação com o emprego formal, ao assegurar o acesso à proteção social contributiva e não contributiva, contando com a gestão descentralizada e com a participação social (Brasil, 2009a; Jaccoud, 2009; Organização Pan-Americana de Saúde, 2015). 
De fato, verifica-se que nos anos 1980 inicia-se a reforma das políticas de seguridade social, tanto no Brasil quanto em outros países, instituindo ações para o enfrentamento do aumento da pobreza e das vulnerabilidades sociais (Vaitsman et al., 2009). Constata-se, portanto, que a proteção social, desde a CF de 1988, insere-se no Brasil em uma política de programas contributivos e não contributivos.

Os programas contributivos são responsáveis pela oferta de recursos ao segurado (contribuinte com a Previdência Social) e à sua família, em ocasiões previstas por lei, como idade avançada, perda da capacidade de trabalho, óbito, reclusão, dentre outras (Organização Pan-Americana de Saúde, 2015). Além disso, são garantidos, por meio do Instituto Nacional do Seguro Social (INSS), benefícios previdenciários de apoio, como o auxílio doença, reabilitação profissional, isenção do imposto de renda, entre outros, sendo que todos os benefícios possuem critérios de concessão definidos, podendo ser permanentes ou temporários (auxílio-doença e isenção do imposto de renda). Cada petição é analisada individualmente, por perito médico do INSS, com base na condição clínica e no contexto de vida do paciente (Brasil, 2014b).

Os programas não contributivos seguem a política de Assistência Social e devem amparar, de forma permanente ou provisória, a população desfavorável economicamente, independentemente da contribuição à Previdência Social ou do Seguro Social. Exemplo deste último grupo são os programas federais: o Benefício de Prestação Continuada (BPC), que ampara os inativos temporários ou definitivos (idosos e deficientes, por exemplo) e o Programa Bolsa Família (PBF) (Jaccoud, 2009; Organização Pan-Americana de Saúde, 2015).

O BPC corresponde a um salário mínimo e é destinado às famílias com renda per capita inferior a 25\% do salário mínimo. Ademais, é necessário ter entre 65 e 70 anos e não ser beneficiado por outros recursos oferecidos pela Seguridade Social. Podem pleitear tal benefício, aqueles que apresentem "impedimentos de longo prazo de natureza física, mental, intelectual e/ou sensorial que, em interação com diversas barreiras, acarretem limitações e restrições para o exercício de atividades e participação social”. O BPC é um direito do portador de TB quando este atender a todos os requisitos legais: presença de alterações decorrentes da doença ou eventos adversos causados pelos medicamentos, com limitação no desempenho de atividades, além do critério de renda mencionado anteriormente. $\mathrm{O}$ beneficiário é avaliado a cada dois anos podendo, assim, ter o BPC cancelado ou prorrogado. No caso das necessidades em saúde serem superadas, morte, irregularidades ou ingresso no 
mercado de trabalho, o benefício é interrompido. O Instituto Nacional do Seguro Social (INSS) é responsável pela avaliação pericial e pelo controle da distribuição do benefício (Brasil, 2009a, 2009b, 2014b; Organização Pan-Americana de Saúde, 2015).

O PBF foi criado em 2003, pela Lei $n^{\circ} 10.836 / 2004$, como um Programa de Transferência de Renda Condicionada (PTRC), para beneficiar famílias em situação de pobreza (renda mensal por pessoa entre $\mathrm{R} \$ 77,01$ e $\mathrm{R} \$ 154,00^{1}$ ) e para famílias em situação de extrema pobreza (renda mensal por pessoa de até $\mathrm{R} \$ 77,00$ ). Além disso, unificou outros programas de proteção social, criados na gestão federal correspondente ao período de 1995 a 2003, por três diferentes Ministérios: o Programa Bolsa-Escola (Ministério da Educação), a Bolsa-Alimentação (Ministério da Saúde) e o Auxílio-Gás (Ministério de Minas e Energia). Destes programas, apenas o Bolsa-Escola possuía condicionalidades como contrapartida ao benefício. Antes disso, não havia programas federais que amparassem monetariamente as famílias em situação de pobreza e de extrema pobreza. Apenas existiam alguns programas municipais de transferência de renda, como no município de Campinas e no Distrito Federal (Vaitsman et al., 2009). As condicionalidades previstas pelo PBF são: a matrícula e a frequência escolar mínima de $85 \%$ para crianças e adolescentes entre seis e 15 anos e de $75 \%$ para adolescentes entre 16 a 17 anos, o acompanhamento do calendário vacinal para as crianças com até sete anos, pré-natal em dia, o acompanhamento de nutrizes e ações socioeducativas para as crianças em situação de trabalho infantil, que são acompanhadas pelo MDS por meio do CadÚnico (Brasil, 2009a). As condicionalidades deste Programa o diferenciam dos outros PTRC. Isto porque se procura induzir um comportamento das famílias em investir na saúde e na educação das próximas gerações. O monitoramento destas condicionalidades é, de certa forma, uma maneira de verificação da oferta e do acesso aos serviços de saúde e à educação das famílias cadastradas no Programa. Assim, o não comparecimento a estes pode ser um indício de que a família encontra-se em situação de vulnerabilidade, cabendo ao Estado atuar para remover as barreiras por ela enfrentadas (Brasil, 2009a; Castro, Modesto, 2010).

O valor recebido pela família no PBF consiste na soma dos benefícios que o compõem: Benefício Básico, Benefícios Variáveis e Benefício Variável Vinculado ao Adolescente $(\mathrm{BFJ})$. O Benefício Básico prevê o valor de $\mathrm{R} \$ 77,00$, sendo concedido apenas às famílias consideradas extremamente pobres. Já o Programa de Benefícios Variáveis (que

\footnotetext{
Valores referentes à U\$20,81 e U\$20,27 (fonte: Banco Central do Brasil, 22/11/2015, http://www4.bcb.gov.br/pec/conversao/conversao.asp).

2 Dados fornecidos pelo PCT/COVISA do Município de São Paulo.
} 
contempla crianças entre 0 a 15 anos, gestantes e nutrizes) concede o valor de $\mathrm{R} \$ 35,00$, com limite máximo de cinco pessoas para cada família. O BVJ (adolescente de 16 a 17 anos) prevê o valor de R \$ 42,00 e é limitado a dois jovens por família. Desta forma, a família em situação de pobreza, cadastrada no PBF, pode receber benefício que varia entre $\mathrm{R} \$ 35,00$ a $\mathrm{R} \$ 259,00$; e a família em situação de extrema pobreza, cadastrada no PBF, pode receber um valor que varia entre $R$ \$ 77,00 a $R$ \$ 336,00 (Brasil, 2009a, 2015b).

Além destas medidas de proteção social, que amparam as pessoas em situação de vulnerabilidade social, que não são exclusivas às pessoas acometidas pela doença em questão, há no Brasil, incentivos que auxiliam o paciente em tratamento da TB para apoiar a adesão à terapia medicamentosa. A adesão é de grande importância, pois a irregularidade pode levar à ao prolongamento da terapia medicamentosa, à resistência aos fármacos, à falência do tratamento, ao maior sofrimento das pessoas acometidas, à disseminação do bacilo e ao aumento da taxa de mortalidade (Brasil, 2011b).

Assim, apresentados alguns aspectos a respeito do que se considera como medidas de proteção social, a próxima seção tratará de algumas estratégias que têm sido empregadas para o incremento da adesão ao tratamento.

\subsection{A ADESÃO À TERAPIA MEDICAMENTOSA E INCENTIVOS PARA O TRATAMENTO}

A não adesão ao tratamento possibilita a disseminação da TB, a emergência de recidiva e potencializa o risco do desenvolvimento da resistência à medicação. A adesão não se reduz a um ato volitivo e de caráter apenas de decisão individual, mas está associado a situações que envolvem barreiras socioeconômicas, culturais, demográficas e geográficas; condições relacionadas ao próprio tratamento medicamentoso (efeitos colaterais, por exemplo); ao vínculo do profissional de saúde com o paciente, assim como a organização do serviço de saúde e as condições que se relacionam à acessibilidade. Ademais, a precária situação social, a demora na procura da assistência e a falta de informação acerca da enfermidade e sobre o tratamento contribuem para a não adesão ao tratamento da TB (Belo et al., 2006; Sánchez, Bertolozzi, 2009; Orr, 2011; Gler et al., 2012; World Health Organization, 2013). 
O tratamento supervisionado é estratégia, conforme anteriormente mencionado, instituída para incrementar a adesão ao tratamento. Entretanto, vai além da deglutição do medicamento. No Brasil, para motivá-la e, até mesmo, amenizar os desgastes ocasionados pela própria doença, no âmbito da DOTS, são recomendados incentivos como lanches, auxílio alimentação e vale transporte. Tais incentivos podem ser muito importantes, ainda que se tenha conhecimento de que apenas contribuem para aliviar necessidades e não transformar a condição social dos doentes (Terra, Bertolozzi, 2008; Brasil, 2011b).

Entretanto, não há legislação específica, no âmbito nacional, que garanta a oferta de auxílio-alimentação aos pacientes em tratamento supervisionado. O contrário pode ser observado no caso de transporte, pois há legislação específica, de âmbito local, que pode conceder o benefício às pessoas em tratamento da doença. Como exemplo, destaca-se o Município de São Paulo, que isenta o paciente do pagamento em transportes coletivos para seu deslocamento até a unidade de tratamento (Brasil, 2005a; Organização Pan-Americana de Saúde, 2015). Além disso, este Município implantou, em 2004, a distribuição de cestas básicas e lanches para os pacientes em TDO. Nesse ano, a taxa de adesão dos pacientes em TDO foi de 90\%, sendo que nos anos anteriores nunca superou 80\% (Brasil, 2007).

Políticas públicas voltadas à proteção social apoiam famílias, tanto em relação ao suporte econômico quanto em relação ao enfrentamento das vulnerabilidades sociais (Pinheiro et al., 2013). De fato, no sentido de buscar amenizar vulnerabilidades sociais e promover equidade na distribuição dos recursos para auxiliar o tratamento da TB, municípios realizam parcerias com as Secretarias Municipais da área social, além de outras parcerias públicas ou privadas, integradamente ao PNCT (Pinto et al., 2006).

É importante lembrar que a TB relaciona-se intimamente às condições de vida e aos processos de exclusão social. A abordagem da enfermidade, dos pacientes que dela padecem e de seu controle, deve ser realizada a partir dessa perspectiva. Particularizando o caso do Brasil, Victora et al. (2011), em estudo que integra a série de artigos sobre a Saúde no Brasil, mostram a melhora dos indicadores socioeconômicos e de saúde de 1960 comparados a 2009. Advogam que tal melhora é resultado da reforma no setor da saúde nos anos de 1970 e 1980 atrelados, entre outras iniciativas, à política de transferência de renda, os quais causaram impacto na redução da exclusão social. 
Ainda que os últimos anos apresentem, progressivamente, melhora dos indicadores sociais, de modo geral, o processo de desenvolvimento econômico é caracterizado, no plano social, pela desigualdade, exclusão social e investimentos públicos insuficientes. Assim, as iniquidades sociais, que se evidenciam na distribuição desigual de renda, na carência de saneamento básico, na frágil educação para a população e nas disparidades no acesso aos serviços de saúde, dentre outros exemplos, também contribuem para a exacerbação das diferenças no processo saúde-doença dos diferentes grupos sociais (Hino et al., 2011).

Em revisão da literatura nas bases de dados do PubMed e BVS (Biblioteca Virtual em Saúde), considerando o período de 2010 a 2014, com as seguintes palavras-chave: tuberculosis treatment, patient compliance e motivation, encontrou-se, na primeira base de dados 77 artigos e, na segunda, 56 artigos. Desse universo, após verificação da pertinência do título e resumo e sua relação ao tema do presente estudo, foram analisados 10 artigos que, após leitura na íntegra, possibilitaram identificar o "estado da arte" em relação aos processos que levam à adesão ao tratamento e à importância de alguma forma de apoio para tal. A síntese de tais artigos encontra-se a seguir apresentada.

Nos EUA, no caso de crianças e adolescentes portadores de TB, por exemplo, ofertamse brinquedos, excursões/passeios com amigos, além de apoio monetário, para apoiar o tratamento (Cass et al., 2005; Kominsk et al., 2007; Defulio, Silverman, 2012).

Estudo realizado em San Diego avaliou crianças em tratamento de infecção latente da tuberculose (ILTB): em cada consulta mensal, a família da criança que apresentasse o impresso de controle da ingesta da medicação inteiramente preenchido recebia um brinquedo. A equipe de educação em saúde detectou que a adesão ao tratamento aumentou significativamente e os autores apontam que os custos para a implementação dessa estratégia foram mínimos comparados aos benefícios, com gasto de US\$3.00/criança. Tal valor foi considerado, pelos autores, como moderado, quando comparado ao gasto de US\$16,40, estimado para o tratamento de casos novos com TB na forma ativa (Cass et al., 2005).

No Canadá, estudo explorou estratégias que melhoraram a adesão dos indígenas ao tratamento da TB, que também é população vulnerável nesse país. Relata-se a utilização da estratégia DOTS em conjunto com incentivo (alimentos, roupas, moradia, ajuda monetária e vale-transporte ou assistência para locomoção) para melhorar a adesão. Destaca-se a oferta de 
incentivos alimentares, pois a doença pode levar à desnutrição e os medicamentos podem causar desconforto gastrointestinal (Orr, 2011).

Em estudo realizado na cidade de Manila, capital das Filipinas, entre os anos de 1999 a 2006, com o objetivo de determinar as características sociodemográficas associadas ao abandono do tratamento da tuberculose MDR e o impacto de medidas de apoio a esses pacientes, foram avaliadas as seguintes medidas: vale-transporte; auxílio para alojamento; cestas básicas; gratuidade de drogas para os eventos adversos decorridos do tratamento medicamentoso; encaminhamento para internação hospitalar (quando necessária); e descentralização do tratamento, no caso de necessidade de transferência da unidade central, responsável pela assistência aos pacientes MDR, para uma unidade de saúde local. Todas essas medidas eram fornecidas quando necessárias e a oferta era realizada pelo profissional de saúde. Das medidas de apoio citadas, apenas a descentralização apresentou significância estatística $(\mathrm{p}<0,001)$. Porém, o fornecimento de cestas básicas foi apontado por 231/265 pacientes que não abandonaram o tratamento (Gler et al., 2012).

Lutge et al. (2012) avaliaram os efeitos dos incentivos em pacientes em tratamento de tuberculose pulmonar, na forma ativa e latente. Verificou-se que a taxa de retorno para a leitura de resultados, como o teste tuberculínico, era maior em pacientes que recebiam incentivos, em comparação aos pacientes que apenas recebiam o tratamento convencional. Observou-se, também, que os incentivos monetários foram mais eficazes do que os incentivos não monetários.

Estudo realizado na Rússia, entre 2001 a 2004, com pacientes em tratamento para a TB e considerados desfavorecidos economicamente, investigou a introdução de incentivos alimentares (entrega de pacotes contendo alimentos para serem consumidos no decorrer do dia) e suporte social, materializado por ações de educação em saúde e orientação por profissionais de saúde em relação aos direitos legais durante o DOTS. Os autores concluem que a introdução do benefício alimentar apresentou impacto positivo na adesão ao tratamento, pois $59,0 \%$ dos pacientes o completaram, comparados aos 31,0\% do grupo controle (Garden et al., 2013).

Motivados pela escassez de estudos que avaliem os benefícios das medidas de proteção aos pacientes em tratamento da TB, Lutge et al. (2013) realizaram uma pesquisa, entre 2009 e 2010, na África do Sul, para investigar se a oferta de apoio econômico exercia 
algum impacto na adesão dos pacientes em tratamento nos ambulatórios públicos do país. Foi oferecido aos participantes um vale, no valor de aproximadamente US $\$ 15,00$ até o final do tratamento, esperando-se, com isso, que o benefício possibilitasse o aumento do consumo de produtos alimentares que melhorassem a segurança alimentar das famílias e, consequentemente, o estado nutricional do paciente. Um total de 4.091 pacientes foi incluído no estudo (1.984 para controle e 2.107 para intervenção). O benefício só foi concedido aos pacientes que se encontravam em precária situação econômica. A taxa de sucesso do tratamento de pacientes que o receberam foi de $90 \%$, quando comparada aos $68,3 \%$ dos pacientes que não receberam qualquer benefício.

Em estudo realizado na Tanzânia, em 2010, analisou-se a percepção dos pacientes sobre os fatores que influenciavam a adesão ao tratamento da TB. Mostrou-se que os participantes consideravam como medidas de apoio não apenas o auxílio financeiro, mas também a assistência material (alimentos fornecidos pela igreja, por exemplo), o apoio emocional ou, até mesmo, o simples ato de ser lembrado a ingerir o medicamento pelos familiares. Além de ser um facilitador da adesão, as medidas de apoio desencadearam expectativas entre os familiares dos participantes, fazendo-os atuarem como importantes motivadores na adesão ao tratamento dos participantes. Os pacientes apontaram que o transporte para dirigir-se à unidade de saúde constituía-se em barreira para o tratamento, porém não a ponto de resultar no abandono do tratamento, dado que era necessário pagar pelo mesmo para comparecer à unidade de saúde. Os autores relatam que ajudar na superação de barreiras à adesão, por meio do fornecimento de alimentos e incentivos monetários, pode ser eficaz no caso de pacientes que pretendem aderir. Entretanto, advogam que isto não ocorre no caso dos pacientes que não demonstram tal intenção. Esta conclusão parte da verificação de que a intenção de aderir pode ajudar a superar as barreiras percebidas para a adesão ao tratamento da tuberculose (Boogaard et al., 2014).

No Brasil, Belo et al. (2006), em estudo realizado no Estado do Rio de Janeiro, em 2004, foram analisados incentivos para melhorar a adesão ao tratamento. Foi atribuído um escore a cada incentivo: suporte financeiro (vale refeição, vale transporte, cesta básica), suporte dos serviços de saúde (psicológico, do profissional do serviço social, atenção médica, busca de contatos e orientação, acesso aos exames laboratoriais), organização administrativa (agendamento de consultas, disponibilidade de consultas aos sábados, disponibilidade de consultas ao entardecer, entrega da medicação no domicílio, visita domiciliária por profissionais da saúde) e hábitos (permissão para fumar e beber durante o tratamento).Dos 
incentivos mencionados, cinco foram considerados fundamentais por no mínimo metade dos pacientes: acesso aos exames laboratoriais, cestas básicas, vale transporte, entrega de medicação no domicílio e atenção médica. Em geral, os incentivos que perfazem o suporte do serviço de saúde foram os mais importantes para os pacientes que, em geral, são classificados como mais pobres. Os autores enfatizam a necessidade de compromisso profissional para garantir que tais incentivos sejam direcionados aos grupos que mais necessitam deste suporte.

É necessário apontar que foi observada, durante a busca bibliográfica, carência de estudos sobre medidas de proteção no Brasil e se apresentam impacto na adesão ao tratamento da doença, com consequente melhora dos indicadores epidemiológicos de cura e de abandono.

Neste sentido é que se justificou a realização do presente estudo. Conforme anteriormente apontado, conhecer esta faceta da realidade pode contribuir para o aprimoramento das políticas públicas de controle da doença, mas é importante deixar claro que medidas de proteção social que apenas mitigam a situação de vulnerabilidade em que se encontram as pessoas e que mantém os pacientes sob o manto do serviço de saúde não conduzem à emancipação, à autonomia e ao desenvolvimento da vida digna. Tampouco podem transformar a realidade epidemiológica da TB. 


\section{OBJETIVOS}

\subsection{OBJETIVO GERAL}

Analisar a influência de medidas de apoio na adesão ao tratamento da tuberculose em algumas Coordenadorias de Saúde do Município de São Paulo, na perspectiva de profissionais de saúde.

\subsection{OBJETIVOS ESPECÍFICOS}

a) Identificar as modalidades de apoio proporcionadas às pessoas com tuberculose

b) Identificar as percepções dos profissionais de saúde a respeito das potencialidades e as fragilidades das medidas de apoio em relação ao processo de adesão ao tratamento

c) Verificar a percepção dos profissionais de saúde a respeito de ações que compõem o Programa de Controle da TB. 


\section{MATERIAIS E MÉTODOS}

\subsection{DELINEAMENTO DO ESTUDO E REFERENCIAL TEÓRICO}

Estudo exploratório e descritivo, com corte transversal e de abordagem qualiquantitativa.

De acordo com Gil (2008), as pesquisas exploratórias visam o esclarecimento de ideias ou de determinado fato. Envolvem levantamento bibliográfico e documental. Portanto, é realizada quando o tema escolhido é pouco explorado. Em relação às pesquisas descritivas, segundo o mesmo autor, visam descrever as características ou percepção de uma população ou fenômeno abordado e utilizam de técnicas padronizadas de coleta de dados. As pesquisas descritivas, assim como as exploratórias, são usuais entre os pesquisadores preocupados com a atuação prática (Gil, 2008).

O corte transversal é dado como um desenho do estudo no qual a produção do dado ou observação do fenômeno é realizada em um único momento no tempo, ou seja, um "corte no fluxo histórico da doença, evidenciando as suas características e correlações”. Este tipo de desenho utiliza-se de amostra representativa da população e é frequentemente utilizado no campo da Saúde Coletiva (Almeida Filho, Rouquayrol; 2006).

A Determinação Social norteou a concepção da saúde-doença (Breilh, Granda, 1989). Esta considera os processos estruturais da sociedade na compreensão das condições de vida das pessoas, dos perfis de reprodução social (produção e consumo) e do processo de adoecer (Breilh, Granda, 1989). Esta concepção não se limita aos processos individuais e biológicos, mas transcende para a interpretação do processo saúde-doença em sua dimensão coletiva. A frequência e a intensidade dos fenômenos que se manifestam no processo de adoecer e morrer variam no tempo e no espaço. Tais fenômenos podem se apresentar em três dimensões, articuladas e interdependentes: dimensão individual (refere-se às pessoas e famílias e manifesta-se na individualidade, por exemplo, sexo, idade, religião, escolaridade, renda), dimensão particular (corresponde aos modos de viver e de trabalhar que se manifestam por meio de perfis de morbimortalidade específicos de cada grupo social), e dimensão estrutural 
(refere-se aos processos de desenvolvimento das forças produtivas e das relações sociais; é composta pelo modo de produção: a economia e pela sustentação político, jurídica e ideológica) (Fonseca et al., 2001). Portanto, entende-se que a saúde-doença é mediada por tais dimensões que atuam conjuntamente.

Para a compreensão do termo adesão, valeu-se do conceito proposto por Bertolozzi (2005), que defende que a adesão ao tratamento está associada à inserção social dos indivíduos, à organização dos processos de trabalho na assistência à saúde (que não apenas está restrita ao atendimento às necessidades biológicas e clínicas, mas incorpora as de âmbito social e correspondentes à inserção na sociedade) e na acessibilidade às condições dignas para a vida.

\subsection{LOCAL}

O estudo foi realizado no Município de São Paulo-SP (MSP), que possui população estimada de 11.967.825 habitantes (Instituto Brasileiro de Geografia e Estatística - IBGE, 2015). No âmbito da saúde, o Município é dividido em seis Coordenadorias Regionais de Saúde (CRS): Centro, Oeste, Sudeste, Leste, Norte e Sul. Por sua vez, estas Coordenadorias são subdivididas em Supervisões Técnicas de Saúde (STS), totalizadas em 25. Além disso, a Coordenação de Vigilância em Saúde (COVISA) responsabiliza-se pela Vigilância Ambiental, Sanitária e Epidemiológica e descentraliza sua atuação nas Supervisões de Vigilância em Saúde (SUVIS). As SUVIS estão distribuídas pelas CRS, totalizadas em 26. Entre outras ações, estas participam do planejamento, da avaliação, da orientação e fiscalização das ações de vigilância em saúde da sua região adstrita (Brasil, 2014c, 2015c; São Paulo, 2015). A seguir, observa-se a divisão do MSP por CRS. 
Figura 1 - $\quad$ Coordenadorias Regionais de Saúde do Município de São Paulo. 2015.

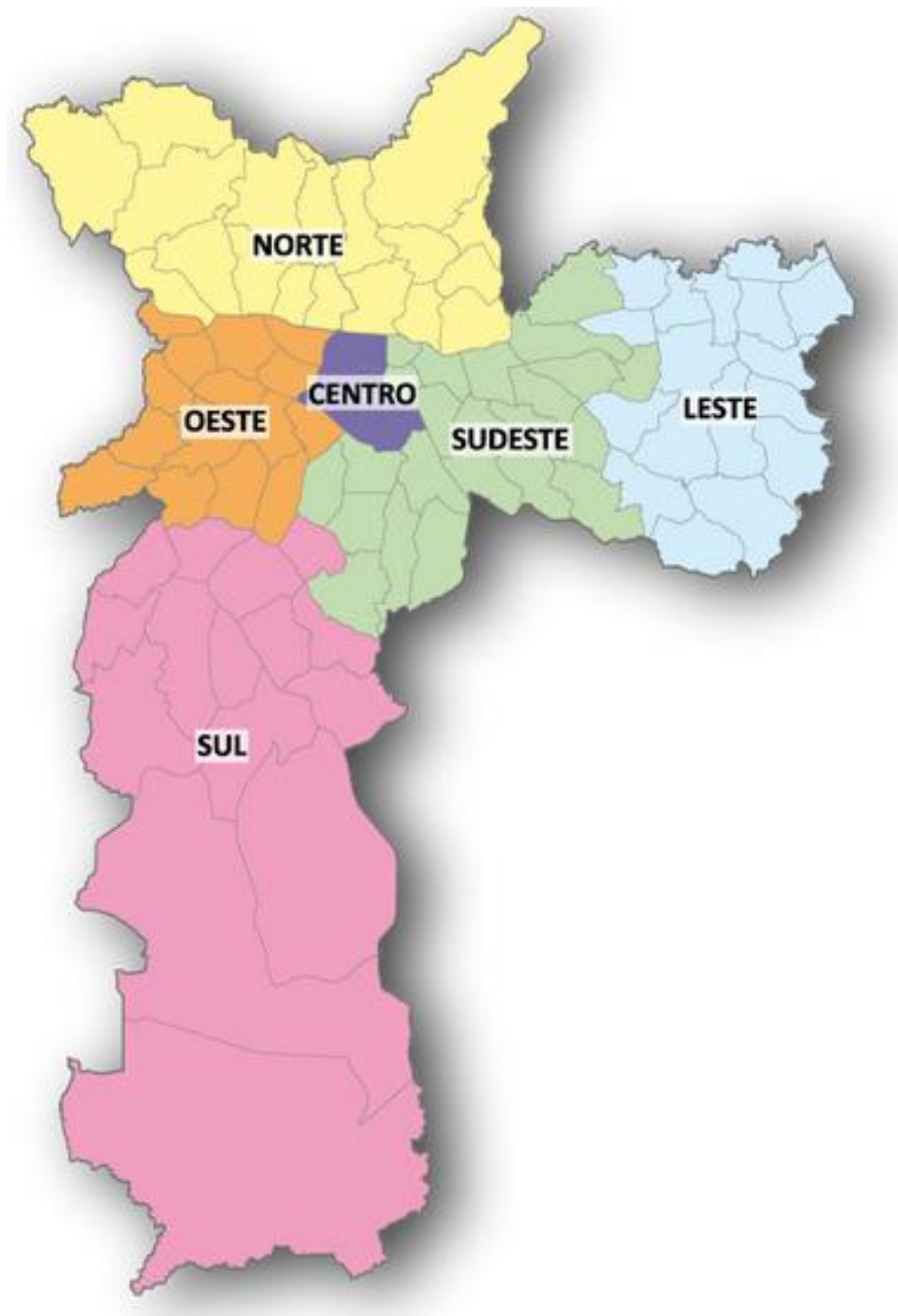

Fonte: Secretaria de Saúde do Município de São Paulo, Coordenadorias de Saúde. Disponível em: http://www.prefeitura.sp.gov.br/cidade/secretarias/saude/organizacao/coordenadorias_saude/index. php?p=6541; acessado em 15/09/2015.

Das 25 STS, foram escolhidas para amostra do MSP, Unidades Básicas de Saúde (UBS) selecionadas das STS: Butantã, Campo Limpo e Penha. A primeira STS foi escolhida, pois representava uma das maiores taxas de cura do MSP (81,8\%). Campo Limpo evidenciava uma das menores taxas de abandono $(7,8 \%)$ e a Penha uma das maiores taxas de abandono (21,3\%), de acordo com o boletim da TB publicado pelo Município, contendo dados por SUVIS (Brasil, 2009c).

A SMS iniciou a descentralização do diagnóstico e do tratamento da tuberculose a partir de 2004 (Brasil, 2011a). No ano de realização do presente estudo, o Município apresentava os seguintes serviços de saúde para suporte e tratamento do paciente com TB: 
454 Unidades Básicas de Saúde (UBS), 12 unidades de pronto-socorro, 4 unidades de pronto atendimento, 133 unidades de assistência médica ambulatorial (AMA) e 27 hospitais públicos (Brasil, 2015c).

\subsection{POPULAÇÃO DO ESTUDO}

Foram sujeitos do estudo, profissionais de saúde: médicos e enfermeiras que assistiam o paciente em tratamento da TB nas unidades básicas de saúde das STS já descritas. Foi critério de exclusão, atuar na unidade de saúde em período inferior à seis meses.

\subsection{PLANO DE VARIÁVEIS}

Para melhor compreensão do objeto de estudo, o instrumento para a captação dos dados procurou abranger diversas variáveis referentes ao perfil dos profissionais de saúde e à organização do serviço para atender as pessoas em tratamento da tuberculose:

a) Variáveis relativas às características pessoais dos profissionais de saúde:

- Profissão: médico ou enfermeiro;

- Sexo: masculino ou feminino;

- Formação complementar: pós-graduação Latu Senso ou Strito Senso;

- Participação em capacitações sobre TB no último ano;

- Tempo de atuação profissional com atendimentos de paciente com TB;

- Tipo(s) de unidade(s) de saúde onde o profissional atua;

- Número de unidades de saúde que o profissional atua em ações de controle da TB.

b) Variáveis relativas ao conhecimento dos profissionais de saúde sobre a TB no Município:

- Indicadores relacionados à TB na região que trabalha;

- Ações que compõem as políticas públicas de saúde municipais relacionadas à TB; 
- Prioridade da TB no Município;

- Repasse financeiro para o Município e investimento municipal no controle da TB;

- Participação do profissional em discussões a respeito do repasse de recursos financeiros para o controle da TB;

- Incentivos municipais fornecidos ao paciente em tratamento da TB;

- Regularidade da distribuição dos incentivos oferecidos ao paciente em tratamento da TB;

- Ações voltadas ao paciente em caso de abandono ao tratamento;

- Contribuição do TDO na adesão ao tratamento.

c) Variáveis relacionadas à organização do serviço de saúde para atendimento do paciente com tuberculose:

- Número de vezes por semana que a unidade de saúde realiza o tratamento supervisionado: $\geq 3$ vezes na semana e $<3$ vezes na semana;

- Quem supervisiona o tratamento: enfermeiro, auxiliar/técnico de enfermagem, agente comunitário de saúde ou outro;

- Regularidade na distribuição da medicação: sim ou não;

- Tempo para recebimento do resultado do exame de baciloscopia de escarro: número de dias ou meses;

- Tempo para o recebimento do resultado da radiografia de tórax: número de dias ou meses;

- Realização da prova tuberculínica na unidade de saúde: sim ou não.

O mesmo instrumento continha questões abertas, das quais emergiram os seguintes significados contidos na análise dos depoimentos dos profissionais de saúde que foram estabelecidos a posteriori da realização das entrevistas: significados sobre a relevância dos incentivos na adesão do paciente ao tratamento da TB, significados sobre as condições de vida dos pacientes acometidos pela enfermidade, significados sobre o vínculo e adesão ao tratamento e, por fim, sugestões dos profissionais de saúde para melhorar a situação epidemiológica da TB. 


\subsection{COLETA DOS DADOS}

A coleta de dados foi realizada por meio de entrevistas junto aos sujeitos do estudo, conforme instrumento em anexo (APÊNDICE A). Tal instrumento era semiestruturado e continha questões fechadas (para a caracterização dos sujeitos e do serviço) e abertas. Estas últimas se referiam à percepção do sujeito entrevistado a respeito do significado dos incentivos para o alcance da cura do paciente e sobre o que poderia ser feito para melhorar a atual situação epidemiológica do Município. Isto se fez necessário para permitir a captação mais adequada das informações, tendo sido gravada esta parte específica.

Também foram utilizadas informações sobre os pacientes que realizaram o tratamento da TB no Município de São Paulo, contidas no banco dados do TBWEB, Sistema de Notificação e de Acompanhamento dos Casos de Tuberculose do Estado de São Paulo, referentes ao período de 2014. O TBWEB é uma parceria entre a Secretaria de Estado da Saúde e a Companhia de Processamento de Dados do Estado de São Paulo, com o apoio do Ministério da Saúde. Os casos são cadastrados via internet e monitorados até a conclusão do tratamento (Brasil, 2008).

As entrevistas foram realizadas no período de 12 de maio a 30 de julho de 2015, principalmente pela própria autora desta Dissertação de Mestrado. Contou-se com o apoio de uma colaboradora devidamente treinada em cerca de um quarto das entrevistas. Todos os profissionais de saúde foram entrevistados no serviço de saúde de atuação, em local privado, mantendo-se o sigilo necessário.

A captação das informações junto ao TBWEB ocorreu em agosto e setembro de 2015. Os dados obtidos por esta fonte foram: número de cestas básicas e vales-transportes adquiridos pelo Município para ofertar aos pacientes com tuberculose entre 2009 e 2014, número de pacientes que realizaram tratamento no ano de 2014, taxa de incidência, taxa de abandono e taxa de cura no mesmo ano.

\subsection{ASPECTOS ÉTICOS}

Conforme a Resolução 466/2012, este estudo foi submetido à Plataforma Brasil e aprovado pelo Comitê de Ética em Pesquisa da Escola de Enfermagem da Universidade de 
São Paulo (EEUSP), conforme Parecer de número 952.223 (ANEXO 1), no dia 09/02/2015, e pelo Comitê de Ética em Pesquisa da Secretaria de Saúde do Município de São Paulo, conforme Parecer de número 973.030 (ANEXO 2), no dia 05/03/2015.

Após as devidas autorizações, a proposta do estudo foi apresentada aos gerentes e profissionais de cada unidade de saúde participante, em reunião técnica de equipe ou em horário agendado previamente. Em seguida, as entrevistas foram organizadas a fim de não prejudicar o atendimento e a rotina nas unidades de saúde. Os profissionais foram convidados a participar do estudo mediante ciência do Termo de Consentimento Livre e Esclarecido TCLE (APENDICE B).

Para a utilização dos dados contidos no banco de dados do TBWEB, foi solicitada autorização junto à Coordenação do Programa Municipal de Controle da Tuberculose.

\subsection{ANÁLISE DOS DADOS}

As variáveis quantitativas foram sistematizadas em um banco de dados no Microsoft Office Excel 2007 e transferidas ao programa Statistical Package for the Social Sciences versão 22.0 (SPSS Inc., Chicago, IL, EUA), para a realização da análise descritiva dos dados (distribuição das frequências).

As informações referentes ao banco de dados do TBWEB também foram transferidas para uma planilha no Microsoft Office Excel 2007. Apenas os dados referentes ao número de cestas básicas adquiridas pela Secretaria de Saúde do Município aos pacientes em TDO (variável independente) e a taxa de cura da doença (variável dependente) foram transferidas ao Software SPSS para a aplicação da Equação da Reta no modelo de Regressão Linear Simples (RLS). Tal procedimento foi realizado para verificar a existência de relação funcional entre estas variáveis. Utilizou-se o coeficiente de correlação de Pearson (r) para medir o grau de relação entre essas variáveis. Esse coeficiente varia de -1 a 1 . O sinal indica direção positiva ou negativa do relacionamento e o valor sugere a força da relação entre as variáveis. Calculado o valor do coeficiente de correlação de Pearson, utilizou-se a seguinte classificação para verificar a força da relação entre as variáveis: $r=0,10$ até 0,30 (fraca); $r=0,40$ até 0,60 (moderada); $r=0,70$ até 1 (forte) (Figueiredo Filho, Silva Junior, 2009). 
A análise dos depoimentos dos sujeitos, obtidos por meio das questões abertas, foi realizada após sua transcrição na íntegra. É importante destacar que, segundo Minayo (2008), os pesquisadores encontram três obstáculos na análise do material coletado em campo: a compreensão espontânea do discurso, nele projetando a sua própria subjetividade; a submissão à "magia de métodos e técnicas", esquecendo-se do real significado e da essência do discurso; e, por último, a dificuldade em associar os conceitos teóricos com o material coletado. Portanto, na análise de achados qualitativos, segundo Minayo (2008), deve-se buscar superar o empirismo e, para tanto, a autora propõe que o pesquisador aprofunde-se na realidade vivenciada pela população de estudo.

Assim, os depoimentos dos sujeitos foram analisados por meio de técnica apropriada, que tem base na Teoria do Percurso Gerativo de Sentido, proposta por Fiorin (1989) e adaptada por Car e Bertolozzi (1999). Nesta técnica, a análise parte "do mais concreto ao mais abstrato, do mais complexo ao mais simples". Assim, a análise tem início a partir da identificação de elementos concretos (figuras) e de elementos abstratos (temas) (Fiorin, 1989; Car, Bertolozzi. 1999). Segundo Fiorin (1989, p.65):

\footnotetext{
A figura é o termo que remete a algo do mundo natural: árvore, vagalume, sol, correr, brincar, vermelho, quente, etc. Assim, a figura é todo conteúdo de qualquer sistema de representação que tem um correspondente perceptível no mundo natural. [...] Tema é um investimento semântico, de natureza puramente conceptual, que não remete ao mundo do natural. Temas são categorias que organizam, categorizam, ordenam os elementos do mundo natural: elegância, vergonha, raciocinar, calculista, orgulhoso, etc.
}

Portanto, após a transcrição dos depoimentos, a primeira etapa realizada foi a leitura em profundidade do material empírico para identificar e destacar as figuras e os temas. A segunda etapa consistiu na articulação entre as figuras e os temas, "identificando congruências e/ou ambiguidades" no discurso. Em seguida, foram construídas frases temáticas (APÊNDICE C) que sintetizam "os temas e subtemas do discurso em sua totalidade". Essas frases foram agrupadas segundo os significados prevalentes.

Cada sujeito recebeu uma letra alfabética e cada frase temática apresenta essa letra seguida de um número ordenado sequencialmente, por exemplo: A1. Trata-se do sujeito A, cuja frase é de número 1. Somente foram selecionadas as frases temáticas que guardavam alguma correlação ao objeto central do estudo. 


\section{RESULTADOS}

Os resultados obtidos estão distribuídos de acordo com os grupos de variáveis demonstrados em seção anterior.

\subsection{CARACTERÍSTICAS PESSOAIS DOS PROFISSIONAIS DE SAÚDE}

Foram entrevistados 86 profissionais de saúde, sendo 60,5\% (52) enfermeiros e, os demais, médicos (Tabela 1). Encontrou-se uma média de 10,0 anos de serviço (desvio padrão $=8,74 ; 0,6 \pm 40,0)$. Destes profissionais, a maioria, 75,6\% (65) era de mulheres; $88,4 \%$ (76) possuíam curso de pós-graduação Lato Senso e 4,7\% (4) possuíam curso de pós-graduação Stricto Senso.

Em relação ao número de serviços de saúde que o profissional atuava em ações de controle da TB, 7,0\% (6) relataram trabalhar também em outro serviço. É importante ressaltar que $65,1 \%$ (56) relataram não ter participado de capacitação sobre TB no último ano, tendo como referência a data de realização da entrevista.

Tabela 1 - $\quad$ Características pessoais dos sujeitos. São Paulo, 2015.

\begin{tabular}{cccc}
\hline Indicador & Variável & $\mathbf{N}^{\mathbf{o}}$ & $\boldsymbol{\%}$ \\
\hline \multirow{2}{*}{ Profissão } & Enfermeiro & 52 & 60,5 \\
& Médico & 34 & 39,5 \\
\hline \multirow{2}{*}{ Sexo } & Masculino & 21 & 24,4 \\
& Feminino & 65 & 75,6 \\
\hline \multirow{2}{*}{ Pós-graduação Lato Senso } & Sim & 76 & 88,4 \\
& Não & 8 & 9,3 \\
& Cursando & 2 & 2,3 \\
\hline \multirow{2}{*}{ Pós-graduação Stricto Senso } & Sim & 4 & 4,7 \\
& Não & 81 & 94,1 \\
\hline \multirow{2}{*}{${ }^{\circ}$ de serviços de saúde em que atuavam no } & Cursando & 1 & 1,2 \\
\hline controle da TB & Um & 80 & 93,0 \\
\hline \multirow{2}{*}{ Capacitação em TB } & Dois & 6 & 7,0 \\
\hline
\end{tabular}


Observa-se, na Tabela 2, que 43,0\% (37) dos profissionais entrevistados pertenciam à STS Butantã, 39,6\% (34) à STS Campo Limpo e 17,4\% (15) à STS Penha. O menor número de profissionais entrevistados na Penha decorreu do menor número de equipes de saúde e porque só foi possível a realização do estudo em 4 UBS, do total de 5 que tinham potencial para a participação, pois não foi obtida resposta por parte da quinta Unidade. Nestas STS, $44,2 \%$ (38) das unidades de saúde às quais atuavam os sujeitos do estudo eram mistas, ou seja, Unidade Básica de Saúde com Estratégia de Saúde da Família e Unidade Básica de Saúde (UBSF/UBS) e 39,5\% (34) eram UBSF.

Tabela 2 - Distribuição dos sujeitos segundo Supervisão Técnica de Saúde (STS) e modalidade de Unidade. São Paulo, 2015.

\begin{tabular}{ccc}
\hline STS/Modalidade de Unidade de Saúde & $\mathbf{N}^{\circ}$ & $\boldsymbol{\%}$ \\
\hline Campo Limpo & 34 & 39,6 \\
Butantã & 37 & 43,0 \\
Penha & 15 & 17,4 \\
\hline UBSF & 34 & 39,5 \\
UBS & 14 & 16,3 \\
Mista & 38 & 44,2 \\
\hline
\end{tabular}

\subsection{CONHECIMENTO DOS PROFISSIONAIS DE SAÚDE SOBRE A TB NO MUNICÍPIO}

Dos profissionais entrevistados, 39,5\% (34) souberam informar sobre indicadores sobre TB da área de abrangência da unidade em que trabalhavam e 81,4\% (70) consideraram a tuberculose prioritária no Município. Em relação ao conhecimento sobre as ações que compõem as políticas públicas de saúde municipais voltadas para o controle da TB, 4,6\% (4) referiram desconhecê-las; 7,0\% (7) não souberam informar se existiam e os demais $(88,4 \%$ 76) afirmaram saber sobre sua existência. As ações apontadas com maior frequência foram as seguintes: TDO, incentivos sociais, sistemas de vigilância do Município, busca ativa de sintomáticos respiratórios, controle da solicitação mensal mínima de baciloscopias de escarro, encaminhamento do paciente para isenção do imposto de renda para a pessoa com TB, 
divulgação sobre a doença na unidade de saúde por meio de panfletos, capacitações e fóruns oferecidos pela Secretaria de Saúde.

Observa-se, na Tabela 3, que 52,3\% dos entrevistados não sabiam da existência de repasse de recursos financeiros para ações de controle da TB no Município e 57,0\% não sabiam se havia investimento do Município no controle da TB. Verifica-se, portanto, desconhecimento pela maioria dos profissionais sobre como é realizado o financiamento das ações de controle da doença. Esta desinformação pode ser justificada quando apenas 2,3\% (2) dos profissionais entrevistados relataram ter participado de alguma discussão ou reunião que elucidasse a respeito dos recursos financeiros destinados ao controle da TB.

Tabela 3 Distribuição dos sujeitos em relação ao conhecimento sobre financiamento para o controle da tuberculose. São Paulo, 2015.

\begin{tabular}{ccccc}
\hline Variável & $\begin{array}{c}\text { Sim } \\
\mathbf{N}^{\circ}(\boldsymbol{\%})\end{array}$ & $\begin{array}{c}\text { Não } \\
\mathbf{N}^{\circ}(\boldsymbol{\%})\end{array}$ & $\begin{array}{c}\text { Não sabe } \\
\mathbf{N}^{\circ}(\boldsymbol{\%})\end{array}$ & $\begin{array}{c}\text { Total } \\
\mathbf{N}^{\circ}(\boldsymbol{\%})\end{array}$ \\
\hline Repasse de recursos financeiros para o Município & $34(39,6)$ & $7(8,1)$ & $45(52,3)$ & $86(100)$ \\
Investimento financeiro próprio do Município & $24(27,9)$ & $13(15,1)$ & $49(57,0)$ & $86(100)$ \\
\hline
\end{tabular}

Sobre os incentivos por parte do Município de São Paulo aos pacientes com TB, 91,8\% (79) afirmaram que eram ofertados. Porém, observa-se desconhecimento por parte dos profissionais quando 3,5\% relataram que não havia oferta e 4,7\% relataram não saber se tais incentivos eram fornecidos. Além disso, 14,0\% (12) dos sujeitos disseram que os incentivos não eram mantidos regularmente e $2,3 \%$ (2) manifestaram que isto ocorria às vezes (Tabela 4).

Tabela 4 - Distribuição dos sujeitos segundo conhecimento sobre os incentivos para a tuberculose sua regularidade. São Paulo, 2015.

\begin{tabular}{cccccc}
\hline Variável & Sim & $\begin{array}{c}\text { Não } \\
\mathbf{N}(\boldsymbol{\%})\end{array}$ & $\begin{array}{c}\text { Às vezes } \\
\mathbf{N}(\boldsymbol{\%})\end{array}$ & $\begin{array}{c}\text { Não sabe } \\
\mathbf{N}(\boldsymbol{\%})\end{array}$ & $\begin{array}{c}\text { Total } \\
\mathbf{N}(\boldsymbol{\%})\end{array}$ \\
\hline Oferta de incentivos & $79(91,8)$ & $3(3,5)$ & - & $4(4,7)$ & $86(100)$ \\
Regularidade do incentivo & $64(74,4)$ & $12(14,0)$ & $2(2,3)$ & $8(9,3)$ & $86(100)$ \\
\hline
\end{tabular}


Pode-se observar, na Tabela 5, um importante desconhecimento dos profissionais em relação às modalidades de incentivos oferecidos pelo Município aos pacientes em tratamento da TB. Em relação à cesta básica, apenas 84,9\% (73) sabiam sobre sua existência; 69,8\% (60) sabiam do vale-transporte e 5,8\% (5) desconheciam a existência de algum tipo de incentivo ao tratamento da doença.

Dos profissionais que relataram haver outros tipos de incentivos (16,3\%), é interessante ressaltar que foram considerados por eles como incentivos: lanche para os comunicantes, internação hospitalar, voucher (vale-alimentação), livre acesso à unidade de saúde, medicação, e Programa Bolsa Família e Lei Orgânica da Assistência Social (LOAS). Ressalta-se que não há documentos Municipais a respeito da oferta de lanche para os comunicantes. A internação hospitalar não é um incentivo ao tratamento, mas sim uma recomendação do MS à pacientes em situação de vulnerabilidade (moradores de rua, por exemplo) ou no caso de indicação médica. $\mathrm{O}$ voucher (vale-alimentação) é uma alternativa para as pessoas que não querem receber a cesta básica no domicílio e, portanto, dá o direito do paciente retirar a cesta em locais específicos na região, e os quatro últimos informados não são incentivos ao tratamento da tuberculose e sim direitos de todo os cidadãos.

Tabela 5 - Distribuição dos sujeitos do estudo segundo conhecimento sobre os incentivos ofertados pelo Município. São Paulo, 2015.

\begin{tabular}{ccccc}
\hline Incentivos & $\begin{array}{c}\text { Sim } \\
\mathbf{N}^{\circ}(\boldsymbol{\%})\end{array}$ & $\begin{array}{c}\text { Não } \\
\mathbf{N}^{\circ}(\boldsymbol{\%})\end{array}$ & $\begin{array}{c}\text { Não sabe } \\
\mathbf{N}^{\circ}(\boldsymbol{\%})\end{array}$ & $\begin{array}{c}\text { Total } \\
\mathbf{N}^{\circ}(\boldsymbol{\%})\end{array}$ \\
\hline Cesta básica & $73(84,9)$ & $8(9,3)$ & $5(5,8)$ & $86(100,0)$ \\
Café da manhã & $1(1,2)$ & $80(93)$ & $5(5,8)$ & $86(100,0)$ \\
Lanche & $10(11,6)$ & $71(82,6)$ & $5(5,8)$ & $86(100,0)$ \\
Vale-transporte & $60(69,8)$ & $21(24,4)$ & $5(5,8)$ & $86(100,0)$ \\
Outros & $14(16,3)$ & $72(83,7)$ & - & $86(100,0)$ \\
\hline
\end{tabular}

Em relação ao TDO, 90,7\% (78) dos profissionais entrevistados disseram que a estratégia contribui para a adesão do paciente ao tratamento da TB; 5,8\% (5) disseram não contribuir para a adesão e 3,5\% (3) relataram que contribui "às vezes". Os profissionais que se posicionaram negativamente ao TDO declararam que os pacientes "possuem dificuldades em vir todos os dias", que o TDO "é um tratamento difícil para a rotina do paciente" e porque "há pacientes que não precisam, depende da situação socioeconômica". 


\subsection{ORGANIZAÇÃO DO SERVIÇO DE SAÚdE PARA O ATENDIMENTO DO PACIENTE COM TB}

Pode-se observar, na Tabela 6 , que $81,4 \%$ dos entrevistados sabiam informar que a unidade de saúde realiza TDO três vezes ou mais durante a semana e 22,1\%, relataram que isto ocorria menos do que três vezes na semana. Alguns profissionais relataram que, mesmo que na unidade de saúde seja disponibilizado o TDO mais de três vezes na semana, há pacientes que recorrem à unidade de saúde menos do que três vezes na semana. Vale ressaltar que $10,5 \%$ dos profissionais entrevistados não sabiam relatar a forma como a unidade está organizada para realizar o TDO.

Continuando a descrição dos resultados contidos na Tabela 6, a respeito da supervisão do tratamento, verifica-se que 53,5\% dos profissionais relataram o auxiliar/técnico de enfermagem a realiza, 47,7\% apontam o enfermeiro, 27,9\% a Equipe de Vigilância Epidemiológica, 24,4\% o agente comunitário de saúde (ACS), sendo este profissional mencionado apenas para o TDO realizado no domicílio do paciente, 7,0\% o médico e 1,2\% o assistente social. Vale ressaltar que 5,8\% dos profissionais também não souberam responder quem realiza a supervisão. É importante esclarecer que os profissionais elencaram mais de um profissional na realização da supervisão do TDO.

Tabela 6 - Distribuição dos sujeitos segundo frequência semanal do Tratamento

Diretamente Observado e categoria profissional que realiza a supervisão.

São Paulo, 2015.

\begin{tabular}{ccccc}
\hline Frequência TDO/Profissional que supervisiona & $\begin{array}{c}\text { Sim } \\
\mathbf{N}^{\circ}(\boldsymbol{\%})\end{array}$ & $\begin{array}{c}\text { Não } \\
\mathbf{N}^{\circ}(\boldsymbol{\%})\end{array}$ & $\begin{array}{c}\text { Não sabe } \\
\mathbf{N}^{\circ}(\boldsymbol{\%})\end{array}$ & $\begin{array}{c}\text { Total } \\
\mathbf{N}^{\circ}(\boldsymbol{\%})\end{array}$ \\
\hline$\geq 3$ vezes & $70(81,4)$ & $7(8,1)$ & $9(10,5)$ & $86(100)$ \\
$<3$ vezes & $19(22,1)$ & $58(67,4)$ & $9(10,5)$ & $86(100)$ \\
\hline Auxiliar/técnico de enfermagem & $46(53,5)$ & $35(40,7)$ & $5(5,8)$ & $86(100)$ \\
Enfermeiro & $41(47,7)$ & $40(46,5)$ & $5(5,8)$ & $86(100)$ \\
Equipe de Vigilância Epidemiológica & $24(27,9)$ & $57(66,3)$ & $5(5,8)$ & $86(100)$ \\
ACS & $21(24,4)$ & $60(69,8)$ & $5(5,8)$ & $86(100)$ \\
Médico & $6(7,0)$ & $75(87,2)$ & $5(5,8)$ & $86(100)$ \\
Assistente social & $1(1,2)$ & $80(93,0)$ & $5(5,8)$ & $86(100)$ \\
\hline
\end{tabular}


Nas unidades de saúde que possuem Equipe de Vigilância Epidemiológica, composta por enfermeiro e auxiliar/técnico de enfermagem, o paciente é acompanhando pela equipe da ESF e a equipe de Vigilância Epidemiológica realiza o TDO.

Em caso de abandono do TDO, 98,8\% (85) dos profissionais souberam informar que a unidade realiza ações para tentar resgatar o paciente, mas chama a atenção que 1,2\% relataram que nenhuma ação é realizada. As ações relatadas foram "busca ativa", "visita domiciliar", e "contato telefônico".

Em relação à regularidade na distribuição da medicação para o Município, 91,8\% (79) profissionais apontaram que é realizada em tempo hábil para não faltar ao paciente; 1,2\% (1) não soube informar; 5,8\% (5) relataram que é feita "às vezes” em tempo hábil, declarando que "houve falta da medicação no ano passado" (isto é, em 2014) e que "às vezes há falta do medicamento e a unidade precisa esperar pelo abastecimento da farmácia”; e 1,2\% (1) relatou que a distribuição não era feita em tempo hábil, declarando que "já faltou medicamento várias vezes".

Em relação à realização de radiografia de tórax, 61,6\% (53) dos profissionais relataram que a unidade realiza este exame. Os profissionais que responderam negativamente justificaram solicitar o exame para todos os pacientes, os quais são encaminhados ao serviço de referência. Portanto, a radiografia de tórax é solicitada a todos os pacientes, porém, alguns a realizam na própria unidade de saúde que o assiste e outros a realizam no serviço de referência da UBS.

Na Tabela 7, observa-se que apenas 31,4\% dos profissionais responderam que os resultados de baciloscopia de escarro chegam à unidade em menos que cinco dias e 15,1\% dos profissionais responderam que os resultados deste exame chegam à unidade entre 6 a 10 dias. Vale ressaltar que muitos profissionais declararam que, quando positivo, o resultado é informado pelo laboratório que o realizou, em três dias por telefone ou por correio eletrônico, para que a unidade convoque o paciente. Porém, o resultado impresso demora a chegar. Em relação à radiografia de tórax, $79,1 \%$ dos profissionais relataram que o resultado é recebido em menos que cinco dias. 
Tabela 7 Distribuição dos sujeitos segundo menção ao período de tempo para recebimento do resultado de exames para diagnóstico da tuberculose. São Paulo, 2015.

\begin{tabular}{ccccccccc}
\hline $\begin{array}{c}\text { Exame/Frequência } \\
(\mathbf{e m ~ d i a s})\end{array}$ & $\begin{array}{c}\mathbf{1 - 5} \\
\mathbf{N}^{\circ}(\boldsymbol{\%})\end{array}$ & $\begin{array}{c}\mathbf{6 - 1 0} \\
\mathbf{N}^{\circ}(\boldsymbol{\%})\end{array}$ & $\begin{array}{c}\mathbf{1 1 - 1 5} \\
\mathbf{N}^{\circ}(\boldsymbol{\%})\end{array}$ & $\begin{array}{c}\mathbf{1 6 - 2 0} \\
\mathbf{N}^{\circ}(\boldsymbol{\%})\end{array}$ & $\begin{array}{c}\mathbf{2 1 - 3 0} \\
\mathbf{N}^{\circ}(\boldsymbol{\%})\end{array}$ & $\begin{array}{c}\mathbf{3 0 - 6 0} \\
\mathbf{N}^{\circ}(\boldsymbol{\%})\end{array}$ & $\begin{array}{c}\text { Não sabe } \\
\mathbf{N}^{\circ}(\boldsymbol{\%})\end{array}$ & $\begin{array}{c}\text { Total } \\
\mathbf{N}^{\circ}(\boldsymbol{\%})\end{array}$ \\
\hline $\begin{array}{c}\text { Baciloscopia de } \\
\text { escarro }\end{array}$ & $27(31,4)$ & $13(15,1)$ & $17(19,8)$ & $11(12,8)$ & $11(12,8)$ & $2(2,3)$ & $5(5,8)$ & $86(100)$ \\
$\begin{array}{c}\text { Radiografia de tórax } \\
\text { (68) }\end{array}$ & $79,1)$ & $7(8,1)$ & $7(8,1)$ & $1(1,2)$ & - & - & $3(3,5)$ & $86(100)$ \\
\hline
\end{tabular}

Em relação à realização da prova tuberculínica, 14,0\% (12) dos profissionais relataram que a unidade de saúde oferecia o exame; 79,0\% (68) mencionaram que a unidade não o realiza, declarando que, em caso de necessidade, encaminhavam o paciente ao serviço de referência"; e os restantes (7\% - 6) relataram não saber se a unidade disponibilizava o teste, mostrando, novamente, o desconhecimento de profissionais sobre a rotina do serviço em que trabalham.

\subsection{SIGNIFICADOS CONTIDOS NA ANÁLISE DOS DEPOIMENTOS DOS PROFISSIONAIS DE SAÚDE}

Conforme mencionado no capítulo referente aos "Métodos", os depoimentos dos profissionais de saúde foram analisados por técnica que permitiu a decodificação dos depoimentos em frases temáticas. Da análise dos depoimentos emergiram quatro conjuntos de significados, sendo que o primeiro foi decomposto em dois, dada a sua especificidade, os quais são apresentadas no quadro (Quadro 1) abaixo.

Quadro 1 - Significados que emergiram da análise dos depoimentos dos profissionais de saúde. São Paulo, 2015.

\begin{tabular}{|c|c|c|c|c|}
\hline \multirow{2}{*}{$\begin{array}{c}\text { I. Os incentivos: } \\
\text { a) Importância para a } \\
\text { adesão ao tratamento } \\
\text { b) Irrelevância para a } \\
\text { adesão ao tratamento }\end{array}$} & $\begin{array}{c}\text { II. Condições de vida } \\
\text { das pessoas acometidas } \\
\text { pela tuberculose }\end{array}$ & $\begin{array}{c}\text { III. Vínculo formado } \\
\text { entre a equipe de saúde e } \\
\text { o paciente durante o } \\
\text { tratamento }\end{array}$ & $\begin{array}{c}\text { IV. Sugestões de } \\
\text { mudança da situação } \\
\text { epidemiológica da TB }\end{array}$ \\
\hline
\end{tabular}




\subsubsection{Significado I: Os incentivos}

Identificou-se, nos discursos dos profissionais, que os incentivos oferecidos pelo Município, ao paciente em tratamento da tuberculose, são importantes para a adesão ao tratamento para determinados grupos e irrelevantes para outros, conforme será verificado a seguir, separadamente, para objetivar a apresentação.

a) Importância para a adesão tratamento

$\mathrm{Na}$ análise dos depoimentos identificou-se apenas um profissional que apontou não se lembrar de nenhum caso em que os incentivos sociais significaram cura para o paciente. Os demais profissionais ressaltaram a importância da oferta dos incentivos (C5, C6, I2, L2, L3, P2, P3, S1, T1, T6), apontando-se que são fundamentais aos pacientes com menor poder aquisitivo e em situação de vulnerabilidade social (G3, I1, J1, K1, M1, P1, Q1, R1, T2, T3, $\mathrm{U} 1, \mathrm{~V} 1, \mathrm{~W} 1, \mathrm{X} 1, \mathrm{Y} 1, \mathrm{Z1})$, conforme pode-se verificar nos excetos abaixo:

- $\quad$ “... ajuda muito no tratamento, porque a pessoas sabe que ela só vai receber a cesta básica se ela fizer o tratamento muito regular... são pacientes com baixa renda..., com uma vulnerabilidade social maior" (U1).

- “... quanto mais carente esse paciente for, realmente, a cesta básica faz um diferencial muito grande, porque ele vira como um meio de sustento pra essa família..." (V1).

- “... não era só uma pessoa que vivia nessa casa e eles não tinha renda... não tinha benefício nenhum... foi uma adesão muito grande porque ela sabia que podia contar com essa cesta básica,... que podia contar com esse benefício" (Z1).

Os sujeitos do estudo apontaram que, mesmo no caso de pacientes que não consideravam a cesta básica como algo fundamental ao tratamento $(\mathrm{G} 7, \mathrm{P} 2)$, ela era positiva, pois os pacientes vivem “... numa região de vulnerabilidade, onde o poder aquisitivo é baixo... pra eles é um plus... é bom ter a cesta” (G7).

Diversos profissionais apontaram a importância da cesta básica para a "nutrição adequada” (B1) do paciente durante o tratamento da doença (B1, C9, G1, K2, L1, M1, N1), 
sendo que muitos pacientes, por vivenciarem restrições socioeconômicas, "... sustentam a família inteira com a cesta básica" (C11, H1, H2, J4, K1, L1, V1). Os profissionais de saúde mencionaram que alguns pacientes vivenciam situação social complexa, de tal forma que é necessária a coparticipação do Núcleo de Apoio à Saúde da Família (NASF) e da SUVIS para auxiliar na condução dos problemas (Z2), pois transcendem a esfera biológica.

A satisfação dos pacientes, ao serem informados sobre o direto aos incentivos foi evidenciada, como no relato: “... a gente vê os olhos dos pacientes brilharem em questão do benefício" ( $(\mathrm{C} 1, \mathrm{C} 2, \mathrm{O} 1, \mathrm{R} 2)$. Assim, também, em alguns casos, utiliza-se da possível interrupção do incentivo para que o paciente mantenha a assiduidade no TDO (C7, C8, G2).

Constatou-se que o lanche não era oferecido nas regiões onde foi desenvolvido o estudo. Alguns profissionais manifestaram sentimento de pesar por tal falta. Um deles manifestou sentir comiseração ao atender os pacientes em jejum: “... a gente pega nossa bolacha”, oferecendo-a ao paciente (K7). Outros alegaram que a adesão era significativa quando os pacientes recebiam este incentivo, além de mencionarem que possibilitava um momento de aproximação entre os profissionais e os pacientes (C13-15, M1): "... tomavam café... e era oportunidade de conversar sobre a vida" (C14).

Apontou-se que a oferta do lanche, mesmo que para alguns profissionais pudesse parecer insignificante (K6), para os pacientes que "não tem condições financeiras” (K6), é essencial para o sucesso do TDO, afirmando-se que o tratamento era realizado "direitinho... porque tinha o cafe’” (K5).Em algumas UBS foram constatadas singularidades, a exemplo das unidades pertencentes à região da STS Penha, que apresentava importante demanda de pacientes oriundos da Bolívia. Para estes pacientes, o TDO, associado aos incentivos, é fundamental para a adesão e finalização do tratamento da doença (E3, L1, L2, N1, T2-4), principalmente pelo fato de que tais pessoas mudam de trabalho com frequência e, consequentemente, de endereço. Assim, o vale-transporte significa “... incentivo para continuar o tratamento dele até o final, independente do lugar onde ele esteja” (T4).

Mas, não somente para a população boliviana o vale-transporte é considerado como incentivo ao tratamento. Um dos profissionais de saúde apontou a sua importância deste incentivo no caso de necessidade de realização de radiografia de tórax em unidade de referência (W1).

b) Irrelevância para a adesão ao tratamento 
Identificaram-se cinco profissionais que não se lembravam de casos em que os incentivos foram irrelevantes para a cura do paciente. Outros profissionais (7) relataram lembrar-se de casos em que o incentivo não foi significativo para a adesão e cura do paciente em tratamento da TB (B2, C19, C20, C22, D1, D2, D3, E4, E5, G5, H3, I3), pois nesses casos os pacientes são considerados de "dificil controle" (G4). Seguem-se excertos de depoimentos que ilustram tal afirmação:

- $\quad$ Negligência da mãe com o tratamento de uma criança (B2, Z3): “... a mãe... era muito relapsa” (Z3);

- $\quad$ Negligência do paciente com a própria saúde (C20, N2): “comia a hora que ele queria... fumava demais... não tomava a medicação... o final de semana, apesar de levar" (N2), visto que "... quando o paciente não quer mesmo se envolver com a saúde" (C20);

- Histórico de violência na família: “... prejudicava e dificultava ela vir... questão importante de violência que ela sofria pelo marido" (O3);

- Uso de drogas ilícitas, etilismo ou tráfico de drogas (C22, E4, E5, J3, S2, V2, Y2, Z3): “... você pode oferecer o que... quiser... nada segura, porque se ele não tá a fim de largar isso... não tem dinheiro nenhum que faça ele aderir e chegar à cura ...por mais que eu tivesse feito, que acolhi com tudo... não teve jeito ... passando fome, sem emprego, sem nada ... a cesta era uma ajuda ...e ... mesmo assim, você vê que não é isso que vai segurá-los" (E4, E5);

- $\quad$ Situação econômica estável (D3, F2, O2, U2, V2, W2): “... classe média... que tá perto da unidade, que, às vezes, tem convênio" (F2), "pra ela não mudava nada... falava da questão do emprego, que ela não precisava” (O2);

- Paciente jovem (D3, D4): “... jovem... que tinha alguns recursos... $e$ trabalhava... que, apesar de receber a cesta básica... isso para ela não fazia diferença... provavelmente ela... dava pra outras pessoas" (D3);

- Compreensão da importância do tratamento independente de incentivos (G5, T7, U2): “queria era se livrar da doença... tinha um objetivo... o objetivo dela era concluir... todo o esclarecimento que ela tinha, ajudou a entender a importância 
do tratamento... esclarecimento de ela saber que é parte da saúde dela... foi primordial pra ela fazer o tratamento até o final... ela compreendeu a necessidade de ter um rigor no tratamento" (T7).

- $\quad$ Moradores de rua (H3, I3, I4): “eles não tem como tá recebendo... não querem pegar o voucher... não tem o discernimento... que o incentivo social... pode ser um auxílio para o tratamento” (H3), “... pegava a cesta básica, mas acho que ele trocava até por bebida" (I4). Além disso, os profissionais ponderam que esta população não possui um lugar para preparar os alimentos fornecidos por meio da cesta básica: “... contribuía mais a gente dar dois pãezinhos para ele...” (I3);

- Não aceitação da doença: “como ela tinha diabetes, ela achava que o problema dela era só diabetes" (K3).

Alguns profissionais admitem o incentivo apenas como ferramenta para intimidar o paciente e não como facilitador para a adesão, "é mais aquela questão de intimidação... não aquilo auxiliando por si só... é mais por medo de perder o beneficio” (A4), apontando que há pacientes que, diante da possibilidade de perda do benefício dizem: “não me importo” (C21).

A contribuição para a Previdência Social concede o direito da pessoa requerer o benefício quando em caso de afastamento do trabalho pela doença. A este respeito, relatou-se dificuldade dos pacientes em conseguir este benefício (C16, C19): "... tá um pouco distante da gente... é algo muito complicado... É muita burocracia" (C16).Em relação à aposentadoria por invalidez, mencionou-se que há empresas que tentam aposentar o paciente por preconceito à doença, porém os profissionais entrevistados desconheciam pacientes que houvessem obtido esta modalidade de aposentadoria, devido à dificuldade em sua tramitação $(\mathrm{C} 17, \mathrm{C} 18)$.

Dentre os profissionais que relaram não considerar o incentivo como benéfico para a adesão ao tratamento, apontou-o como positivo para melhorar a vida das pessoas, ou seja, não associam o incentivo como um benefício à saúde e sim como um benefício social: “... Bolsa Família, ou qualquer outro incentivo desse tipo... ajuda a melhorar a qualidade de vida da pessoa, da família, mas isso aí acaba não ficando bem colado na saúde” (A1). 


\subsubsection{II: Condições de vida das pessoas acometidas pela tuberculose}

Considerando-se que a tuberculose é uma doença determinada socialmente e que, portanto, está associada às condições de vida e de trabalho as quais a pessoas estão submetidas, temos nesta categoria a materialização de potenciais de desgaste relatados pelos profissionais e que revelam a expressão da enfermidade.

Relata-se que as pessoas acometidas pela TB, de maneira geral, "sustentam a família inteira com a cesta básica", possuem "baixa renda", "moram mal”, "passam fome”, vivenciam uma "situação precária" de vida e de "vulnerabilidade muito extrema em relação ao seu trabalho" e utilizam os benefícios sociais para a "manutenção familiar" (C11, C12, E2, H1, L1, M1, T8, U1, Z1).

Alega-se que esta enfermidade é prevalente em regiões periféricas, onde há pessoas que realmente precisam dos incentivos (J2), sendo que "os maiores casos de gravidade que a gente tem, são pessoas que tem uma situação precária...” (T8).

Afirma-se que, pelo fato dos pacientes acometidos pela doença, de maneira geral, apresentarem "baixa renda", já estão cadastrados no Programa Bolsa Família (C12) e que, muitas vezes, a oferta do incentivo, principalmente a cesta básica, é “... camuflado pela real necessidade que as famílias hoje passam no bairro" (C10). Neste sentido, o lanche/café da manhã, que anteriormente era oferecido regularmente pelo Município para integrar o TDO, é lembrado como muito importante, pois em muitos casos, era "a única alimentação que tinha durante o dia" (M1).

O benefício da cesta básica é o incentivo identificado como o mais significativo para pessoas em "situação precária" de vida (B1, C11, L1), na medida em que muitos pacientes "sustentam a família inteira com a cesta básica" (C1), “... na maioria das vezes... não tem o que comer... ajudam a família..." (L1). Observou-se, também que, para alguns profissionais de saúde, a precariedade de vida de certos pacientes faz com que não queiram finalizar o tratamento para poderem continuar a receber a cesta básica ou, até mesmo, abandonam o tratamento no último mês para continuar recebendo-a $(\mathrm{C} 3, \mathrm{C} 4, \mathrm{E} 2)$.

Outros relatos sobre a importância da cesta básica como fortalecimento para a adesão ao tratamento da TB são evidenciados abaixo: 
- “ajuda muito no tratamento porque a pessoas sabe que ela só vai receber a cesta básica se ela fizer o tratamento muito regular... são pacientes com baixa renda..., com uma vulnerabilidade social maior" (U1);

- “... não era só uma pessoa que vivia nessa casa e eles não tinham renda... não tinham benefício nenhum... foi uma adesão muito grande porque ela sabia que podia contar com essa cesta básica,... que podia contar com esse benefício" (Z1).

Para alguns casos de pessoas procedentes da Bolívia que "moram mal”, "passam fome" e por vivenciarem "situação de vulnerabilidade muito extrema com relação ao seu trabalho... renda muito diminuida" (H1), a cesta básica atua como uma forma de “manutenção familiar" para que, além do paciente, toda a família possa alimentar-se e por este motivo são motivados a realizar o TDO diariamente (E2).

\subsubsection{Significado III: Vínculo formado entre a equipe de saúde e o paciente durante o tratamento}

Os depoimentos sinalizaram a importância da associação entre os incentivos e o vínculo entre os profissionais de saúde e o paciente para a consecução da adesão ao tratamento (A2, A3, A5, F1, Q3 T5, X2-X4). Considera-se que o "vínculo com o paciente... é a base, é fundamental" (A3) para a cura da doença, pois possibilita "amarrar o tratamento" (F1), principalmente nos casos de famílias vulneráveis.

A importância do vínculo construído durante o TDO é evidenciada no seguinte depoimento: “... vínculo, de você entregar todo dia o medicamento pra ele... e mostrando a importância do tratamento... é diferente de você entregar uma vez. por mês... você acaba nem conhecendo o paciente da área" (X3).

Em especial, o vínculo é muito relevante no caso dos pacientes oriundos de outro país, como no caso dos bolivianos. Apontou-se, inclusive, a necessidade de estabelecimento de vínculo com o "chefe" do local onde estas pessoas trabalham para que entendam a importância do tratamento do paciente e facilitem a sua liberação para a condução do TDO (T5). Da mesma forma, para a população provida de melhor condição socioeconômica, em 
que o incentivo foi apontado como não significativo pelos profissionais, o vínculo fortalece a compreensão da importância do tratamento ser conduzido corretamente para o alcance da cura (X2).

Mencionou-se, também, a relevância da Estratégia de Saúde da Família, pois facilita a formação de vínculo “... com o posto, com a unidade” (A2) e possibilita o acesso a toda a família (A2, X4):

- “... ir na casa do paciente... conhecer a família dele,... explicar pra família porque que é tuberculose, a importância que ele faça o tratamento... conhecer a família... filho, filha, outros parentes envolvidos... acaba-se tendo uma rede familiar que ajuda no tratamento" (X4).

\subsubsection{Significado IV: Sugestões de mudança da situação epidemiológica da TB}

Os profissionais de saúde manifestaram sua posição a respeito do que pode melhorar a atual situação epidemiológica do MSP

Assim, verificou-se que os profissionais ponderam que o País deveria investir no modelo de atenção de promoção à saúde:

- “... o Brasil tem uma cultura muito curativa e não preventiva... não adianta só forçar mesmo essas questões de hospitais de ponta, tecnologia... a gente não tem uma boa estrutura de base... se o problema de base, relacionado à prevenção, à promoção de saúde fosse resolvido, se as unidades tivessem o tempo necessário para resolver, para planejar, implantar e implementar essas ações” (T11);

- “mudar a mentalidade dos profissionais... mudar a cultura brasileira... procuramos saúde quando estamos doentes, nós não procuramos saúde pra prevenção” (V5).

Também foi verificado que os sujeitos do estudo percebem a necessidade de envolvimento das equipes de saúde para a efetivação de mudanças: “... das políticas que são elaboradas de cima pra baixo, mas, também, do movimento da cadeia daqueles que estão na 
ponta..., fazer com que o funcionário compreenda o papel dele na sociedade... como um agente transformador" (V5).

Outro aspecto importante refere-se à necessidade de difusão da situação da TB: " $a$ mídia deveria divulgar mais" (H4, N3, S3, U4, U5, Z6). A deficiência da difusão de informação provoca o falso pensamento de que "a tuberculose foi erradicada" (S3), ou: "o que atrapalha... muitos tratamentos é a desinformação... que gera o preconceito e este faz com que o paciente se esconda” (A10).

Além da divulgação nos meios de comunicação, pondera-se a necessidade de divulgação do Programa de Controle da Tuberculose em outros equipamentos, como escolas e estações de metrô (F3, U5). Além disso, apontou-se como fundamental a sensibilização dos futuros profissionais de saúde durante a formação acadêmica (E7): “o povo morre disso” (E7) e os profissionais que "chegam agora pra trabalhar na ponta... não valorizam essa questão da tuberculose" (E6).

Sugeriu-se que as informações do sistema TBWEB sejam disponibilizadas para acesso dos profissionais que trabalham em hospitais e UBS, o que possibilitaria saber o histórico do paciente em relação ao tratamento da TB (quantos tratamentos o paciente já realizou, se houve abandono do tratamento, por exemplo) (U4). Isto porque afirmou-se que o profissional de saúde dispende longo tempo para entrar em contato com a SUVIS e obter a informação necessária para o estabelecimento da conduta. Por vezes, ocorre que o paciente inclusive já recebeu uma conduta médica e que não é conhecida pelos profissionais que farão atendimentos posteriores. Assim, dispor da informação do TBWEB tornaria o processo mais ágil, e contar-se-ia com informação fidedigna a respeito do tratamento que pode ser sido instituído.

Apontou-se a necessidade de prover recursos econômicos ao setor da saúde (W3), assim como a necessidade de "organização do serviço de gestão" para interligar unidades, formando redes de atenção à saúde (C23), além de ter sido mencionada a necessidade de uma política de ação que ampare os pacientes usuários de drogas ilícitas e que realizam o tratamento da TB, com local especifico para o seu acompanhamento (U4). Também foi indicada a necessidade de dispor de serviço de referência para o encaminhamento de pacientes com TB resistente e extrapulmonar, pois estes apresentam "mais dificuldade no manejo dos casos" (W3). 
Em relação aos incentivos, defendeu-se a necessidade de esclarecer os profissionais de saúde a respeito das medidas de apoio (I5). Além disto, incrementar as medidas de apoio já existentes para melhorar a vida das pessoas, como o Programa Bolsa Família, a cesta básica e o vale-transporte (B4, I5, Q2, R4).

Foram apontadas críticas ao modelo atual de atendimento aos usuários do serviço de saúde, alegando-se a necessidade de aumentar o tempo estipulado para o atendimento ambulatorial: "quinze minutos é impossível... você pode tá atendendo um paciente diabético, hipertenso e ele ser um paciente com tuberculose e você talvez não consiga na consulta identificar, porque o tempo é curto" (Y3). Ao contrário da maior parcela dos sujeitos deste estudo, um deles questionou a forma como o Programa de Controle da TB recomenda a realização do TDO, ponderando-se que a supervisão da tomada da medicação dificulta o estabelecimento do vínculo: "expira falta de confiança para com o paciente... você acaba quebrando um vínculo de confiança" (C25). Sugeriu-se, ainda, que a assistência deve ser individualizada, pactuando-se a condução do tratamento com o paciente e "não só a imposição... tentar partilhar este plano mesmo com cada um” (D5).

Os sujeitos do estudo também indicaram a necessidade de tratamento adequado de pacientes nos presídios (P4), apadrinhamento em caso de pacientes "dificeis" como usuário de drogas e moradores de rua (P4), fixação de médicos na rede de unidades básicas de saúde, com bons salários (V5) e a criação de um "dispositivo de fazer teste mais rápido... na unidade de saúde" (I5).

Com o intuito de melhorar a situação atual da tuberculose no MSP, apontou-se a necessidade de continuar a conscientização da população e com a "busca ativa", realizada nas unidades de saúde (A6, F3, Q2, G8, H4, J5, N3, R4, V5, W3, X5), esta última, inclusive durante as "consultas... até os que parecem que não são nada", incrementando-a onde há importante concentração de jovens, à exemplo de "baile funk" e "balada", escolas e empresas (N3, F3).

Entretanto, para que estas ações ocorram de maneira efetiva, faz-se necessário o quadro de funcionários completo (A6, G8, L4). Também apontou-se que o "monitoramento dos comunicantes" consiste em uma ação "muito importante" já realizada nas unidades de saúde, porém alega-se que sua realização "ainda é falha” (F4), devido à carência de recursos humanos. 
Apontou-se, ainda, a necessidade de "investimento em vigilância", com a disponibilidade de um enfermeiro ou uma equipe exclusiva para monitorar a vigilância em saúde nas unidades de saúde (G8, L4, O4). Porém, mencionou-se que, em caso de provimento desta equipe, ela deve estabelecer parceria constante com a equipe de saúde para que todos se responsabilizem pelo cuidado do paciente para: "entender os problemas, entender as dificuldades e, a partir dai, ter um olhar de como melhorar esse serviço" (O4). Da mesma forma, apontou-se como fundamental que a SUVIS esteja "mais próxima" das unidades de saúde (Z5).

Declarou-se necessária a sensibilização dos profissionais em relação à situação da tuberculose, pois muitos profissionais recém-formados e que trabalham em convênio (E8), não valorizam a doença e, mesmo os profissionais que atuam na atenção primária à saúde (APS) "não são conscientes da importância do papel da atuação deles frente ao paciente com tuberculose" (U4). Além deste, outros depoimentos apontaram a importância da motivação do profissional de saúde na prevenção da TB (P4, R4, Y3). Isto porque, afirmou-se que o profissional de saúde “... não tem responsabilidade, ele cumpre metas... é da responsabilidade do profissional que tem que ter essa visão ampla do que é saúde pública" (V6).

Em relação ao TDO, admitiu-se a importância do atendimento humanizado (C23) e da criação do "vinculo" entre a equipe de saúde e o paciente (C23, Q2). Verificou-se preocupação em relação aos pacientes que residem "longe” (G8), e a necessidade de melhorar o espaço físico para o atendimento dos pacientes submetidos à estratégia, devido ao aumento do número de casos em profissionais da saúde (I5). Outras necessidades também foram apontadas pelos profissionais para garantir a agilidade e a qualidade nos exames laboratoriais para o diagnóstico e o acompanhamento dos casos, a exemplo da disposição de equipamento para armazenamento adequado das amostras de material coletado em visitas domiciliares e eficiência na manutenção dos equipamentos de armazenamento do material biológico na unidade de saúde (M2).

Em relação aos aspectos voltados diretamente aos pacientes, ponderou-se que "é muito difícil a gente mudar a mentalidade de algumas pessoas em relação a se comprometer com a própria saúde... eles se comprometem com o cartão (vale-transporte), com cesta básica, com Bolsa Família” (T10). Neste sentido, apontou-se dificuldade na implementação de ações educativas e de prevenção à saúde, pautada no entendimento de que, nos últimos tempos 
houve "uma ascensão de poder aquisitivo das pessoas, mas elas só pensam de suprir necessidades de conquistas materiais... mas a saúde não é cuidada... o próprio cidadão chega ... só querendo a troca da receita, querendo resolver o problema, mas a gente tenta fazer ações educativas, não tem aderência e eles acham que não tem necessidade” (T2).

Em relação aos incentivos, alega-se que "a população tem mais medo de perder o benefício do que, muitas vezes, da própria doença” (A9) e que “... infelizmente, na população brasileira o que funciona não é o dar... o que funciona mesmo é o risco de perder aquele incentivo” (A7). Portanto, sugere-se que incentivos públicos (federal, estadual, municipal) sejam retirados em caso de pacientes que não aderem ao tratamento, como "uma punição" (A8).

Ainda sobre os incentivos, sugere-se a entrega da cesta básica no domicílio dos pacientes, em virtude da debilidade que em geral apresentam: "não conseguem carregar... pagar alguém pra ir buscar, eles não tem condições” (K4). Em relação ao incentivo do lanche/café, preconizado pelo MS, solicita-se o seu retorno, integrando o TDO, pois “facilitaria o supervisionado”, para que o paciente não permaneça em jejum após tomar a medicação (K4).

\subsection{A SITUAÇÃO EPIDEMIOLÓGICA DA TB NO MUNICÍPIO DE SÃO PAULO E O PROVIMENTO DE INCENTIVOS}

Conforme exposto em seção anterior, os dados a seguir apresentados foram obtidos a partir da base denominada TBWEB, e foram fornecidos pela Coordenação de Vigilância em Saúde (COVISA) e pelo Programa de Controle da Tuberculose do Município de São Paulo (PCT). Estes dados possibilitam identificar a distribuição demográfica da doença no MSP e confrontar os aspectos positivos da distribuição de cestas básicas com a taxa de cura da doença.

Até o momento da obtenção das informações, o banco de dados com os casos novos de tuberculose apresentava $5.672^{2}$ casos no Município, com taxa de incidência de 49,3/100.000 habitantes ${ }^{1}$. Apresenta-se, no Gráfico 1 , a distribuição da taxa de incidência por SUVIS. As SUVIS referentes às STS Butantã, Campo Limpo, e Penha, regiões onde se desenvolveu o

2 Dados fornecidos pelo PCT/COVISA do Município de São Paulo. 
presente estudo, apresentam taxa de incidência de 41,8/100.000 habitantes, 44,7/100.000 habitantes e 45,3/100.000 habitantes, respectivamente. Observa-se que a SUVIS Itaim Paulista apresenta a maior taxa de incidência do MSP (68,7/100.000 habitantes), seguida da SUVIS Sé (65,9/100.000 habitantes). Já a SUVIS Lapa/Pinheiros apresenta a menor taxa de incidência do Município (22,3/100.000 habitantes $)^{3}$.

3 Dado extraído do TBWEB dia 11/09/2015 pelo Programa de Controle da Tuberculose do Município de São Paulo, cujo banco de dados ainda não havia sido finalizado. Desta forma, os dados referentes ao ano de 2014 são considerados provisórios. 
Gráfico 1 - $\quad$ Taxa de incidência da tuberculose por Supervisão Técnica de Vigilância em Saúde. São Paulo, 2015.

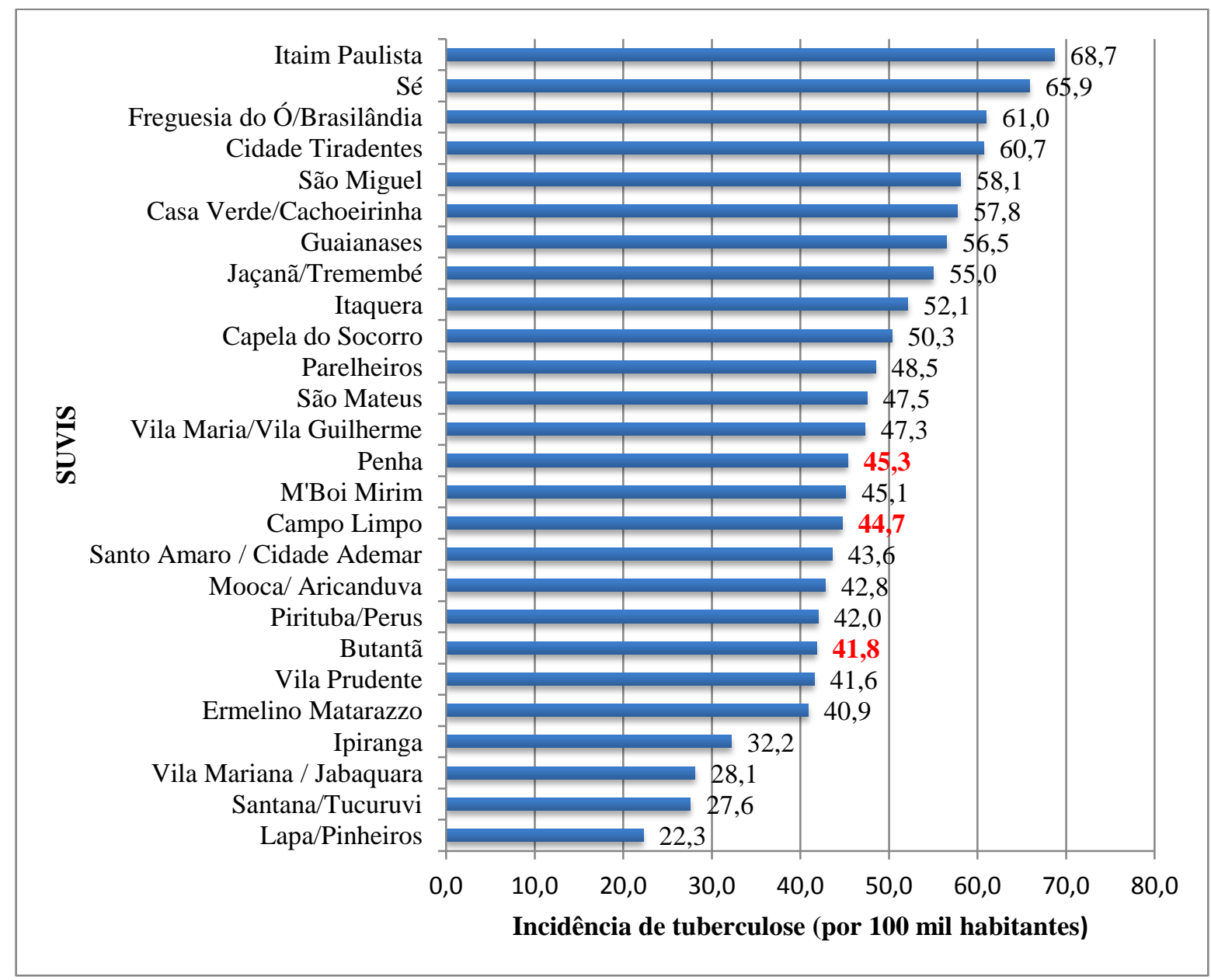

Fonte: $\quad$ TBWEB/PCT/COVISA, acesso em 11/09/2015.

Em 2014, o MSP apresentava 71,5\% de cura ${ }^{1,2}$, e as SUVIS Campo Limpo, Butantã e Penha $81,9 \%, 73,9 \%$ e $71,9 \%$ respectivamente, com taxa de abandono de 6,0\%, 9,4\% e 15,2\%, respectivamente. A SUVIS M’Boi Mirim foi a única a alcançar a meta de cura proposta pela OMS $(85,5 \%)$ e, concomitantemente, apresentou a menor taxa de abandono do Município (5,0\%). A SUVIS Sé apresentou a menor taxa de cura $(65,8 \%)$ e a SUVIS Pirituba/Perus a maior taxa de abandono do Município - 18,9\% - (Gráfico 2$)^{2}$. 
Gráfico 2 - $\quad$ Taxa de cura e abandono de casos novos de tuberculose por Supervisão de Vigilância em Saúde de residência. São Paulo, 2015.

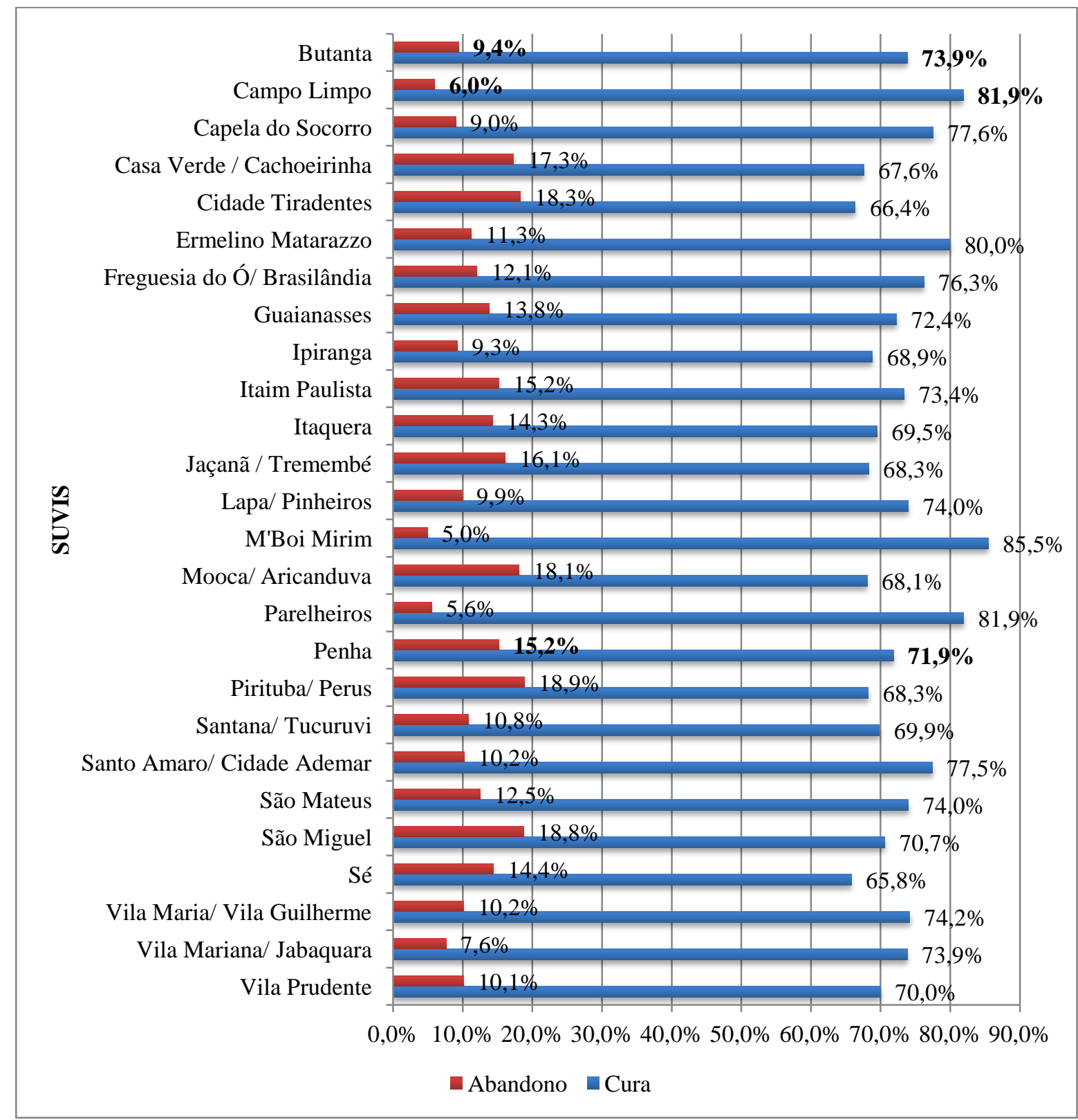

Fonte: $\quad$ TBWEB/PCT/COVISA, acessado em 11/09/2015.

O Gráfico 3 mostra a taxa de cura de casos novos da TB desde 1998, ano de início da implantação do DOTS no MSP (Boletim TB/SP 2007) até 2014². Observa-se, em 2004, o aumento da taxa de cura da doença em relação aos anos anteriores. Este fato pode estar relacionado à introdução da oferta de incentivos (cesta básica e lanche) no MSP nesse mesmo ano (Brasil, 2007), sendo que, em 2012, verificou-se a maior taxa de cura. 
Gráfico 3 - Taxa de cura de casos novos de tuberculose por ano de início de tratamento da doença. São Paulo, 2015.

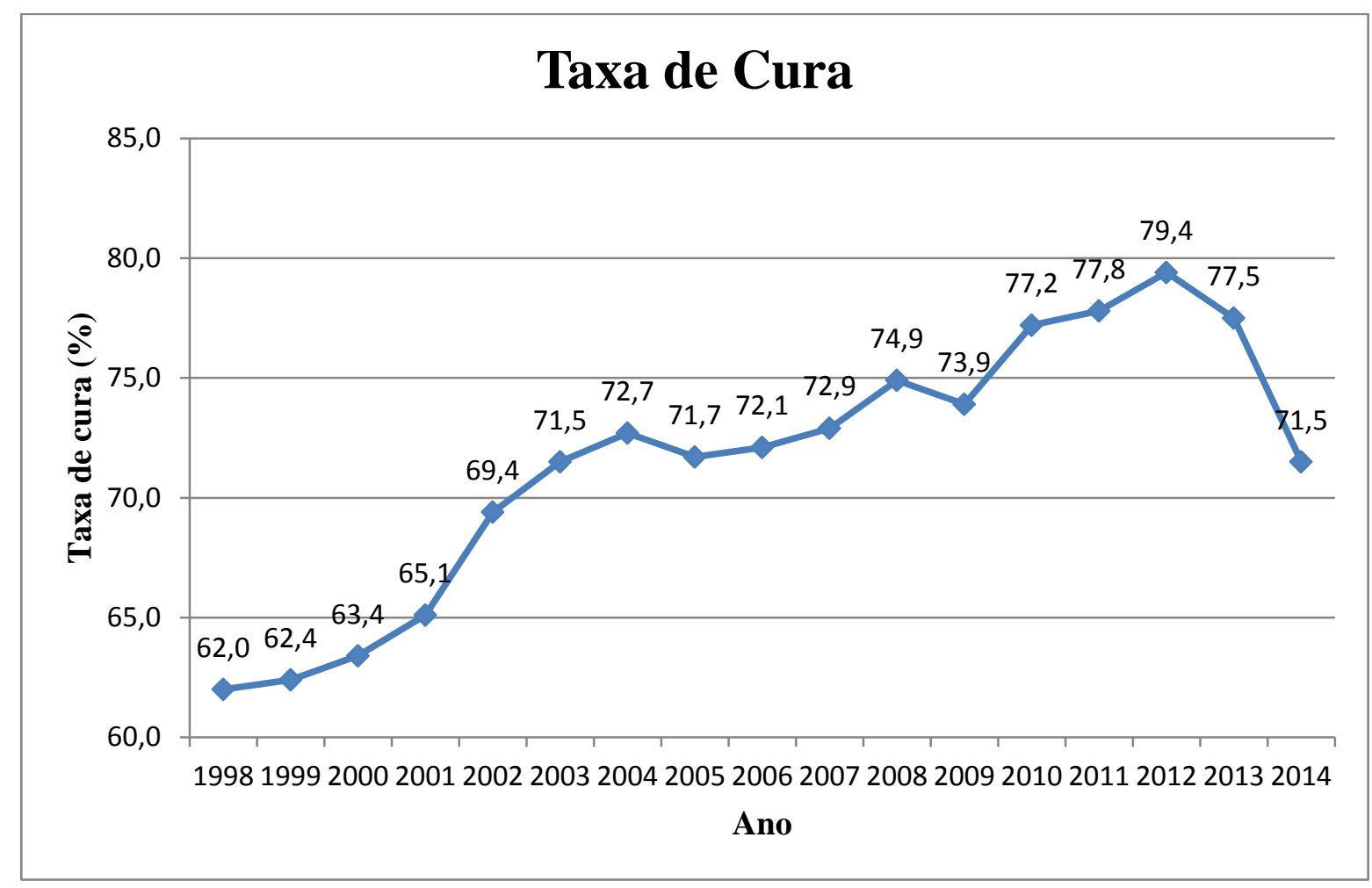

Fonte: $\quad$ TBWEB/PCT/COVISA, dados extraídos em 01/09/2015 (até 2013) e em 11/09/2015 (2014).

A Tabela 8 mostra o número de cestas básicas e vale-transporte adquiridos pelo MSP entre 2009 e 2014. Apesar da oferta de incentivos pelo Município ter se iniciado em 2004, o registro de sua aquisição pelo MSP estavam disponíveis somente a partir de 2009. É necessário ressaltar que o montante correspondente ao vale-transporte consiste em uma informação condensada do incentivo, integrando pacientes em tratamento e comunicantes dos pacientes. 
Tabela 8 - Cestas básicas e vales-transportes adquiridos pelo Município. São Paulo, 2015.

\begin{tabular}{ccc}
\hline Ano & Cesta Básica $\left(\mathbf{N}^{\circ}\right)$ & Vale transporte $\left(\mathbf{N}^{\circ}\right)$ \\
\hline $\mathbf{2 0 0 9}$ & 16.913 & 9.456 \\
$\mathbf{2 0 1 0}$ & 18.251 & 68.836 \\
$\mathbf{2 0 1 1}$ & 22.148 & 79.926 \\
$\mathbf{2 0 1 2}$ & 20.327 & 69.529 \\
$\mathbf{2 0 1 3}$ & 20.082 & 24.080 \\
$\mathbf{2 0 1 4}$ & 20.388 & 17.016 \\
\hline
\end{tabular}

Fonte: $\quad$ PCT/COVISA. Dados disponibilizados em 01/09/2015.

Observam-se, no diagrama de dispersão (Figura 2), círculos que representam a distribuição da taxa de cura entre 2009 a 2013, pois o último ano (2014) foi descartado, uma vez que os dados ainda eram provisórios. A reta representa a relação entre a taxa de cura e a oferta de cestas no mesmo período de tempo ${ }^{4}$, verificando-se correlação positiva, ou seja, a taxa de cura aumenta conforme aumenta o número de cestas básicas adquiridas pela Secretaria de Saúde do Município. No sentido de identificar a potência dessa correlação, aplicou-se o coeficiente de correlação de Pearson (r), que resultou em $r=0,66$. Portanto, tal correlação entre mostra-se positiva e moderada.

4 Cálculo realizado com base na informação disponível pelo PCT/COVISA em relação ao número de cestas básicas adquiridas pela Secretaria de Saúde do Município de São Paulo. 
Figura 2 - $\quad$ Associação entre a taxa de cura da tuberculose e a aquisição de cestas básicas pelo Município. São Paulo-SP, 2015.

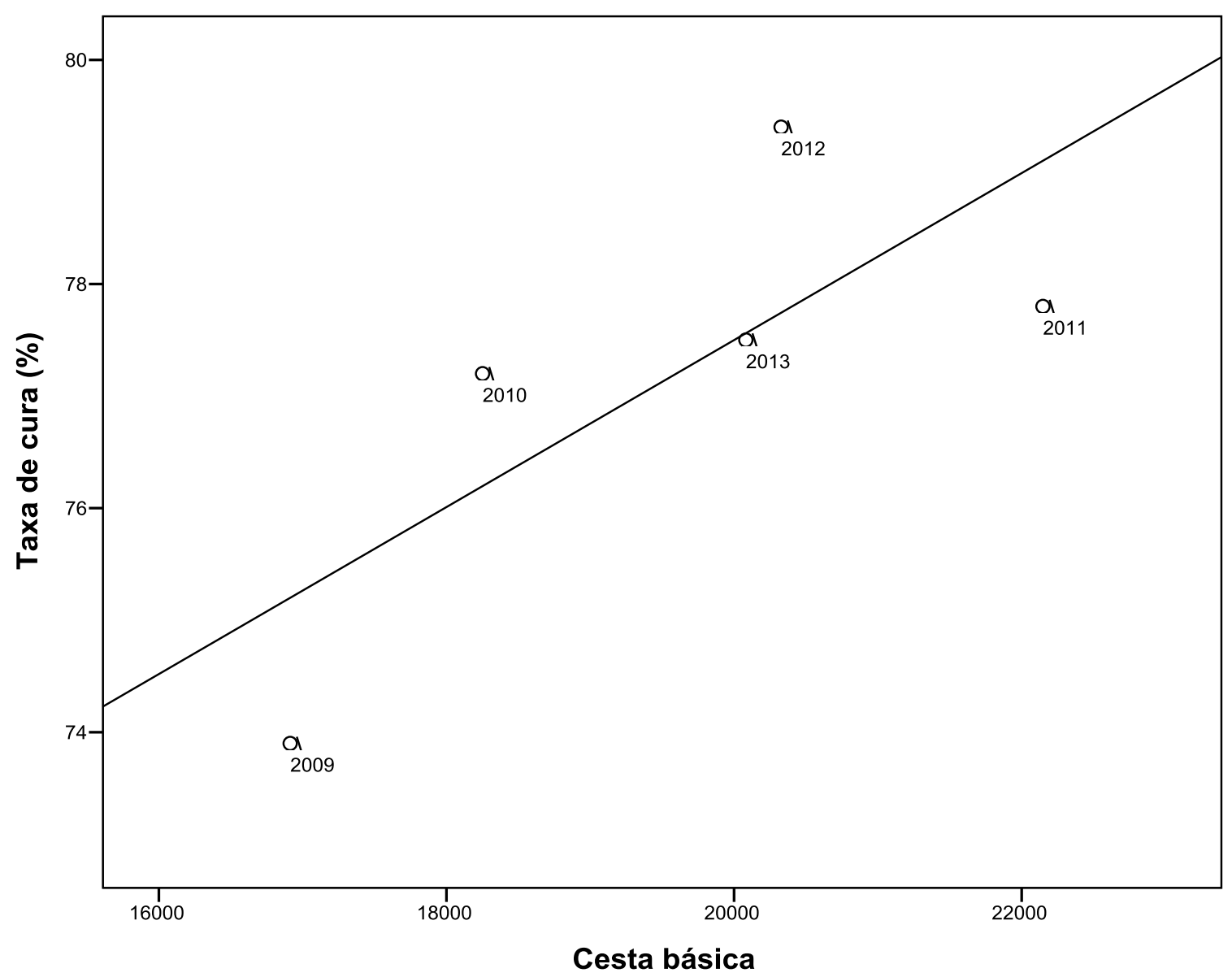

Fonte: $\quad$ TBWEB/PCT/COVISA. Dados extraídos em 01/09/2015 e em 11/09/2015.

É necessário esclarecer que não foi possível obter o número de cestas e vale-transporte ofertados para cada paciente, o que limita a apresentação destes resultados. No momento em que foi realizado presente estudo, lanches não eram ofertados pela Secretaria de Saúde do Município. A concessão por algumas Coordenadorias de Saúde dependia de decisão específica da gestão.

A ausência do controle do número de pacientes que recebem cesta básica e valetransporte (dado que apenas dispunha-se do número de cestas básicas adquiridas pelo Município) limita a extrapolação dos dados. A ausência de informações específicas relacionadas à destinação de vale-transporte para os pacientes impossibilitou identificar a relação entre este incentivo e a taxa de cura, por meio da análise de regressão linear simples. 


\section{DISCUSSÃO}

Iniciando a discussão a respeito dos resultados, as variáveis que compõem a percepção dos profissionais, em geral, mostram-se positivas a respeito do que se segue: tuberculose como uma doença prioritária no Município, conhecimento sobre as ações que integram a política municipal para o controle da TB; conhecimento sobre a oferta de incentivos para a doença pelo Município (cesta básica e vale-transporte), e que estes eram mantidos regularmente; TDO como fortalecedor da adesão ao tratamento; realização do TDO em pelo menos três vezes na semana, sendo indicados principalmente os técnicos/auxiliares de enfermagem e enfermeiros como supervisores mais frequentes da estratégia; conhecimento sobre a realização de busca ativa para resgatar pacientes faltosos; realização de exames preconizados pelo MS (radiografia de tórax, baciloscopia de escarro e prova tuberculínica).

Por outro lado, evidenciou-se que poucos profissionais de saúde informaram ter participado de capacitação sobre temas relacionados à TB. A maior parcela desconhecia: os indicadores de TB, as formas de financiamento das ações de controle da doença e o funcionamento do TDO na unidade de saúde. Fez-se menção à ausência de oferta do lanche e insucesso de quaisquer incentivos em se tratando de pessoas usuárias de drogas e álcool, em situação econômica estável, moradores de rua e indivíduos que apresentam negligência em relação à própria saúde.

Iniciando a discussão a respeito de um aspecto apontado como positivo para a adesão ao tratamento, verificou-se que a maior parte dos sujeitos do estudo advoga que o TDO fortalece a adesão. Mesmo que alguns profissionais não souberam relatar a modalidade de tratamento (se TDO ou autoadministrado) realizada pela unidade de saúde em que atuavam, a maioria dos relatos mostrou que esses serviços de saúde realizam a supervisão da tomada da medicação pelo menos três vezes na semana. Além disso, prevaleceu a indicação dos auxiliares/técnicos de enfermagem e dos enfermeiros como os profissionais que realizam essa ação, como mencionado acima.

Estudos abordando o DOTS em países latino-americanos colocam o enfermeiro como importante profissional na execução de ações assistenciais, como em El Salvador e no Peru, países onde as enfermeiras são responsáveis pela supervisão da tomada do medicamento e 
pelas visitas domiciliárias para o acompanhamento do paciente e suas famílias. Além desta função, a enfermeira é apontada profissional fundamental nas ações de promoção e de educação em saúde e na inclusão da população em atividades intramuros apresentando, portanto, forte atuação nas ações do programa de controle e prevenção da TB. Objetivando o combate da doença, também são apontadas outras ações atribuídas ao enfermeiro, como aquelas que perfazem a esfera administrativa, de pesquisa e docência (Oblitas et al., 2010).

O reconhecimento dos entrevistados a respeito da importância do TDO é confirmado em outros estudos que demonstram baixa taxa de abandono nesta modalidade de tratamento, quando comparado ao tratamento autoadministrado (Ferreira et al., 2011; Ibanês et al., 2013; Latrilha, 2014). Outras localidades que adotam o TDO também mostram resultados que evidenciam a importância da estratégia, de forma associada a incentivos, como no caso de Taiwan, onde os pacientes em TDO recebem apoio do serviço social e vale-alimentação no valor equivalente a U\$2/dia. Pacientes nessa estratégia apresentaram, no período de 2006 a 2010, 55\% da taxa de mortalidade mais baixa quando comparados aos pacientes que realizaram o tratamento autoadministrado (Yen et al., 2013)

Outro achado positivo do presente estudo refere-se à relevância do vínculo entre o paciente e a equipe para a adesão ao tratamento da TB. Apontou-se a Estratégia de Saúde da Família como importante ferramenta para facilitar a construção do vínculo, pois possibilita realizar visitas domiciliárias para conhecer o território onde reside o paciente e sua família, facilitando ações de reabilitação, promoção e prevenção à saúde.

A este respeito do que foi mencionado no parágrafo anterior, estudo realizado no Japão expõe o desejo dos pacientes em sentirem-se verdadeiramente cuidados como pessoas, referindo-se ao TDO em moradores de rua. Diversos pacientes entrevistados relataram apresentar melhora na autoestima e conduta durante o tratamento, pois muitos se diziam autodestrutivos, agressivos e que não gostavam de si mesmos anteriormente ao início do tratamento da TB. Os pacientes ressaltam que tal transformação ocorreu, principalmente, em decorrência do cuidado, da motivação, da escuta qualificada e do carinho oferecidos pelo profissional enfermeiro (Kawatsu et al., 2013).

No Brasil, estudos mostram que o TDO aproxima os profissionais de saúde ao paciente por meio do vínculo formado durante as consultas, além de aproximar a equipe de saúde do contexto social e familiar dos pacientes, reduzindo, desta forma, o abandono do 
tratamento (Sá et al., 2011; Queiroz et al., 2012; Souza et al., 2014). Além disso, o TDO propicia momentos de compartilha das necessidades dos pacientes e suscita, no paciente, sentimento de valorização, acolhida e inclusão social (Bertolozzi, 2005). A ESF é referida como estratégia organizadora dos serviços de saúde, facilitando o acesso das pessoas à equipe multiprofissional. Com isto, também permite a identificação precoce de sintomáticos respiratórios (Sá et al., 2011).

O MS recomenda o TDO para o alcance da cura das pessoas em tratamento da doença, além de exames para diagnóstico e acompanhamento dos pacientes para a detecção precoce e controle da evolução da doença (Brasil, 2011b). Em relação a estes exames, no presente estudo, os profissionais de saúde mencionaram que a radiografia de tórax é solicitada a todos os pacientes com tuberculose, mesmo que o exame não seja realizado na unidade de saúde e o paciente tenha que ser encaminhado a outro serviço. A baciloscopia de escarro também é solicitada, e o resultado é informado à unidade de saúde, geralmente, em período que varia entre 1 a 10 dias. Em relação à prova tuberculínica, mesmo que alguns profissionais desconheçam sobre a realização deste teste, a maioria apontou a sua realização na própria unidade ou em unidade de referência.

Estes dados mostram que as unidades de saúde seguem a recomendação do MS a respeito dos exames necessários para a busca ativa e acompanhamento da TB. Em relação à radiografia de tórax, o MS orienta a solicitação para todas as pessoas com suspeita de TB pulmonar, pois possibilita a exclusão de outras doenças pulmonares associadas e permite o acompanhamento da evolução radiológica do paciente. A baciloscopia do escarro permite detectar cerca de $60 \%$ a $80 \%$ dos casos de TB pulmonar, portanto, é indicada aos sintomáticos respiratórios (tosse há mais de três semanas) e pessoas em situação de suspeita clínica ou radiológica de TB pulmonar (independente do tempo de tosse) (Brasil, 2011b).

Já a prova tuberculínica consiste na introdução, por via intradérmica, de um derivado proteico do bacilo, o Derivado Proteico Purificado - Purified Protein Derivative (PPD) e é utilizada para o diagnóstico de infecção latente pelo bacilo (ILTB) em adultos e crianças (Brasil, 2011b). O fato dos profissionais de saúde apontar a não realização do teste nas unidades de saúde pode ser explicado, pois houve falhas no provimento do PPD em todo o País. 
Em continuação da discussão a respeito dos exames recomendados pelo MS, em 2014, incorporou-se o diagnóstico por meio do Teste Rápido Molecular para a TB pulmonar (TRMTB), o qual, além de identificar a contaminação pelo bacilo, identifica, também, a resistência à rifampicina. Por meio deste exame é possível detectar o DNA do bacilo. Portanto, o paciente que o apresenta terá resultado positivo por tempo indeterminado, justificando sua realização apenas para o diagnóstico da doença. O resultado do TRM-TB pode ser concluído em menos duas horas, sem necessitar de tratamento da amostra ou de recursos humanos especializados em biologia molecular (Delocco et al., 2011; Brasil, 2015d). Assim, espera-se que sua introdução possibilite a detecção precoce da doença e implementação imediata do tratamento. Entretanto, há que se apontar que o custo do equipamento (média de $\mathrm{R} \$ 28.070,00)$ se constitui como um dos aspectos que limitam a sua introdução na rede de serviços de saúde (Delocco et al., 2011).

Outra questão relevante e que foi apontada pelos profissionais de saúde no presente estudo refere-se ao fato que a maioria relatou a não participação em capacitação sobre a TB no último ano que antecedeu a coleta de dados. Da mesma forma, menos da metade dos profissionais soube informar a respeito de indicadores relacionados à $\mathrm{TB}$, referentes à área de abrangência da unidade de saúde em que trabalhavam. Estudos mostram que profissionais que não participam de treinamentos ou capacitação realizam o TDO a partir do que pensam ser adequado. Estes estudos sugerem a troca de experiências e a qualificação dos profissionais como potencializadores do DOTS, almejando-se, com isto, que tenham uma compreensão mais ampla sobre a doença, além do desenvolvimento de habilidades e competências para sua prevenção e controle (Terra, Bertolozzi, 2008; Queiroz et al., 2012; Silva et al., 2014).

Em Fortaleza, Façanha et al. (2009) realizaram, em 2003, um estudo de intervenção em que profissionais de saúde de uma unidade com a ESF (enfermeiros, médicos e ACS) foram treinados e sensibilizados para a detecção de sintomáticos respiratórios. Comparou-se o total de casos diagnosticados no período antes e depois da intervenção e os resultados demonstraram um grande aumento na detecção dos casos. Isto pode ser verificado pelo aumento dos indicadores: em 2002 foi detectado apenas um caso e, em 2004, após a intervenção, foram detectados 22 casos.

A deficiência no conhecimento sobre as políticas de saúde voltadas ao paciente com TB e formas de financiamento para o controle da doença foram questões relevantes apontadas pelos profissionais neste estudo (apenas 2,3\% dos profissionais relataram ter participado de 
reuniões que elucidassem estes assuntos). A respeito destas questões, estudo realizado no Rio de Janeiro mostrou desconhecimento das atividades do PCT por parte dos profissionais de saúde, sendo que muitos profissionais demonstraram desconhecer que o MS recomenda o TDO a todos os pacientes acometidos pela doença. De fato, os sujeitos desse estudo relataram que a indicação do TDO se fazia apenas aos usuários de drogas e álcool, pacientes que, em geral, apresentam difícil adesão e considerados como "irresponsáveis" em relação a seu próprio tratamento (Cardoso et al., 2012).

Ainda que em realidade bastante diferente do Brasil, em termos de organização da sociedade, estudo realizado em hospitais públicos na Tailândia evidencia que metade dos profissionais de saúde (médicos e enfermeiras) entrevistados desconheciam as orientações contidas no manual nacional para o tratamento da TB e mencionaram falta de clareza nas políticas públicas nacionais para o tratamento, o que se concretiza em barreira na prestação do cuidado (Moolphate et al, 2013). Tal pesquisa, portanto, reitera os achados deste presente estudo.

Em relação ao financiamento do PCT no Brasil, além do fomento federal, estadual e municipal, recebe investimentos do Fundo Global de Combate à Aids, Tuberculose e Malária. O financiamento pelo Fundo Nacional de Saúde (FNS) é destinado aos Fundos Estaduais de Saúde para a intensificação das ações de vigilância e controle da TB e para o fortalecimento dos laboratórios centrais de saúde pública. O FNS também financia os Fundos Municipais de Saúde dos 155 municípios de maior incidência da doença para intensificarem as ações de vigilância e controle da enfermidade (Brasil, 2005b, 2005c, 2006b, 2011b).

Por meio do depoimento dos sujeitos, captou-se sua percepção a respeito da situação epidemiológica da doença e sugestões para reversão. A esse respeito, relata-se a escassez de divulgação da doença na mídia, nos equipamentos sociais e em locais de grande trânsito populacional, a exemplo de estações de trem, metrô, ônibus. De fato, este dado é corroborado em estudo realizado na Nigéria, que ressalta que a informação sobre a doença, através da mídia, é insuficiente e que, portanto, pode não abranger ou, até mesmo, sensibilizar, todos os casos potenciais de TB. Estes autores relatam que $15 \%$ dos entrevistados obtiveram informações sobre TB a partir de amigos e familiares, e apontam que a sensibilização da população da área de abrangência das unidades de saúde pode evitar a desinformação e reduzir o atraso no diagnóstico da enfermidade (Biya et al., 2014). 
Em continuação à discussão da divulgação de informações sobre TB por meio da mídia, no Peru, estudo qualitativo apresenta o relato dos pacientes sobre a educação em saúde e a enfermidade. Enfatiza-se a necessidade da divulgação de informações à população e, principalmente às famílias dos pacientes, sobre a prevenção, o tratamento e a possibilidade de cura, sugerindo-se campanhas em todas as formas de mídia e programas de divulgação em escolas e às famílias (Paz-Soldán et al., 2013).

Os discursos dos profissionais, no presente estudo, sugerem a sensibilização, no curso de graduação em enfermagem, a respeito da TB, assim como motivar os profissionais de saúde, que atuam em serviços particulares e recém-formados. É importante destacar que somente os serviços da rede pública oferecem a medicação gratuita e isto tem garantido o controle da enfermidade, ainda que com todos os problemas apontados no estudo. A padronização do esquema de tratamento, no âmbito nacional, possibilita condução única, o que reduz as chances de resistência às drogas.

A sensibilização dos profissionais de saúde, principalmente os profissionais de instituições privadas foi objeto de estudo na Índia. Nesse país, os casos de TB são tratados também pelo setor privado. Esse estudo comparou o conhecimento sobre TB entre os médicos do setor público e privado, evidenciando que os primeiros possuem melhor conhecimento sobre o diagnóstico, tratamento e manejo das formas extrapulmonares (Vandan et al., 2009). Por outro lado, outros estudos, também realizados em países estrangeiros, mostram que, mesmo sabendo sobre a necessidade da notificação da $\mathrm{TB}$, os médicos de instituições particulares não a realizam, pois acreditam que tal procedimento pode violar a privacidade do paciente. Observa-se também, nestes estudos, que a notificação não é realizada pelos profissionais e isto é explicado pela impunidade por não realizar esta ação. Também verificase que o DOTS não é amplamente compreendido entre os profissionais de saúde, de maneira geral, pois um outro estudo demonstrou que acreditavam que aplicava-se apenas às pessoas que não possuíam condições de pagar o tratamento (Than et al., 2009; Philip et al, 2014). Desta forma, observa-se a necessidade de esclarecimento das estratégias para o controle da enfermidade como realidade mundial.

Sobre as condições de vida e trabalho das pessoas acometidas pela enfermidade, verificou-se, por meio da análise dos depoimentos dos profissionais de saúde, que a doença é relacionada à baixa renda e às condições inadequadas de moradia, de trabalho e nutrição. Verificou-se que muitos pacientes, por possuírem rendimento salarial baixo, já estão 
cadastrados no Programa Bolsa Família, o que já caracteriza sua situação de vulnerabilidade social. Não é novo o fato que a TB é prevalente em populações ou grupos sociais que vivenciam vulnerabilidade social e econômica (Basta et al., 2013; Oliveira et al., 2013; Shimazaki et al., 2013; Wong et al., 2013; Jiménez-Fuentes et al., 2014). Na Índia, por exemplo, a prevalência da TB é maior em populações extremamente pobres e pobres sendo que esta prevalência diminui linearmente conforme aumenta o nível de riqueza das pessoas. Aponta-se, também, que baixo índice de massa corpórea e uso de álcool estão associados aos níveis de pobreza (Oxlade, Murray, 2012).

No Brasil, estudo realizado no município de Manaus, apresentou associação entre os casos de pacientes internados com TB e renda inferior a um salário mínimo, sendo que as fontes de renda predominantes foram aposentadoria e Programa Bolsa Família. Além disso, evidenciou-se associação entre a doença e não ter moradia de alvenaria e ausência de coleta de lixo diária (Oliveira et al, 2013).

Em relação aos incentivos ofertados pelo MSP aos pacientes com TB, a maioria dos profissionais mencionou conhecer o direito do paciente em receber a cesta básica e o valetransporte. A análise dos discursos possibilita compreender que a oferta dos incentivos é de grande importância para a adesão ao TDO devido às condições de vida as quais a maioria dos pacientes em tratamento está submetida, sendo a cesta básica possibilidade de fortalecimento dos pacientes, os quais a utilizam também para o sustento nutricional da família.

Os incentivos e medidas de proteção social são relatados como fortalecedores do TDO em pacientes com MDR-TB, os quais são submetidos a tratamento prolongado (realizado em 18 e 24 meses). A primeira fase é composta pela administração de drogas injetáveis e, no Brasil, geralmente, é realizada nos centros de referência para a tuberculose, ou em conjunto com as unidades básicas de saúde. Portanto, nesses casos há necessidade de deslocamento da residência até o centro de referência, que pode, inclusive, estar localizado em outra cidade, o que corrobora a necessidade de apoio para os pacientes em tratamento que não apresentem condições para arcar com tal despesa (Brasil, 2011b; Ferreira, 2011). Estudo internacional enfatiza que estes pacientes, muitas vezes, são obrigados a descontinuar suas atividades laborais, com repercussões de ordem financeira, o que aponta mais um elemento em favor de apoiar tais pacientes com incentivos, a exemplo do vale-transporte (Baral et al., 2014). 
A oferta do lanche, mesmo que não distribuído nas regiões onde ocorreu a coleta de dados, é lembrada como ação que facilita o tratamento, pois os pacientes necessitam apresentarem-se em jejum para a ingesta da medicação. Também para os pacientes em situação de rua tem se mostrado como importante, em decorrência de sua própria situação de vida. Da mesma forma, o vale-transporte é admitido como relevante, principalmente no caso dos pacientes estrangeiros, como os bolivianos, uma vez que garante-se o acompanhamento do tratamento, mesmo que ocorra mudança de trabalho e, consequentemente, de endereço.

Ainda que em realidade bastante distinta da brasileira, estudo realizado em Cingapura, em uma unidade de referência para a doença, responsável pela maioria dos casos em tratamento da TB, comparou os resultados relativos pré e pós-implantação da oferta de um incentivo (vale-alimentação). Tal incentivo é financiado por uma organização não governamental. Os achados do estudo demonstram que a taxa de conclusão do tratamento da doença aumentou de $85,3 \%$ para $87,2 \%(\mathrm{p}=0,02)$. Além disso, foram comparados os pacientes em tratamento, que estavam inscritos neste programa de incentivos, com os pacientes não inscritos e a taxa de conclusão foi de $86,4 \%$ para os pacientes que não receberam o valealimentação e de 90,0\% para os pacientes que receberam este incentivo (p <0,01) (Chua et al., 2015).

Relatório elaborado pela parceria entre a United State Agency for International Development e a Rational Pharmaceutical Management Plus, apresenta revisão da literatura sobre o tema relativo à incentivos para melhorar o desempenho do DOTS. Conclui-se que há indícios de que os incentivos alimentares ao pacientes com TB melhoram a adesão ao tratamento, além de serem fundamentais para o suprimento das necessidades nutricionais das pessoas acometidas pela doença. O Relatório faz menção a países que apresentam grupos de pessoas que vivem em situação de pobreza ou de extrema pobreza, relatando experiências bem sucedidas de oferta de incentivo alimentar, como no Camboja, Brasil, El Salvador, Haiti, Peru e Rússia. Conclui-se que os incentivos contribuem para um melhor desempenho do tratamento da doença em quase todos os programas analisados, tanto para aqueles que implementaram incentivos monetários quanto para não monetários (como cestas básicas, por exemplo) (Mookherji, Beith, 2006).

Valeu-se das informações obtidas pelo TBWEB para identificar a situação epidemiológica da TB no MSP. Todas as SUVIS que constituíram região do presente estudo 
apresentaram taxa de incidência similar, porém todas apresentam taxas abaixo da incidência do Município de São Paulo (49,3/100.000).

Em continuação a estas informações, em 2004, houve aumento da taxa de cura. Há que apontar que nesse mesmo ano teve início a oferta de incentivos para os pacientes em TDO no MSP (Brasil, 2007), o que permite inferir provável associação entre os mesmos e as taxas de cura, pois, a partir deste momento, estas sempre foram superiores ao período em que não havia tal política de incentivos. Além disso, afirmou-se a correlação positiva moderada entre a aquisição de cestas básicas pelo Município (e, consequentemente, a oferta deste incentivo aos pacientes com TB) e a taxa de cura.

A respeito desta correlação, estudo comparou o investimento em proteção social e as taxas de incidência e mortalidade pela doença de 21 países na Europa. A associação entre estas variáveis mostrou forte correlação inversa, ou seja, conforme estes países aumentaram o investimento em proteção social, as taxas de incidência e mortalidade da TB diminuíram. Outro resultado foi a associação entre o aumento das despesas com o serviço público de saúde e a redução da taxa de incidência, prevalência e mortalidade pela doença (Reeves et al., 2014).

Também há evidência de que as medidas de proteção social podem ajudar na melhora dos resultados clínicos no tratamento da TB e da infecção latente da TB (ILTB), especialmente entre as pessoas que vivenciam maior vulnerabilidade social (Orr, 2011; Garden et al., 2013; Lutge et al., 2013, Boogaard et al., 2014). A proteção social é uma das estratégias da Estratégia Global pós-2015 para alcançar a meta de 95\% no número de mortes causadas pela tuberculose e reduzir 90\% da taxa de incidência entre 2015 e 2035 (Lönnroth et al, 2014).

Continuando a análise dos significados atribuídos pelos sujeitos em relação ao objeto de estudo, é importante apontar que os incentivos não são admitidos como fortalecedores da adesão em caso de grupos específicos, como: jovens, moradores de rua, usuários de drogas ilícitas, alcoólatras, traficantes de drogas, pessoas em situação econômica estável e pessoas tidas como esclarecidas culturalmente/intelectualmente. Além destes, observa-se que os incentivos não potencializam a adesão no caso de pacientes que "negligenciam" a própria saúde, que não aceitam a doença ou que vivenciam situação de violência familiar.

Couto et al. (2014) analisaram qualitativamente entrevistas realizadas com pacientes internados em um hospital localizado no município de João Pessoa. Para estes autores, o uso 
de álcool e drogas influencia, negativamente, o seguimento do tratamento da enfermidade. Além da adição ao álcool e drogas, os pacientes entrevistados relatam enfrentar exclusão social, conflitos psicológicos e emocionais e falta de apoio familiar, potencializando a possibilidade de abandono do tratamento.

Estudos mostram que grupos vulneráveis como moradores de rua e usuários de álcool e drogas estão menos propensos a alcançarem resultados positivos no tratamento da TB, mesmo em países considerados desenvolvidos, como a Inglaterra (Burki, 2010; Couto et al., 2014; Lackey et al., 2015). Na Polônia, país onde o consumo alcoólico constitui importante problema social, constatou-se que os pacientes em tratamento da TB e que são dependentes do álcool apresentam possibilidade de tratamento mal sucedido $84 \%$ superior do que os pacientes não dependentes. Além disso, constatou associação entre o alcoolismo e o desenvolvimento de eventos adversos à terapia medicamentosa (Przybylski et al., 2014).

De fato, apesar dos incentivos não se mostrarem eficazes em algumas populações, estudos mostram que locais que alcançaram baixa taxa da doença realizaram uma combinação entre medidas de proteção social, desenvolvimento econômico e acesso universal (ou parcialmente universal) para o diagnóstico e tratamento da TB conduzindo, desta forma, a melhora das condições de vida e trabalho da população (Lönnroth, 2010, 2014). Enfatiza-se que a eliminação da doença requer medidas que visem a superação da pobreza e o combate à exclusão e à discriminação social (Keshavjee et al., 2010).

A respeito das medidas de proteção social, para Marmot et al. (2012), as ações no campo da proteção social são as mais concretas e eficazes para o alcance de uma sociedade saudável, proporcionando vida digna e manutenção da saúde. Neste sentido, os incentivos podem atuar como uma medida de apoio para amenizar os desgastes vivenciados pelas pessoas com TB e diminuir as barreiras para a participação destas pessoas na sociedade. 


\section{CONCLUSÃO}

O tema central do presente estudo, que se refere à percepção de profissionais de saúde a respeito da influência de medidas de apoio é atual e vem constituindo uma das linhas de operação da Organização Mundial da Saúde. Ainda que não tenha sido desenvolvido na totalidade do Município de São Paulo, a amostra investigada pode proporcionar uma faceta do que pensam os profissionais de saúde a respeito dos incentivos em relação à adesão ao tratamento da TB. Considera-se, portanto, que os objetivos do estudo foram atendidos e podem oferecer pistas para a implementação de ações no âmbito do Município de São Paulo, ainda que os achados sejam específicos para as regiões alvo do estudo.

Foi possível constatar que medidas de apoio, a exemplo de cesta básica, valetransporte e a oferta de lanche, no momento em que ocorre o TDO, possuem influência na adesão ao tratamento da tuberculose, na perspectiva de profissionais de saúde de três Coordenadorias de Saúde do Município de São Paulo. Tais incentivos são admitidos como importantes principalmente às pessoas em situação de vulnerabilidade social para as quais essas medidas amenizam, mas não eliminam o sofrimento causado pela doença.

A influência positiva dos incentivos é associada ao vínculo estabelecido entre a equipe de saúde e o paciente, e isto é facilitado em unidades de saúde que possuem a Estratégia de Saúde da Família.

A cesta básica parece ser a modalidade de apoio que mais fortalece a adesão ao tratamento. Este incentivo, ainda que pontual, ajuda a mitigar a debilidade causada pela enfermidade. $\mathrm{O}$ vale-transporte também mostrou-se como potencialidade para a adesão, principalmente, quando oferecido aos pacientes oriundos de outro país, em especial, os bolivianos que, não raramente mudam de local de trabalho e necessitam locomover-se até a unidade de saúde.

Entretanto, os incentivos não melhoram a adesão no caso de pacientes que fazem uso de drogas ilícitas ou álcool, moradores de rua e pessoas que "negligenciam" a própria saúde. Necessita-se, portanto, de articulação efetiva entre as unidades de atenção primária à saúde 
com outros serviços de apoio da rede de atenção para encontrar estratégias que ajudem a superar as barreiras inerentes à peculiaridade de cada uma dessas situações.

Apesar da maioria dos profissionais terem conhecimento da oferta dos incentivos pelo Município, uma parcela os desconhecia, o que pode causar fraturas no manejo do programa de controle da TB. Ademais, apenas a concessão de cesta básica, vale-transporte e lanche, integram o imaginário dos sujeitos entrevistados, identificando-se lacuna no conhecimento a respeito das medidas de proteção social garantidas às pessoas com a doença, como, por exemplo, isenção do imposto de renda, aposentadoria por invalidez e auxílio-doença, os quais podem auxiliar a adesão ao tratamento. Aqueles que demonstraram saber a respeito de tais medidas, desconheciam a tramitação para a sua consecução, o que limita que os pacientes tenham tal direito garantido.

Verificou-se, por outro lado que, em geral, os profissionais de saúde conhecem as ações que compõem o Programa de Controle da TB. Porém, é notável que isto não ocorra para a totalidade dos profissionais, o que pode decorrer-se em falhas na adesão do paciente ao tratamento. É de se indagar o fato de que a maior parcela dos sujeitos do estudo tenha admitido não ter participado de capacitações e discussões a respeito da doença. Conjectura-se que isto decorre da rotatividade dos profissionais nos serviços de saúde e/ou pela forma como tem sido administrados os serviços de saúde, os quais tem a gestão, progressivamente, concedida a organizações, que não possui em sua raiz a marca dos princípios e diretrizes que sustentam o Sistema Único de Saúde. Ao contrário, certas modalidades de gestão, não concedem aos profissionais espaços para a sua qualificação profissional. A compartilha de informações epidemiológicas e sobre a organização das ações para o manejo das enfermidades, no cotidiano do trabalho, é fundamental para monitorar apropriadamente a ocorrência de agravos no território.

É necessário ponderar que considera-se como limitante do presente estudo, a ausência da percepção do usuário, sujeito para o qual o serviço de saúde deve orientar as melhores práticas de cuidado e para o qual o Estado deve prover condições dignas de vida e de proteção social. Sua vivência sobre a doença e sobre os incentivos pode ampliar a compreensão da utilidade dessas medidas na adesão ao tratamento da TB. Requer-se, portanto, de estudos que investiguem como isto ocorre segundo seu ponto de vista. 
Conclui-se que os incentivos apoiam a adesão ao tratamento para certos grupos de pacientes, sempre que associados ao vínculo na interação com a equipe de saúde. Entretanto, admitindo-se que a TB é resultado das desigualdades sociais, afirma-se que tais incentivos apenas minimizam a situação de sofrimento das pessoas acometidas pela doença. A proteção social deve constituir a estrutura da sociedade e não ser artifício para mitigar situações de pobreza. Ações articuladas e abrangentes que integrem políticas para a superação das desigualdades são fundamentais para a eliminação da TB e para a conquista de sociedade mais justa e com mais igualdade. 


\section{REFERÊNCIAS}

Almeida Filho N, Rouquayrol MZ. Introdução à Epidemiologia. Rio de Janeiro: Guanabara Koogan. 2006.

Arretche M. A política da política de saúde no Brasil. In: Lima NT e colaboradores. Saúde e democracia: história e perspectiva do SUS. Rio de Janeiro: Editora Fiocruz. 2005.

Baral SC, Aryal Y, Bhattrai R, King R, Newell JN. The importance of providing counselling and financial support to patients receiving treatment for multi-drug resistant TB: mixed method qualitative and pilot intervention studies. BMC Public Health. 2014;14(46):1-7.

Basta PC, Marques M, Oliveira RL, Cunha EAT, Resendes APC, Souza-Santos R. Desigualdades sociais e tuberculose: análise segundo raça/cor, Mato Grosso do Sul. Rev Saude Publica. 2013;47(5):854-64.

Belo MTCT, Selig L, Luiz RR, Hanson C, Luna AL, Teixeira EG et al. Choosing incentives to stimulate tuberculosis treatment compliance in a poor country in Rio de Janeiro state, Brazil. Med Sci Monit. 2006;12(5):PH1-5.

Bertolozzi MR. A adesão ao programa de controle da tuberculose no Distrito Sanitário de Butantã-SP [tese de doutorado]. São Paulo (SP): Faculdade de Saúde Pública, Universidade de São Paulo; 1998.

Bertolozzi MR. A adesão ao tratamento da tuberculose na perspectiva da estratégia do tratamento diretamente supervisionado (DOTS) no Município de São Paulo [tese de livredocência]. São Paulo (SP): Escola de Enfermagem, Universidade de São Paulo; 2005.

Boogaard JVD, Msoka E, Homfray M, Kibiki GS, Heldens JJHM, Felling AJA et al. An Exploration of Patient Perceptions of Adherence to Tuberculosis Treatment in Tanzania. Qual Health Res. 2012;22:835-47. 
Brasil. Secretaria de Políticas em Saúde. Departamento de Gestão de Políticas e Estratégias de Saúde. Coordenação Nacional de Pneumologia Sanitária. Plano Nacional de Controle da Tuberculose. Fundação Nacional de Saúde. Brasília: Ministério da Saúde; 1999.

Brasil. Prefeitura Municipal de São Paulo. Secretaria Municipal de Saúde. Coordenação de Vigilância em Saúde. Centro de Controle de Doenças. Programa de Controle de Tuberculose. Boletim TB: Cidade de São Paulo. 2005a.

Brasil. Ministério de Estado da Saúde. Autoriza o repasse do Fundo Nacional de Saúde para os Fundos Estaduais de Saúde para fortalecer as ações dos Laboratórios Centrais de Saúde Pública LACEN na Coordenação da Rede de Laboratórios de Diagnóstico da Tuberculose e dá outras providências pela Portaria nº 543/GM de 8/04/2005. 2005 b.

Brasil. Ministério de Estado da Saúde. Autoriza repasse do Fundo Nacional de Saúde para os Fundos Municipais de Saúde, para intensificação das ações de vigilância e controle da tuberculose, e dá outras providências pela Portaria no 2.603/GM de 28/12/2005. 2005c.

Brasil. Secretaria do Estado de São Paulo. Centro de Vigilância Epidemiológica. Coordenadoria do Controle de Doenças. Programa Nacional de Controle da Tuberculose. Plano Estratégico para o Controle da Tuberculose, Brasil 2007-2015. Brasília; 2006a.

Brasil. Ministério de Estado da Saúde. Autoriza o repasse financeiro do Fundo Nacional de Saúde aos Fundos Estaduais de Saúde destinados à intensificação das ações de vigilância e controle da tuberculose pela Portaria no 3.162 de 14/12/2006. 2006b.

Brasil. Prefeitura Municipal de São Paulo. Secretaria Municipal de Saúde. Coordenação de Vigilância em Saúde. Centro de Controle de Doenças. Programa de Controle de Tuberculose. Boletim TB: Cidade de São Paulo. 2007.

Brasil. Secretaria Estadual de Saúde de São Paulo. Coordenadoria de Controle de Doenças. Centro de Vigilância Epidemiológica. Divisão de Tuberculose. Manual de utilização do TBWEB: versão 1.6. 2008. 
Brasil. Ministério do Desenvolvimento Social e Combate à Fome e Organização das Nações Unidas para a Educação, a Ciência e a Cultura. Concepção e gestão da proteção social não contributiva no Brasil. 2009a.

Brasil. Ministério do Desenvolvimento Social e Combate à Fome. Cartilha BPC - Beneficio de Prestação Continuada de Assistência Social. 2009b.

Brasil. Prefeitura Municipal de São Paulo. Secretaria Municipal de Saúde. Coordenação de Vigilância em Saúde. Centro de Controle de Doenças. Programa de Controle de Tuberculose. Boletim TB: Cidade de São Paulo. 2009c.

Brasil. Secretaria do Estado de São Paulo. Centro de Vigilância Epidemiológica. Coordenadoria do Controle de Doenças. Divisão de Tuberculose. Boletim Tuberculose. São Paulo; 2011a.

Brasil. Ministério da Saúde. Secretaria de Vigilância em Saúde. Departamento de Vigilância Epidemiológica. Manual de recomendações para o controle da tuberculose no Brasil. Brasília: Ministério da Saúde; 2011 b.

Brasil. Ministério da Saúde. Secretaria de Vigilância em Saúde. Departamento de Vigilância Epidemiológica. Tratamento diretamente observado (TDO) da tuberculose na atenção básica: protocolo de enfermagem. Brasília: Ministério da Saúde; 2011c.

Brasil. Centro de Vigilância Epidemiológica. Coordenadoria de Controle de Doenças. Secretaria de Estado de Saúde de São Paulo. Boletim Epidemiológico. BE CVE. 2012; 11(2):177-99.

Brasil. Secretaria de Vigilância em Saúde. Ministério da Saúde. Boletim Epidemiológico. $2013 ; 44(2)$.

Brasil. Secretaria de Vigilância em Saúde. Ministério da Saúde. Boletim Epidemiológico. $2014 \mathrm{a} ; 44(2)$. 
Brasil. Instituto Nacional de Seguro Social. Manual de procedimentos em benefícios por incapacidade: diretrizes de apoio à decisão médico-pericial em clínica médica - Parte III HIV/AIDS, tuberculose e hanseníase. Brasília: Instituto Nacional de Seguro Social; 2014b.

Brasil. Secretaria de Estado da Saúde de São Paulo. Resolve que a Coordenação de Vigilância em Saúde tem as atribuições de coordenação técnica, planejamento, supervisão e avaliação do Sistema Municipal de Vigilância em Saúde pela Portaria nº 2529/2014. 2014c.

Brasil. Ministério da Saúde. Principais indicadores da tuberculose. 2015a [Citado 2015 Mai 18]. Disponível em http://portalsaude.saude.gov.br/images/pdf/2015/abril/10/principaisindicadores.pdf.

Brasil. Ministério do Desenvolvimento Social e Combate à Fome. Valor do Benefício. 2015b [Citado 2015 Fev 19]. Disponível em http://mds.gov.br/assuntos/bolsa-familia.

Brasil. Prefeitura do Município de São Paulo. Secretaria Municipal de Saúde. Coordenação de Epidemiologia e Informação. Relação dos estabelecimentos/serviços da secretaria municipal da saúde por coordenadoria regional de saúde e supervisão técnica de saúde do município de São Paulo. 2015c.

Brasil. Secretaria de Vigilância em Saúde. Ministério da Saúde. Boletim Epidemiológico. 2015d;46(9):1-19.

Biya O, Gidado S, Abraham A, Waziri N, Nguku P, Nsubuga P et al. Knowledge, careseeking behavior, and factors associated with patient delay among newly-diagnosed pulmonary tuberculosis patients, Federal Capital Territory, Nigeria, 2010. Pan Afr Med J. 2014;18(Supp 1):6.

Breilh J, Granda E. Investigação da saúde na sociedade: guia pedagógico sobre um novo enfoque do método epidemiológico [tradução José da Rocha Carvalheiro et al.]. São Paulo: Cortez: Instituto de Saúde; Rio de Janeiro: Associação Brasileira de Pós-Graduação em Saúde Coletiva. 1989. 
Burki T. Tackling tuberculosis in London's homeless population. Lancet. 2010;376:2055-6.

Canesqui AM. Necessidades, apoio e proteção sociais. Ciênc saúde coletiva. 2012;17(5):1100.

Car MR, Bertolozzi MR. O procedimento da análise de discurso. In: Chianca TCM, Antunes MJM (organizadoras). A classificação internacional das práticas de enfermagem em saúde coletiva - CIPESC. Brasília: Associação Brasileira de Enfermagem. 1999; pag. 348-355.

Cardoso GCP, Cruz MM, Abreu DMF, Decotelli PV, Chrispim PPM, Borenstein JS, Santos EM. A conformidade das ações do tratamento diretamente observado para tuberculose na perspectiva dos profissionais de duas unidades de saúde da cidade do Rio de Janeiro. Cad. Saúde Colet. 2012;20(2):203-10

Cass AD, Talavera GA, Gresham LS, Moser KS, Joy W. Structured behavioral intervention to encrease children's adherence to treatment for latent tuberculosis infection. Int J Tuberc Lung Dis. 2005;9(4):415-20.

Castro JA, Modesto L. Bolsa Família 2003-2010: avanços e desafios. Brasília: Ipea; 2010.

Chatham House. Social protection interventions for tuberculosis control: the impact, the challenges, and the way forward. Meeting Summary: centre of global health security. London; 2012.

Chua APG, Lim LKY, Ng H, Chee CBE, Wang YT. Outcome of a grocery voucher incentive scheme for low-income tuberculosis patients on directly observed therapy in Singapore. Singapore Med J. 2015;56(5): 274-279.

Couto DS, Carvalho RN, Azevedo EB, Moraes MN, Pinheiro PGOD, Faustino EB. Fatores determinantes para o abandono do tratamento da tuberculose: representações dos usuários de um hospital público. Saúde Debate. 2014; 38(102):572-81.

Das P. Can social protection improve tuberculosis control? Lancet. 2012; 279(9821):1089.

Defulio A, Silverman K. The use of incentives to reinforce medication adherence. Prev Med. 2012;55(Suppl):S86-94. 
Delocco BAV, Guioti CO, Gava CM, Soares DP, Salomon FCR, Carvalho JLC et al. XPERT® MTB/RIF no diagnóstico da tuberculose pulmonar. Boletim Brasileiro de Avaliação de Tecnologias em Saúde. 2011;16:1-14.

Façanha MC, Melo MA, Vasconcelos FF, Sousa JRP, Pinheiro AS, Porto IA, Parente JM. Treinamento da equipe de saúde e busca ativa na comunidade: estratégias para a detecção de casos de TB. J Bras Pneumol. 2009;35(5):449-54.

Fagnani E. Política Social no Brasil (1964-2002): Entre a Cidadania e a Caridade [tese de doutorado]. Campinas (SP): Instituto de Economia, Universidade Estadual de Campinas; 2005.

Ferreira V, Brito C, Portela M, Escosteguy C, Lima S. DOTS in primary care units in the city of Rio de Janeiro, Southeastern Brazil. Rev Saude Publica. 2011;45(1):40-8.

Ferreira KR. Tuberculose multirresistente em um centro de referência do Estado de São Paulo: perfil e trajetória de pacientes [dissertação de mestrado]. São Paulo (SP): Escola de Enfermagem, Universidade de São Paulo; 2011.

Figueiredo Filho DB, Silva Júnior JA. Desvendando os Mistérios do Coeficiente de Correlação de Pearson (r). Revista Política Hoje. 2009;18(1):115-46.

Fiorin JL. Elementos de análise do discurso. São Paulo: EDUSP; 1989.

Fonseca RMGS, Egry EY, Bertolozzi MR. O materialismo histórico e dialético como teoria da cognição e método para a compreensão do processo saúde-doença. São Paulo, Escola de Enfermagem da Universidade de São Paulo, 2001.

Garden B, Samarina A, Stavchanskaya I, Alsterlund R, Ovregaard A, Taganova O et al. Food incentives improve adherence to tuberculosis drug treatment among homeless patients in Russia. Scand J Caring Sci. 2013;27:117-22.

Gil AC. Métodos e técnicas de pesquisa social. São Paulo: Atlas; 2008. 
Gler MT, Podewils LJ, Munez N, Galipot M, Quelapio MID, Tupasi TE. Impact of patient and program factors on default during treatment of multidrug-resistant tuberculosis. Int $\mathbf{J}$ Tuberc Lung Dis. 2012;16(7):955-60.

Hijjar MA, Gerhardt G, Teixeira GM, Procópio MJ. Retrospecto do controle da tuberculose no Brasil. Rev Saude Publica. 2007;41(supl1):50-8.

Hino P, Villa TCS, Cunha TN, Santos CB. Padrões espaciais da tuberculose e sua associação à condição de vida no município de Ribeirão Preto. Ciênc. saúde coletiva. 2011;16(12):47954802.

Ibanês AS, Carneiro Junior N. Panorama internacional e nacional da estratégia do tratamento diretamente supervisionado (DOTS) nas políticas de controle da tuberculose . ABCS Health Sci. $2013 ; 38(1): 25-32$

Instituto Brasileiro de Geografia e Estatística (IBGE). Sinopse do Censo Demográfico 2010. São Paulo [Citado 2015 Nov 13]. Disponível em: http://cidades.ibge.gov.br/xtras/perfil.php?codmun=355030

Jaccoud L. Série seguridade social: pobres, pobreza e cidadania: os desafios recentes da proteção social. 2009.

Jimenez-Fuentes MA, Milà Augé C , Altet Gómez MN, Solsona Peiró J, de Souza Galvao ML, Maldonado $\mathbf{J}$ et al. Screening for active tuberculosis in high-risk groups.Int $\mathbf{J}$ Tuberc Lung Dis. 2014;18(12):1459-65.

Kawatsu L, Sato N, Ngamvithayapong-Yanai J, Ishikawa N. Leaving the street and reconstructing lives: impact of DOTS in empowering homeless people in Tokyo, Japan. Int $\mathbf{J}$ Tuberc Lung Dis. 2013;17(7):940-46

Keshavjee S, Girard F, Harrington M, Farmer PE. Time for a bold new vision at the Stop TB Partnership. Lancet. 2010;376:1283-4. 
Kominsk GF, Varon SF, Morisky DE, Malotte K, Ebin VJ, Coly A et al. Costs and costeffectiveness of adolescent compliance with treatment for latent tuberculosis infection: results from a randomized trial. J Adolesc Health. 2007;40(1):61-8.

Lackey B, Seas C, Van der Stuyft P, Otero L. Patient Characteristics Associated with Tuberculosis Treatment Default: A Cohort Study in a High-Incidence Area of Lima, Peru. PLoS One. 2015;10(6):1-11.

Latrilha FO. Transmissão e prevalência da resistência de Micobacterium tuberculosis, após a implantação do DOTS, no município de Guarulhos no período de 2007 a 2011 [dissertação]. São Paulo: Coordenadoria de Controle de Doenças da Secretaria de Estado da Saúde de São Paulo; 2014.

Lönnroth K, Castro KG, Chakaya JM, Chauhan LS, Floyd K, Glaziou P et al. Tuberculosis control and elimination 2010-50: cure, care, and social development. Lancet. 2010;375:181429.

Lönnroth K, Glaziou P, Weil D, Floyd K, Uplekar M, Raviglione M. Beyond UHC: Monitoring Health and Social Protection Coverage in the Context of Tuberculosis Care and Prevention. PLOS Medicine. 2014; 11(9):1-10.

Lutge EE, Wiysonge CS, Knight SE, Volmink J. Material incentives and enablers in the management of tuberculosis. Cochrane Database Syst Rev. 2012;1:1-47.

Lutge E, Lewin S, Volmink J, Friedman I, Lombard C. Economic support to improve tuberculosis treatment outcomes in South Africa: a pragmatic cluster-randomized controlled trial. Trials. 2013;14(1):154-66.

Marmot M, Allen J, Bell R, Bloomer E, Goldblatt P. WHO European review of social determinants of health and the health divide. Lancet. 2012;380:1011-29

Maciel MS, Mendes PD, Gomes AP, Siqueira-Batista R. A história da tuberculose no Brasil: os muitos tons (de cinza) da miséria. Rev Bras Clin Med. 2012:10(3):226-30. 
Minayo MCS. O desafio do conhecimento: pesquisa qualitativa em saúde. São Paulo: Hucitec, 2008.

Mookherji S, Beith A. Summary of Current Evidence: Using Incentives and Enablers for Improved DOTS Performance. Submitted to the U.S. Agency for International Development by the Rational Pharmaceutical Management Plus Program.Arlington, VA: Management Sciences for Health. 2006.

Moolphate S, Lawpoolsri S, Pungrassami P, Sanguanwongse N, Yamada N, Kaewkungwal J. Barriers to and Motivations for the Implementation of a Treatment Programme for Latent Tuberculosis Infection using Isoniazid for People Living with HIV, in Upper Northern Thailand. Global Journalof Health Science. 2013;5(4):60-70.

Oblitas FYM, Loncharich N, Salazar ME, David HML, Silva I, Velásquez D. O papel da enfermagem no controle da tuberculose: uma discussão sob a perspectiva da equidade. Rev Lat Am Enfermagem. 2010;18(1):130-38.

Oliveira NF, Gonçalves MJF. Fatores sociais e ambientais associados à hospitalização de pacientes com tuberculose. Rev Lat Am Enfermagem. 2013;21(2):8telas.

Organização Pan-Americana de Saúde. Direitos humanos, cidadania e tuberculose na perspectiva da legislação brasileira. Brasília: OPAS; 2015.

Orr P. Adherence to tuberculosis care in Canadian Aboriginal populations - Part 2: a comprehensive approach to fostering adherence behavior. Int J Circ Health. 2011;70(2):11327.

Ortblad KF, Salomom JA, Bärnighausen T, Atun R. Stopping tuberculosis: a biosocial model for sustainable development. Lancet. 2015;S0140-6736(15)00324-4.

Oxlade O, Murray M. Tuberculosis and Poverty: Why Are the Poor at Greater Risk in India? PLoS One. 2012;7(11):8telas. 
Paz-Soldán VA, Alban RE, Jones CD, Oberhelman RA. The provision of and need for social support among adult and pediatric patients with tuberculosis in Lima, Peru: a qualitative study. BMC Health Serv Res. 2013;13:290-302.

Pinheiro RS, Oliveira GP, Oliveira EXG, Melo ECP, Coeli CM, Carvalho MS. Determinantes sociais e autorrelato de tuberculose nas regiões metropolitanas conforme a Pesquisa Nacional por Amostra de Domicílios, Brasil. Rev Panam Salud Publica. 2013;34(6):446-51.

Pinto VS, Paula RAC, Parron Junior M. Atenção suplementar nos municípios prioritários do Estado de São Paulo para pacientes em tratamento supervisionado da tuberculose. Bol Pneumol Sanit. 2006;14(3):159-66.

Pochmann M. Proteção social na periferia do capitalismo: considerações sobre o Brasil. São Paulo em Perspectiva. 2004;18(2):3-16.

Philip S, Isaakidis P, Sagili KD, Meharunnisa A, Mrithyunjayan S, Kumar AMV. "They Know, They Agree, but They Don't Do": The Paradox of Tuberculosis Case Notification by Private Practitioners in Alappuzha District, Kerala, India. PLoS One. 2015;10(4):13telas.

Przybylski G; Dabrowska A; Trzcinska H. Alcoholism and other socio-demographic risk factors for adverse TB-drug reactions and unsuccessful tuberculosis treatment - data from ten years' observation at the Regional Centre of Pulmonology, Bydgoszcz, Poland. Med_Sci Monit. 2014;20:444-5.

Queiroz EM, De-La-Torre-Ugarte-Guanilo MC, Ferreira KR, Bertolozzi MR. Tuberculose: limites e potencialidades do tratamento supervisionado. Rev Lat Am Enfermagem. 2012;20(2):369-77.

Reeves A, Basu S, McKee M, Stuckler D, Sandgren A, Semenza J. Social protection and tuberculosis control in 21 European countries, 1995-2012: a cross-national statistical modeling Analysis. Lancet Infect Dis. 2014;14:1105-12.

Rodrigues ILA, Monteiro LL, Pacheco RHB, Silva SED. Abandono do tratamento de tuberculose em co-infectados TB/HIV. Rev Esc Enferm USP. 2010;44(2):383-7. 
Sá LD, Gomes ALC, Nogueira JA, Villa TCS, Souza KMJ, Palha PF. Intersetorialidade e vínculo no controle da tuberculose na Saúde da Família. Rev Lat Am Enfermagem. 2011;19(2):09 telas.

Sánchez AIM, Bertolozzi MR. Além da dots (directlyobservedtreatment short-course) no controle da tuberculose: interface e compartilhamento de necessidades. Rev Lat Am Enfermagem. 2009;17(5):689-94.

São Paulo. Prefeitura Municipal de São Paulo. Secretaria Municipal da Saúde. Supervisões de Vigilância em Saúde (SUVIS) [Citado 2015 Set 15]. Disponível em: http://www.prefeitura.sp.gov.br/cidade/secretarias/saude/vigilancia_em_saude/suvis/index.ph $\mathrm{p} ? \mathrm{p}=7345.2015$.

Shimazaki T, Marte SD, Saludar NRD, Dimaano EM, Salva EP, Ariyoshi K et al. Risk factors for death among hospitalised tuberculosis patients in poor urban areas in Manila, The Philippines. Int J Tuberc Lung Dis. 2013;17(11):1420-26.

Silva DM, Nogueira JA, Sá LD, Wysocki AD, Scatena LM, Villa TCS. Avaliação de desempenho de Serviços da Atenção Básica para o tratamento da tuberculose. Rev Esc Enferm USP. 2014; 48(6):1044-53

Souza KMJ, Sá LD, Silva LMC, Palha PF. Atuação da Enfermagem na transferência da política do tratamento diretamente observado da tuberculose. Rev Esc Enferm USP. 2014; 48(5):874-82.

Tan HF, Yeh CY, Chang HW, Chang CK, Tseng HF. Private Doctors' practices, knowledge, and attitude to reporting of communicable diseases: a national survey in Taiwan. BMC Infect Dis. 2009;9(11):18telas.

Terra MF, Bertolozzi MR. Tratamento diretamente supervisionado (dots) contribui para a adesão ao tratamento da tuberculose? Rev Lat Am Enfermagem. 2008;16(4):659-64.

Vaitsman J, Andrade GRB, Farias LO. Proteção social no Brasil: o que mudou na assistência social após a Constituição de 1988. Ciênc. saúde coletiva. 2009;14(3):731-41. 
Vandan N, Ali M, Prasad R, Kuroiwa C. Assessment of doctors' knowledge regarding tuberculosis management in Lucknow, India: A public-private sector comparison. Public Health. 2009;123(7):484-9.

Viana ALA, Elias PEM, Ibañes N. Proteção Social: dilemas e desafios. São Paulo: Hucitec. 2005.

Victora CG, Barreto ML, do Carmo Leal M, Monteiro CA, Schmidt MI, Paim J et al. Health conditions and health-policy innovations in Brazil: the way forward. Lancet. 2011;377(9782):2042-53.

World Health Organization. TB impact measurement policy and recommendations for how to assess the epidemiological burden of TB and the impact of TB control. (Stop TB policy paper; no. 2). Geneva 2009.

World Health Organization. The global plan to stop TB 2011-2015: transforming the fight towards elimination of tuberculosis. Geneva 2010.

World Health Organization.Global tuberculosis report 2013. Geneva 2013.

World Health Organization.Global tuberculosis report 2015. Geneva 2015.

Wong MK, Yadav RP, Nishikiori N, Eang MT. The association between household poverty rates and tuberculosis case notification rates in Cambodia, 2010 Western Pac Surveill Response J. 2013;4(1):25-33.

Yen Y-F, Yen M-Y, Lin Y-P, Shih H-C, Li L-H, Chou P, et al. Directly observed therapy reduces tuberculosis-specific mortality: a population-based follow-up study in Taipei, Taiwan. PLoS One. 2013;8(11):8telas. 
ANEXOS

ANEXO I

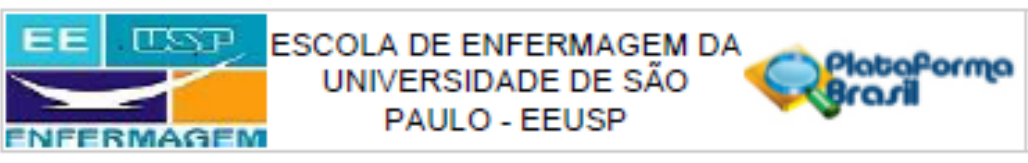

PARECER CONSUBSTANCIADO DO CEP

\section{DADOS DO PROJETO DE PESQUISA}

Titulo da Pesquisa: Avallaçato da efettividade das medidas de proteça social na adesta a tratamento da tuberculose e controle da doença em algumas regloes do Brasill

Pesqulsador: MAFIA RITA BERTCLOZZ:

Área Tematica:

Versao: 2

CAAE: 37254714.0 .1001 .5392

Institulçăo Proponente: Escola de Enfermagem da USP

Patrocinador Principal: Secretarla de Viglancla em Saude

DADOS DO PARECER

Numero do Parecer: 952.223

Data da Relatorla: 0902/2015

Apresentaça do Projeto:

Trata-se de um projeto de pesquisa da Escola de Enfermagem da Universidade de săo Paulo aprovado em edital da Secretaria de Vigliancla em Saude do Ministerio da Saude.

O projeto apresenta revisáo bibllografica sunciente e atualzada sobre a problennatica da tubercuiose (TB) no Brasl e os desaflos programaticos para o controle da doença na rede publlca de saude. A questăo da adesâo das pessoas ao tratamento e a adoçăo de medidas e incentivos que promovam o năo abandono e destacada como um dos principals desafios para 05 pronissionals e gestores da saude.

Trata-se de um estudo transversal, descritivo-exploratorio de abordagem quantl-qualtativo reallzado em quatro municiplos (Sto Paulo, Fuo de Janeiro, Recife e Campina Grande), localizados nas regibes Sudeste e Nordeste. A populaçăo sera constituida por 780 doentes com TB, dlagnosticados no periodo de janelro a dezembro de 2003 e 200 profissionals e gestores da saude, totalzando 980 particlpantes. Define como criterios de inclusăoc 06 doentes com TB com Idade Igual ou malor que 18 anos; residentes nos locals do estudo e que tenham capacidade de comunicaç5̆o verbal e compreensăo preservadas. Quanto aos pronssionals e gestores, serăo incluldos aqueles que atuam no controle da TB ha pelo menos 6 meses. E como criterios de exclusfo: 06 doentes com TB que, no periodo de coleta dos dados, estejam em reclusáo no

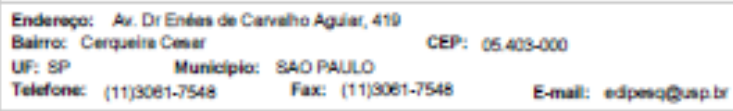




\section{ANEXO I (continuação)}

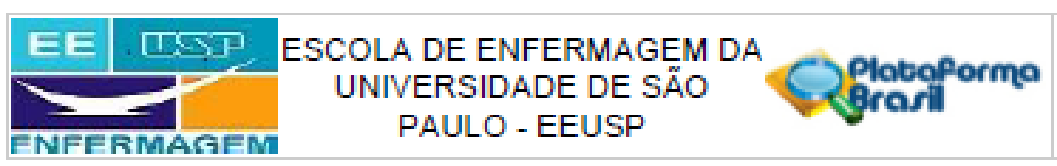

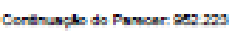

sistema prisional. Para a coleta dos dados sera utllizado um instrumento seml-estruturado, organ/zado em tres partes, sendo a primeira aplicada aos gestores; a segunda a0s profissionals da saude e doentes com TB; e a terceira compreendera a pesquisa em prontuarios. Para a anallse dos dados sera adotado 0 concelto de vuinerabllidade (Ayres, 2006), o qual envolve as dimensठes Indlidual, programatica e social. Para a avallaçắo da efettvidade serăo utllizadas as categorlas da avalaçấo da qualldade de serviços de saude (Estruhura, Processo e Resultado) propostas por

Starfeld (2002). Os dados qualltatlvos serăo analsados segundo o referenclal da Teoria do Percurso Gerativo de Sentldo (Minayo, 2002; Florin, 1989). As varlaveis quantitativas serdo organizadas no Excel 2003 e transferidas para o SPSS, submetidas a anallse descritiva.

Apresenta o cronograma de execuçáo do projeto com termino previsto para abrl de 2016. O orçamento fol detalhado e perfaz um total de RS 198.296,00 financlados pela Secretaria de Vigllancla em Saude do Ministerio da Saude.

\section{Objettvo da Pesquisa:}

Objetvo geral:

Avallar a efetividade das medidas de proteç5̆o social na melhoria dos indicadores programaticos para adesto ao tratamento da tubercuiose e controle da doença em municlpios da reglăo nordeste e sudeste do Brasll.

Objetvos especificos:

1- Caracterizar os pacientes em termos de condiçbes pessoals, economico-socials e de saude-doença; 2- Identificar os elementos de vuinerabilldade Indlvidual e social que podem interferir na adesalo ao tratamento;

3- Identincar a associaçăo entre adesấ a tratamento da tuberculose e $\propto$ deteminantes socials de saude; 4- Identificar as modalidades de incentivo socioeconomico proporclonado as pessoas com tuberculose nos municiplos de Săo PauldSP, Camplna Grande/PB, Recife/PE e Rlo de Janelro/RJ;

5- Caractertzar a utilizaçáo do beneficio aubllo-doença da Previdencia Social pelas pessozs em tratamento para tuberculose, apontando facildades e dinculdades para ta:;

6- Identificar potenclalidades e as traglldades desses beneficlos no processo de adesfo ao tratamento,

7- Identificar os elementos de vulnerablidade programatca que podem interferir na dlsponloildade desses beneficlos soclals as pessoas em tratamento da tuberculose, nas instandas

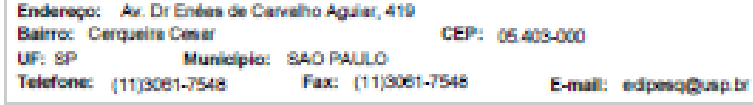


ANEXO I (continuação)

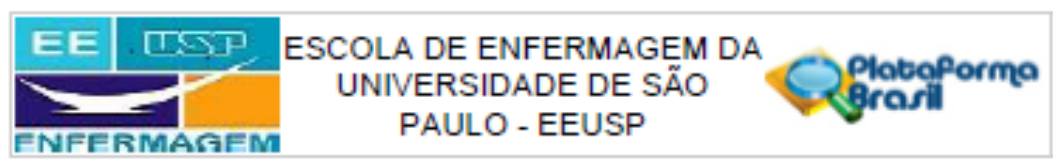

Conthask da Pawcer en 23

federal, estadual e municpal;

8- Avallar o impacto desses beneficlos soclals nos indlcadores programaticos de cura e abandono da tuberculose nos locals em estudo;

9. Apresentar proposta de aprimoramento das estrateglas de proteçáo social visando o fortalecimento do processo de adesăo a tratamento da tuberculose.

Avallaçso dos Rlscos $\theta$ Beneficlos:

O projeto apresenta balxo risco a0s partipantes da pesqulsa. Quanto aos beneficlos podera contribulr no aperfelçoamento das poiricas publicas e das praticas de saude adotadas para a adesto ao tratamento e 0 controle da TB no Sistema Único de Saude.

Comentarlos $\theta$ Consideraçose sobre a Peequlsa:

O projeto esta estruturado de forma adequada e contempla os aspectos eticos. O tema e objeto de Investigaç50 sajo relevantes para o campo da Saude Colettva e poderb̆o contribuir para o alcance das metas definidas na Agenda Estrateglca da Secretaria de Viglancia em Saude.

A pesquisadora anexou os modelos de autorizaçâo que serక̆o enviados as Institulçbes para uso e coleta dos dados secundarios.

Em atençäo ao parecer anterior os instrumentos de coleta dos dados foram anexados ao projeto e 0 cronograma atualizado.

Consideraç0es sobre 08 Termos de apresentaçao obrigatorla:

A pesquisadora apresentou mals dols TCLE, destinados a0s pronssionals da saude e a0s gestores da saude, alem do termo direcionado acs doentes com tuberculose. Inclulu nos TCLE que as entrevistas serd́o gravadzs e terấo duraçấl aproximada de 30 minutos, alem do CEP da EEUSP.

O6 TCLE estăo em consonanda com a resoluçäo 466/2012. Foram redigldos em linguagem adequada e em formato de convite acs partipantes. Informam o objetivo do estudo, asseguram o anonimato e a llberdade de participaç5̆o; o tempo estimado para realizaç5̆o da entrevista; a possibilidade de desistencla a qualquer momento, sem prejulzo ao atendlmento no serviço de saude ou no exerciclo da atlvidade profissional; $0 s$ contatos da pesqulsadora e do CEP da EEUSP; e que serăo assinados em duas vias, sendo uma para a pesquisadora e outra para 05 participantes.

\begin{tabular}{|c|c|c|c|}
\hline $\begin{array}{l}\text { Endereço: Au. Dr Endas de Car } \\
\text { Baitroc Cerqueire Comar }\end{array}$ & Who Aguat, 410 & $-\infty 60$ & \\
\hline UF: $S P$ Muricipia: & SAO PALLO & & \\
\hline (11)3061-7548 & Fax: $[11,9061.7548$ & E-mall: & tapesqeapts \\
\hline
\end{tabular}

Telefone: (11)3061-7548 Fax: (11)9061.7548 E-mall: edpesqeapt 


\section{ANEXO I (continuação)}

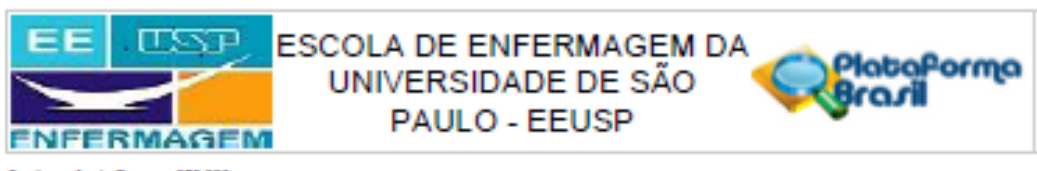

Contnave do Pancar sen 223

Recomendaç0es:

Năo ha recomendaçbes.

Conclusoes ou Pend®nclas $\theta$ Llata de Inadequaçes:

O protocoio de pesquisa náo apresenta colces eticos que impeçam a sua realzaçato. Consta no registro da Platafoma Brasl a seleçáo do CEP da Secretarla Municipal de Saude de Săo Paulo.

Situaçaso do Parecer:

Aprovado

Necesalta Apreclaçaso da CONEP:

Năo

Consideraç0es Finals a criterio do CEP:

A aprovaçăo do Comlte de Ettica em Pesquisa da EEUSP nåo substitul a autorizaçăo da Institulçăo coparticipante para o iniclo da pesquisa.

O CEP EEUSP Informa que ha necessidade de registro dos relatorios: parcial e final da pesquisa, na Plataforma Brasll.

SAO PAULO, 11 de Fevereiro de 2015

Assinado por:

Ruth Natalla Teresa Turrinl

(Coordenador)

Enderege: Ar. Dr Endas de Carveho Agiat, 410

Bairre. Cerqueirs Comat

UF: $\mathrm{SP} \quad$ Muricipia: ShOPAHL

CEP: 05.008000

Telefone: (11)30e1-7548 Fax: (111)9061.754s

E-mal: edpesqeaptr 


\begin{abstract}
ANEXO II

SECRETARIA MUNICIPAL DA
SAUUDE DE SÃO PAULO -
SMSISP

PARECER CONSUBSTANCIADO DO CEP

Elaborado pela Insttulçäo Coparticipante

DADOS DO PROJETO DE PESQUISA

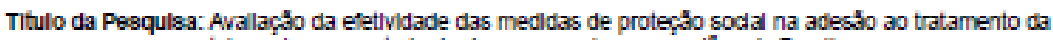
tuberculose e controle da doença em algumas regldes do Brasll

Pesqulsador: MARIA RITA BERTOLOZZ|

Area Tematica:

Versăo: 1

CAAE: 37254714.0 .3001 .0086

Institulçă Proponente:Escola de Erfermagen da USP

Patrocinador Principal: Secretaria de Vglancla em Saude

DADOS DO PARECER

Nünero do Parecer: 973.030

Data da Relatorla: 05/03/2015

Apresentaça do do Projeto:

Trata-6e de estudo descritivo-expiorationio, com recorte transversal, de abordagem quantiqualitativa.

A amostra do estudo compreendera doentes com TB, residentes nas Cldades de Sáo Paulo/SP, Rlo de Janelro/RJ, Redie/PE e Campina Grande/PB, dlagnosticados no periodo de janeiro a dezembro de 2013. Sera selecionado um profissional medlco ou enfermelro, de cada unidade de saude que os doentes realzaram o tratamento e 05 gestores municipals da saude, da vigliancla epidemiologica, da vigliancla em saude, da atençắ basica e do Programa de Controle da TB na estera municipal, estadual e federal. Criterios de inclusăo: doentes com TB e com idade Igual ou maior que 18 anos; residentes nos locals de estudo e que tenham capacidade de comunicaç5o verbal e compreensăo preservadas. Quanto aos pronssionals de saude e gestores, serdo incluidos aqueles que atuam no controle da TB ha pelo menos 6 meses.

Criterios de Exclusấ: doentes com TB que, no periodo da coleta de dados, estejam em reclusăo no sistema prisional.

Para a coleta de dados sera utilzado um Instrumento senv-estruturado contendo trés partes: a primeira parte sera aplicada aos gestores (Secretario Municipal da Saude, Coordenador da
\end{abstract}

\begin{tabular}{|c|c|}
\hline 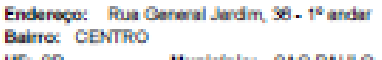 & CEP: ot:22s-010 \\
\hline $\begin{array}{l}\text { UF: } S P \quad \text { Munielpio: SAOPAULO } \\
\text { Telefone: (119927-2484 }\end{array}$ & E-mall: amscis Gomel con \\
\hline
\end{tabular}


ANEXO II (continuação)

SECRETARIA MUNICIPAL DA
EM PESQUUSA.SMS DE SÃO PAULO -
SMSISP

Conthuack da Pawar sma 000

Viglancla Epidemiologica, Coordenador da Vigllancla em Saude, Coordenador da Atençăo Basica e do Programa de Controle da TB na esfera municipal,estadual e federal).

A segunda parte sera aplcada acs protssionals da saude e doentes com TB.

A tercelra parte compreendera 06 dados secundarios dos doentes com TB, para avallar o impacto das medidas de proteçăo social nos indcadores programaticos de cura e abandono. Serăo coletados das fichas de notitcaçäo, prontuario, fichas de acompanhamento do TDO e do sistema de Informaçăo: TEWEB, na cidade de S5̆o Paulo e SINAN (Sistema de Informaçăo de Agravos e Notincaçбes), em Recife e em Campina Grande. As variavels e Categorias do Estudo referem-se:

- as caracteristicas pessoals, economico-socials e de saude-doença;

- a0s determinantes socials;

- as dimensbes da Vulnerabilldade: Indlvidual, Social e Programatica (inciulndo os elementos de gestáo do serviço relacionados as medldas de proteçăo socialbeneficios concedidos a0s doentes para a adeş̆o ao tratamento).

A coleta sera reallzada no periodo de janeiro a abril de 2014. A analse dos dados compreendera 05

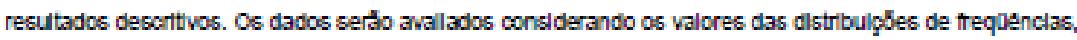
valores medios,medianos eiou modals, bem como medldas de dispersăo das variavels socio-economicas e

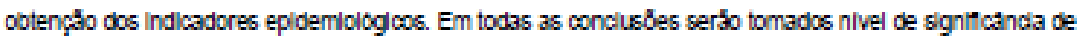
$0,05 \%$.

Objetivo da Pesqulsa:

Geral:

Avalar a efetividade das medid3s de proteç5o social na melhoria dos indicadores programaticos para adesáo 30 tratamento da tuberculose e controle da doença em municipios da regla nordeste e sudeste do Brasil.

Especincos:

- Caracterizar os pacientes en termos de condlọbes pessoas, economico-socials e de saude-doença:

- Identificar os elementos de vuinerabilidade indlvidual e soclal que podem Interferir na ades5̆o ao tratamento;

- Identincar a associaçấo entre a ades55o ao tratamento da tuberculose e 06 determinantes sociais de saude;

- Identincar as modalidades de incentivo socioeconómico proporcionado as pessoas com tuberculose nos muriciplos de Sä PauldSP, Campina Grande/PG,

Enderego: Fua Certaral Jindin, $30-1^{6}$ anda: Bairrec CENTROO 
ANEXO II (continuação)

SECRETARIA MUNICIPAL DA
EM PESQUISA-SMS

Corthasces da Pancer smoso

Reciferpe e FJo de JaneiroR:;

- Caractertzar a utllzaç50 do beneficlo auxillo-doença da Previdencla social pelas pessoas em tratamento para tuberculose, apontando as faclidades e difculdades para tal;

- Identificar as potencialdades e 36 fraglldades desses beneficlos no processo de adesfo ao tratamento;

- Identificar os elementos de vuinerablidade programatica que podem interfertr na disponilildade desses beneficios socials as pessoas en tratamento da tuberculose, nas instanclas federal, estadual e municipal;

- Avallar o impacto desses beneficios socials nos indlcadores programaticos de cura

e abandono da tuberculose nos locals em estudo.

- Apresentar proposta de aprimoramento das estrateglas de proteçato social visando o fortalecimento do processo de adesăo ao tratamento da tuberculose.

Avallaç:so dos Riscos $\theta$ Beneficlos:

Riscos: minimos relacionados a algum desconforto durante a entrevista para coleta dos dados. Beneficios: contribulr com as pollticas publlcas de saude no que diz respelto a adesto ao tratamento da tuberculose, visando o controle da doença.

Comentarios $\theta$ Consideraçoes sobre a Pesqulsa:

Trata-se de estudo de relevancla. A pesqulsadora tem doutorado e e professora na area de Saude Coletiva, ja tendo desenvolvido alguns trabahos relacionados a tuberculose.

A metodologla descrita e adequada aos objetvos propostos.

Consideraç®es sobre 08 Termos de apresentaçäo obrigatorla:

A Folha de Rosto esta corretamente preenchida, foram identifcadas institulçăo proponente e coparticipante,

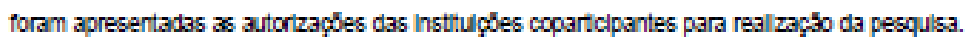

Cronograma e orçamento detainado estắo adequados, 05 custos do projeto estarăo a cargo da Secretarla de Viglancla a saude.

Ha beneficios previstos na realzaçáo do estudo.

TCLE fol retificado.

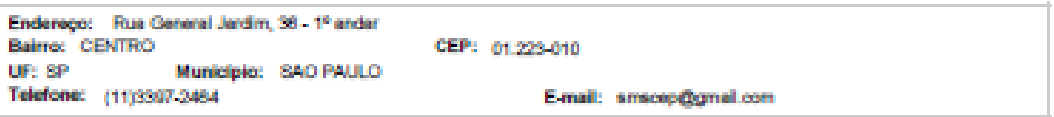


ANEXO II (continuação)

SECRETARIA MUNICIPAL DA
SAÚDE DE SÃO PAULO -
SMSISP

Corthasce do Pawcer snowo

Conclus0es ou Pendenclas $\theta$ Llata de Inadequaç0es:

Sem pendenclas ou inadequaçbes.

situaçaso do Parecer:

Aprovado

Necessita Apreclaçao da CONEP:

Nåo

Consideraçoes Finals a criterio do CEP:

Para Iniclo da coleta dos dados, o pesquisador devera se apresentar na mesma instancia que autorizou a realzaçấo do estudo (Coordenadorla, Supervisafo, SMSIGab, etc).

Se o projeto prever apllcaçăo de TCLE, todas as paginas do documento deverăo ser rubricadas pelo pesquisador e pelo voiuntario e a ultima pagina assinada por ambos, conforme Carta Circular no 003/2011 da CONEPICNS.

Salentamos que o pesquisador deve desenvolver a pesquisa conforme delneada no protocolo aprovado. Eventuals modincaçbes ou emendas ao protocolo devem ser apresentadas a CEP de forma clara e sucinta, Identuficando a parte do protocoio a ser modificada e suas Justificativas. Lembramos que esta modincaçăo necessitara de aprovaçăo etica do CeP antes de ser implementada.

De acordo com a Res. CNS 466/12, o pesquisador deve apresentar a este CEP/SMS os relatorios semestrals. O relatorio tnal devera ser enviado atraves da Plataforma Brasl, icone Notifcaç5̆o. Uma copla digtal (CDVDVD) do projeto finalzado devera ser enviada a Instancla que autonzou a realizaçăo do estudo, vla correlo ou entregue pesscaimente, logo que o mesmo estiver concluido.

SAO PAULO, 04 de Março de 2015

Assinado por:

SIMONE MONGELU DE FANTINI

(Coordenador)

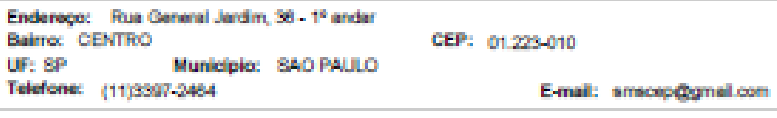




\section{APENDICES}

\section{APENDICE A}

QUESTIONÁRIO: A SER APLICADO JUNTO AOS PROFISSIONAIS DE SAÚDE.

\begin{tabular}{|c|}
\hline 1. IDENTIFICAÇÃO DO PROFISSIONAL DE SAÚDE \\
\hline 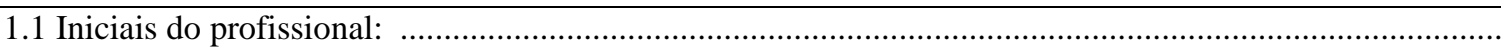 \\
\hline 1.2 Profissão: 1( ) Médico \\
\hline 1.3 Sexo: 1( ) Masculino 2( ) Feminino \\
\hline 1.4 Quanto tempo trabalha com TB? ___ anos ___ meses \\
\hline 1.5 Formação: 1 ( ) Pós-Graduação Latu Senso $\quad 2$ ( ) Pós-Graduação Strito Senso \\
\hline 1.6 Realizou capacitação em TB? 1( ) sim 2( ) não \\
\hline 1.7. Nome da Unid Saúde (US): . \\
\hline 1.8. Nome Distrito US: \\
\hline 1.9. Endereço da US: \\
\hline 1.10 Telefone da Unidade: \\
\hline 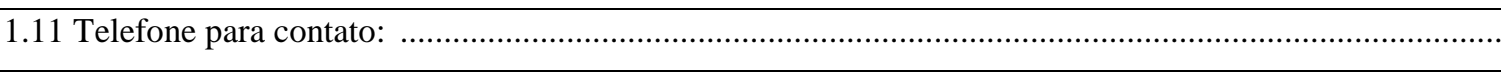 \\
\hline 1.12. Tipo de US: 1( ) UBSF 2( ) UBSF/PACS 3( ) UBS 4( ) Amb. Ref. TB5 ( ) UBSF/UBS \\
\hline
\end{tabular}

2) $\mathrm{O}(\mathrm{A}) \operatorname{Sr}(\mathrm{a})$ saberia informar sobre alguns indicadores relacionados à TB nesta região?
1( ) $\operatorname{sim}$
2( ) não
3( ) alguns/às vezes
99( ) NS/NR

3) Indicadores Epidemiológicos:

\begin{tabular}{|l|l|l|l|l|l|l|l|}
\hline ANO & $\begin{array}{l}\text { Número } \\
\text { de Casos }\end{array}$ & $\begin{array}{l}\text { Taxa } \\
\text { Incidência }\end{array}$ & $\begin{array}{l}\text { Taxa } \\
\text { Incidência } \\
\text { Bacilíferos }\end{array}$ & $\begin{array}{l}\text { Taxa } \\
\text { Mortalidade } \\
\text { por TB }\end{array}$ & $\begin{array}{l}\text { Taxa de Resistência } \\
\text { Adquirida e } \\
\text { Multirresistência }\end{array}$ & $\begin{array}{l}\text { Taxa Co- } \\
\text { Infectados } \\
\text { TB-HIV }\end{array}$ & $\begin{array}{l}\text { Co- } \\
\text { associação } \\
\text { TB/Diabettes }\end{array}$ \\
\hline 2015 & & & & & & & \\
\hline
\end{tabular}

\subsection{Observação:}

4) O município tem política de saúde voltada para a tuberculose?

1( ) $\mathrm{Sim}$

Quais?

2( ) Não

$3($ ) às vezes

99( ) NS/NR 
5) A TB é considerada doença prioritária no quadro sanitário do município?

1( ) Sim. Por quê?

2 ( ) Não. Por quê?

3 ( ) às vezes

99( ) NS/NR

6) No repasse dos recursos financeiros para o município são definidas linhas específicas para a TB?

1( ) Sim. Quais?

2 ( ) Não. Por quê?

3 ( ) às vezes

99( ) NS/NR

7) $\mathrm{O}(\mathrm{A}) \mathrm{Sr}(\mathrm{a})$ participa na discussão e definição de aplicação de recursos financeiros para o controle da TB?

1( ) Sim. De que forma?

2 ( ) Não. Por quê?

$3($ ) às vezes

99( ) NS/NR

8) O município investe recursos próprios para a TB?

1( ) Sim. Qual é o \% do orçamento para a saúde?

2 ( ) Não. Por quê?

$3($ ) às vezes

99( ) NS/NR

9) Caso o doente com TB necessite, algum incentivo socioeconômico é disponibilizado?

1( ) Sim. Qual? 1a( ) cesta básica 1b( ) café da manhã no serviço de saúde 1c ( ) lanche

$1 \mathrm{~d}($ ) vale transporte $1 \mathrm{e}($ ) outros

2( ) Não. Por quê?

3 ( ) às vezes

99( ) NS/NR

10) O incentivo é mantido regularmente durante todo o tratamento?

1( ) Sim. Qual a regularidade?

2( ) Não. Por quê?

$3($ ) às vezes

99( ) NS/NR

11) Em caso de abandono do tratamento, o serviço de saúde tem alguma ação voltada para o doente?

1( ) Sim. Qual?

2( ) Não. Por quê?

$3($ ) às vezes

99( ) NS/NR

12) Qual o n ${ }^{\circ}$ de unidades de saúde que o(a) $\mathrm{Sr}$ (a) atua em ações de controle da TB:

$\begin{array}{llllll}\text { 12.1) Tipo de Unidade: } & \text { b1( ) USF } & \text { b2( ) UPA b3( ) AmbRef em TB } & \text { b4( ) Hospital de Ref } \\ \text { TB } & \text { b5( ) UBS } & \text { b6( ) Centro de Saúde b7( ) Outro: } & \end{array}$

13) As unidades de saúde realizam tratamento supervisionado no próprio serviço ou domicílio?

1( ) Sim. Quantas vezes por semana e quem supervisiona?

2 ( ) Não. Por quê?

$3($ ) às vezes

99( ) NS/NR

14) $\mathrm{O}(\mathrm{A}) \mathrm{Sr}(\mathrm{a})$ acredita que o TDO contribui a adesão ao tratamento?

1( ) Sim.

2 ( ) Não. Por quê?

$3($ ) às vezes

99( ) NS/NR 
15) O município disponibiliza recursos necessários para a realização do TDO (transporte; recursos humanos)?

1( ) Sim.

2 ( ) Não. Por quê?

$3($ ) às vezes

99( ) NS/NR

16) A regularidade na distribuição/envio da medicação para os municípios/unidades de saúde é assegurada com tempo hábil?

1( ) Sim.

2 ( ) Não. Por que?

$3($ ) às vezes

99( ) NS/NR

17) O município possui Laboratório da rede SUS para executar baciloscopia?

1( ) Sim. Quantos?

2( ) Não. Por que?

$3($ ) às vezes

99( ) NS/NR

18) Se Sim, qual o tempo para o recebimento do resultado da baciloscopia?

\begin{tabular}{|l|l|}
\hline $\mathrm{a}($ ) 1 a 5 dias & $\mathrm{g}($ ) 3 a 4 meses \\
\hline $\mathrm{b}($ ) 6 a 10 dias & $\mathrm{h}($ ) 5 a 6 meses \\
\hline $\mathrm{c}($ ) 11 a 15 dias & $\mathrm{i}($ ) 7 a 11 meses \\
\hline $\mathrm{d}($ ) 16 a 20 dias & $\mathrm{j}($ ) $>12$ meses \\
\hline $\mathrm{e}($ ) 21 a 30 dias & $99($ ) NS/NR \\
\hline $\mathrm{f}($ ) 1 a 2 meses & \\
\hline
\end{tabular}

19) As unidades de saúde realizam Raio $X$ ?

1( ) Sim

2( ) Não. Por que?

$3($ ) às vezes

99( ) NS/NR

20) Se Sim, qual o tempo para recebimento do resultado?

\begin{tabular}{|l|l|}
\hline $\mathrm{a}($ ) 1 a 5 dias & $\mathrm{g}($ ) 3 a 4 meses \\
\hline $\mathrm{b}($ ) 6 a 10 dias & $\mathrm{h}($ ) 5 a 6 meses \\
\hline $\mathrm{c}($ ) 11 a 15 dias & $\mathrm{i}($ ) 7 a 11 meses \\
\hline $\mathrm{d}($ ) 16 a 20 dias & $\mathrm{j}($ ) $>12$ meses \\
\hline $\mathrm{e}($ ) 21 a 30 dias & $99($ ) NS/NR \\
\hline $\mathrm{f}($ ) 1 a 2 meses & \\
\hline
\end{tabular}

21) As unidades de saúde realizam Prova Tuberculínica?

1( ) Sim

2( ) Não. Por que?

3( ) às vezes

99( ) NS/NR

22) Se Sim, qual o tempo para o recebimento do resultado?

\begin{tabular}{|l|l|}
\hline $\mathrm{a}($ ) 3 a 5 dias & $\mathrm{d}($ ) 16 a 20 dias \\
\hline $\mathrm{b}($ ) 6 a 10 dias & $\mathrm{e}($ ) 21 a 30 dias \\
\hline $\mathrm{c}($ ) 11 a 15 dias & $99($ ) NS/NR \\
\hline
\end{tabular}

\section{3) Dados Qualitativos (a entrevista deverá ser gravada)}

a) Conte um caso que o(a) $\mathrm{Sr}$ (a) considerou que o incentivo oferecido ao doente com TB foi significativo para a cura da doença?

b) Conte um caso que o(a) $\operatorname{Sr}($ a) considerou que o incentivo oferecido ao doente com TBnão foi significativo para a cura da doença?

c) Em sua opinião, o que poderia ser feito para reverter a atual situação epidemiológica da TB na sua cidade? 


\section{APENDICE B}

\section{TERMO DE CONSENTIMENTO LIVRE E ESCLARECIDO}

Prezado (a) Senhor (a) Profissional da Saúde,

$\mathrm{O}$ (A) Senhor(a) está sendo convidado para participar de uma pesquisa chamada "Avaliação da efetividade das medidas de proteção social na adesão ao tratamento da tuberculose e controle da doença em algumas regiões do Brasil", sob coordenação da profa. Dra. Maria

Rita Bertolozzi, da Escola de Enfermagem da Universidade de São Paulo. Sua colaboração será da maior importância para a realização deste trabalho, motivo pelo qual solicito sua participação. O seu consentimento em participar desta pesquisa deve considerar as seguintes informações:

- O objetivo do estudo é avaliar a efetividade das medidas de proteção social na melhoria dos indicadores programáticos para adesão ao tratamento da tuberculose e controle da doença em municípios da região nordeste e sudeste do Brasil.

- A sua participação é voluntária, e consistirá em uma entrevista que será gravada, com duração de aproximadamente 30 minutos. Durante a pesquisa você poderá fazer todas as perguntas que julgar necessárias para o esclarecimento de dúvidas, podendo recusar-se a responder perguntas ou deixar de participar do estudo a qualquer momento, se assim o desejar, sem sofrer nenhum dano no seu atendimento. Você não terá lucros em participar da pesquisa e haverá garantia de indenização diante de eventuais danos decorrentes da pesquisa, ou seja, haverá encaminhamento para solução de eventuais problemas identificados.

- Não é necessária sua identificação e será garantido o seu anonimato e o sigilo das informações, assim como os resultados serão utilizados exclusivamente para fins científicos. Ao final da pesquisa, se for do seu interesse, terá livre acesso ao conteúdo da mesma, podendo discuti-lo junto à pesquisadora.

Desde já agradeço a sua colaboração e me coloco à disposição por meio do telefone (11) 3061-7652 ou pelo e-mail mrbertol@usp.br. Este projeto de pesquisa foi aprovado pelo Comitê de Ética em Pesquisa da Escola de Enfermagem da Universidade de São Paulo (telefone 11 3061-7548; email: edipesq@usp.br).

Diante do exposto, declaro que fui devidamente esclarecido(a) e dou o meu consentimento para participar da pesquisa e para publicação dos resultados. Estou ciente que receberei uma via desse documento.

Assinatura do Participante da Pesquisa

Assinatura da Pesquisadora Responsável

Assinatura do Pesquisador Participante

São Paulo, 


\section{APÊNDICE C \\ FRASES TEMÁTICAS RESULTANTES DOS DEPOIMENTOS DOS PROFISSIONAIS DE SAÚDE}

\section{Profissional A}

A1: A adesão devido a incentivos nunca foi presenciada, mas “... algum incentivo, Bolsa Família, ou qualquer outro incentivo desse tipo... ajuda a melhorar a qualidade de vida da pessoa, da família, mas isso aí acaba não ficando bem colado na saúde".

A2: O que gera adesão ao tratamento é o vínculo com a equipe do Programa de Saúde da Família, “... com o posto, com a unidade".

A3: O "vínculo com o paciente... é a base, é fundamental" para que haja adesão ao tratamento da tuberculose.

A4: Em relação à adesão ao tratamento vinculada aos incentivos sociais, profissional relata que "é mais aquela questão de intimidação [...] não aquilo auxiliando por si só. É mais por medo de perder o beneficio".

A5: Profissional considera que "basicamente todos" os pacientes que receberam incentivo, este não foi significativo para a cura da doença, mas sim o vínculo estabelecido.

A6: A atual situação epidemiológica da TB pode ser revertida: 1) por meio de conscientização da população, o que já é feito na UBS; entretanto poderia ser incrementada, caso o quadro de funcionários fosse completo e segundo disponibilidade de verba; 2) pela acessibilidade à unidade e às equipes; 3) pela captação de pacientes.

A7: Profissional considera, em relação aos incentivos que “... infelizmente, na população brasileira o que funciona não é o dar. O que funciona mesmo é o risco de perder aquele incentivo".

A8: Sugere-se que incentivos públicos sejam fornecidos, pela esfera Federal, Estadual, Municipal e que sejam retirados em caso de pacientes que não aderem ao tratamento, como "uma punição".

A9: Admite-se que "a população tem mais medo de perder o benefício do que, muitas vezes, da própria doença".

A10: Profissional expõe que "o que atrapalha... muitos tratamentos é a desinformação... que gera o preconceito e este faz com que o paciente se esconda". 


\section{Profissional B}

B1: Profissional relata caso de família com precárias condições sociais em que a cesta básica ajudou o tratamento, pois “... se não eles não iam conseguir fazer uma alimentação adequada”.

B2: Relata-se caso em que mesmo com a cesta básica, criança não aderiu ao tratamento, pois a mãe não comparecia ao serviço de saúde para o TS (associava o uso da medicação com a queda de cabelo próprio).

B4: A situação da TB pode ser revertida com a melhora das condições de vida das pessoas e que incentivos já existem, como o Bolsa Família vale transporte, cesta básica. 


\section{Profissional C}

C1: Dado que se trabalha com uma comunidade que possui um poder aquisitivo muito baixo, o incentivo é considerado como necessário: "A gente vê os olhos dos pacientes brilharem em questão do benefício".

C2: O profissional afirma: "A gente vê os olhos dos pacientes brilharem em questão do benefício".

C3: Dada a situação de precariedade, pacientes, muitas vezes, não querem terminar o tratamento para continuar a receber a cesta básica.

C4: Profissional exemplifica a necessidade da cesta básica afirmando que há pacientes que abandonam o tratamento no último mês para continuar a receber a cesta.

C5: A cesta básica é o benefício "mais físico" que mais incentiva o paciente com tuberculose a fazer o DOTS.

C6: Afirma-se que são raros os pacientes que querem fazer o autoadministrado, pois com o DOTS podem receber a cesta básica.

C7: Afirma-se que, quando se percebe que o paciente “... tá querendo desistir, a gente, infelizmente, tem que usar de recursos, de ameaças" com a interrupção da cesta básica.

C8: Considera-se que ameaças sobre a possibilidade da perda da cesta básica estimulam o paciente a dar continuidade ao tratamento.

C9: Reconhece-se que o incentivo da cesta básica não possibilita mudança de vida, mas possibilita melhorar a alimentação e a adesão ao tratamento.

C10: Afirma-se que o real objetivo da cesta básica é “... camuflado pela real necessidade que as famílias hoje passam no bairro".

C11: A cesta básica é considerada essencial, afirmando-se que a situação do paciente com TB é tão crítica "... que eles sustentam a família inteira com a cesta básica".

C12: Afirma-se que muitos pacientes já recebem o Bolsa Família, pois possuem "baixa renda".

C13: Considera-se que a adesão era muito boa quando os pacientes recebiam lanche.

C14: Considera-se que "era bem divertido" à época do lanche, pois os pacientes "tomavam café... e era oportunidade de conversar sobre a vida". 
C15: Afirma-se que a retirada do benefício do "café, dos lanches" foi muito sentida pelos profissionais de saúde, pois os pacientes devem tomar a medicação em jejum: “... vir em jejum e sair em jejum daqui, é meio complicado...".

C16: Considera-se sobre o INSS, "... tá um pouco distante da gente...é algo muito complicado... É muita burocracia", ainda que os pacientes sejam orientados a respeito.

C17: Afirma-se que empresas não querem manter os pacientes por preconceito e acabam tentando aposentá-los.

C18: Admite-se nunca ter sido visto paciente conseguir aposentadoria ou um benefício via INSS.

C19: Afirma-se a existência de pacientes que, mesmo com o benefício, não aderiram ao tratamento, apesar de tal situação ser "muito rara".

C20: Afirma-se que o incentivo não tem significado "... quando o paciente não quer mesmo se envolver com a saúde".

C21: Afirma-se que há pacientes que mesmo com a ameaça de perda da cesta básica não demonstraram sensibilidade: “... não me importo, cesta 'basicazinha' dessa daí que vem com $5 \mathrm{~kg}$ de arroz" e abandonaram o tratamento.

C22: Relata-se a situação de paciente usuário de drogas que abandonou o tratamento mesmo recebendoa cesta básica que era trocada por drogas.

C23: Aponta-se que a situação epidemiológica da TB em São Paulo depende 1) da "a organização do serviço de gestão" da saúde, além da UBS; 2) da humanização, do estabelecimento de vínculo; 3) de redes que interliguem os serviços.

C24: Critica-se a gestão da secretaria de saúde ao ser solicitada ajuda por parte da UBS.

C25: Critica-se a forma como o Programa de Controle da TB recomenda a realização do TDO, pois dificulta o estabelecimento do vínculo, uma vez que se preconiza supervisionar a tomada da medicação: "expira falta de confiança para com o paciente... você acaba quebrando um vínculo de confiança". 


\section{Profissional D}

D1: Profissional de saúde não recorda de caso em que o incentivo foi significativo para a cura da TB.

D2: Profissional afirma que, na maioria dos casos que atendeu, o incentivo não foi importante para a adesão ao tratamento.

D3: Relata caso de uma garota que não aderiu ao tratamento: “... jovem... que tinha alguns recursos... e trabalhava... que, apesar de receber a cesta básica [...] isso para ela não fazia diferença... provavelmente ela [...] dava pra outras pessoas".

D4: Profissional admite que, dado o fato do tratamento ser longo e porque a paciente era jovem, era “... um transtorno ... ficar vindo toda semana no posto, pegar o remédio, assinar o papel”.

D5: A situação da TB poderia ser revertida 1) com o tratamento da infecção latente dos pacientes assintomáticos “... é um achismo ... eu nunca li nada a respeito ... não sei se existe esta obrigatoriedade aqui em São Paulo"; 2) individualizar o tratamento de cada paciente: “... devem ter pacientes que vão se beneficiar com ... a cesta e vale alimentação, transporte... cada paciente com suas particularidades e pactuar este tratamento com o paciente, fazer com que ele participe do tratamento e não só a imposição... tentar partilhar este plano mesmo com cada um". 


\section{Profissional E}

E1: Profissional afirma que "o incentivo da cesta básica dá muito certo com os bolivianos”, pois “... carecem mesmo de muita coisa", mas "não percebo muito isso... com a nossa população brasileira".

E2: Profissional relata que os bolivianos "moram mal" e "passam fome" e, por isso, receber a cesta básica os faz “... animados a vir todos os dias tomar o remédio... dá a impressão de que querem continuar doentes" para continuarem a receber o incentivo social.

E3: Considera-se que a cesta básica para bolivianos aumenta a adesão ao tratamento.

E4: Relata-se que para os pacientes usuários de drogas, o oferecimento de incentivo não promove a adesão ao tratamento: “... você pode oferecer o que... quiser... nada segura porque se ele não tá a fim de largar isso... não tem dinheiro nenhum que faça ele aderir e chegar à cura".

E5: Relata-se caso de um paciente usuário de drogas que "por mais que eu tivesse feito, que acolhi com tudo [...], não teve jeito ... passando fome, sem emprego, sem nada ...a cesta era uma ajuda ...e ... mesmo assim, você vê que não é isso que vai segurá-los".

E6: Considera-se que os profissionais que “... chegam agora pra trabalhar na ponta... não valorizam essa questão da tuberculose".

E7: Considera-se que a situação da TB poderia ser revertida: 1) se os profissionais “... que chegam pra trabalhar na ponta” valorizassem a doença; 2) enfatizar a questão nas universidades: “... o povo morre disso...".

E8: Aponta-se que em pronto-socorro de convênio, assim como profissionais jovens não valorizam a TB. 


\section{Profissional F}

F1: Considera-se que a cesta básica e conversar possibilitam "amarrar o tratamento" (em caso de situação de mãe adolescente, desempregada, com 3 crianças, todas em tratamento para a TB, família sem pai, recebia Bolsa Família).

F2: Incentivos não produzem impacto na adesão ao tratamento em caso de pacientes pertencentes à “classe média... que tá perto da unidade, que, às vezes, tem convênio"; mesmo nesses casos há não adesão.

F3: A situação da TB poderia ser revertida: 1) por meio de maior divulgação do Programa (em escolas, por exemplo); 2) realizar investigação de casos em escolas, em empresas, o que possibilitaria o diagnóstico precoce; 3) monitoramento de comunicantes; 4) melhorar o rastreamento.

F4: Admite-se que o "monitoramento dos comunicantes" é "muito importante", mas "isso ainda é falho". 


\section{Profissional G}

G1: A cesta básica é essencial em pacientes com "situação social bem complicada": usuário de drogas, etilista, dificuldades com os membros das famílias, quando não há condição de conseguir alimentação.

G2: Paciente sabe que o recebimento da cesta básica depende de seu comparecimento ao serviço de saúde para o TDO.

G3: Admite-se que, dada a situação difícil do paciente, ele "tomaria mais um mês de medicação só pra ter certeza que ia receber a cesta".

G4: Há "pacientes difíceis", que recusam a cesta básica e não aderem ao tratamento: são de "difícil controle".

G5: Há pacientes que a cura (por exemplo, a cura do filho) é mais importante do que o recebimento da cesta básica.

G6: Relata-se que na Bahia a cesta básica não é oferecida aos pacientes com TB, ainda que seja muito necessária.

G7: A cesta básica é positiva mesmo em casos de "aceitaram a cesta, fariam do mesmo jeito que não tivesse... porque estavam preocupados em se curar", mas como "tá numa região de vulnerabilidade onde o poder aquisitivo é baixo... pra eles é um plus... é bom ter a cesta”.

G8: Considera-se que a situação da TB pode ser revertida, principalmente, da disponibilidade de profissionais para realizar: 1) busca ativa; 2) TDO em casos de paciente que reside "longe"; 3) investimento em vigilância. 


\section{Profissional H}

H1: A cesta básica (e também o vale transporte) é importante em caso de pacientes oriundos da Bolívia, que apresentam "situação de vulnerabilidade muito extrema com relação ao seu trabalho... renda muito diminuída... ajuda... até mesmo na manutenção familiar".

H2: A cesta básica também é importante em caso de paciente que não conseguem trabalhar, para a “... manutenção da família”.

H3: Admite-se que os incentivos sociais não são significativos em caso de "moradores de rua", porque "eles não tem como tá recebendo... não querem pegar o voucher... não tem o discernimento... que o incentivo social... pode ser um auxílio para o tratamento".

H4: Considera-se que a situação da TB pode ser revertida por meio de: 1) busca ativa, 2) sensibilização, 3) “aumento nessa questão na mídia”. 


\section{Profissional I}

I1: A cesta básica é importante, principalmente, para os pacientes com menor poder aquisitivo.

I2: Os pacientes consideram a cesta básica muito importante, pois a procuram e fazem questão de busca-la.

I3: Os incentivos não são significativos para moradores de rua, pois eles não têm onde cozinhar o alimento da cesta básica; neste caso, considera-se que fornecer pães contribui mais para a adesão do paciente ao tratamento: “contribuía mais a gente dar dois pãezinhos para ele...".

I4: Relata-se caso de morador de rua que “... pegava a cesta básica, mas acho que ele trocava até por bebida".

I5: Considera-se que a situação da TB pode ser revertida: 1) com “... dispositivo de fazer teste mais rápido... na unidade de saúde"; 2) incrementar a cesta básica e vale-transporte; 3) esclarecer os profissionais de saúde a respeito do incentivo; 4) melhorar o espaço físico das unidades de saúde (porque tem aumentado o número de profissionais que adquirem TB). 


\section{Profissional J}

J1: Considera-se que incentivos, como lanche ao receber a medicação ou a cesta básica, promovem a adesão ao tratamento, dada a situação dos pacientes.

J2: A tuberculose tem maior prevalência nas regiões periféricas onde há pessoas que realmente precisam dos incentivos.

J3: Para usuários de drogas o incentivo não melhora a adesão: “... para eles esse incentivo não é nada".

J4: Considera-se que pacientes que tem família realizam o tratamento corretamente: “... mesmo que não tenha o que comer ele vai vir por causa do incentivo".

J5: Considera-se que a situação da TB pode ser revertida por meio: 1) da sensibilização dos profissionais da saúde para a busca ativa, pois “... o agente comunitário que diz que faz a investigação a gente vê que não é...”. 


\section{Profissional K}

K1: A cesta básica ajuda a adesão ao tratamento em caso de paciente que se encontra desempregado e sem condições financeiras.

K2: Paciente não se alimentava corretamente, pois estava desempregado, e isto piorava a dor no estomago devido aos medicamentos, assim, a cesta básica, ao possibilitar melhorar a alimentação, promoveu a adesão ao tratamento.

K3: Relata-se caso em que, mesmo recebendo cesta básica, não ocorreu adesão ao tratamento, pois não se acreditava ter TB: "como ela tinha diabetes, ela achava que o problema dela era só diabetes".

K4: Considera-se que a situação da TB pode ser revertida: 1) entregando-se a cesta básica no domicílio dos pacientes, dada sua situação de fraqueza; 2) fornecer café e lanche da manhã no TDO.

K5: Acredita-se que o paciente realizava o TDO "direitinho... porque tinha o café".

K6: Ainda que para o profissional de saúde, o lanche "não faz diferença", isto ocorre para o paciente, pois "eles não tem condições financeiras".

K7: Profissionais de saúde apresentam sentimento de comiseração ao atender pacientes que realizam o TDO e não recebem lanche e que se apresentam em jejum: "a gente pega nossa bolacha" para oferecer a ele.

K8: Profissional aponta que "o maior problema da tuberculose é a vergonha... a pessoa omite... não trata por vergonha". 


\section{Profissional L}

L1: A cesta básica é considerada como significativa para a adesão ao tratamento no caso dos bolivianos, que, “... na maioria das vezes... não tem o que comer... ajudam a família...”.

L2: Afirma-se que quase todos os bolivianos aceitam o TDO devido à cesta básica.

L3: Considera-se que para "Todo paciente que aceita o TDO é fundamental o incentivo"; afirmando-se que: "não lembra de nenhum caso que tenha abandonado depois de ter começado a receber o incentivo".

L4: Considera-se que a situação da TB poderia ser revertida: 1) contando-se com maior número de recursos humanos: uma enfermeira para a vigilância. 


\section{Profissional M}

M1: Considera-se o incentivo (café da manhã para o TDO) importante para a adesão ao tratamento, pois em muitos casos: "a única alimentação que tinha durante o dia".

M2: Considera-se que a situação da TB pode se revertida: 1) dispondo-se de meios para garantir a agilidade e a qualidade nos exames laboratoriais para a TB, no caso dos ACS: dispor de armazenamento adequado das amostras de escarro coletado até dirigir-se até a UBS/na UBS; 2) eficiência na manutenção dos equipamentos: em caso de quebra de geladeira: garantia de conserto imediato. 


\section{Profissional N}

N1: Considera-se a cesta básica significativa na adesão ao tratamento da TB, em caso de bolivianos “ajudou bastante porque ele quase não se alimentava [...] na casa onde ele vivia tinha que esperar o horário de alimentação, não era regrado e com essa cesta básica só dele ele mesmo preparava a alimentação, então ele comia direitinho nos horários".

N2: Relata-se caso em que o incentivo não foi significativo para a adesão ao tratamento: paciente com TB resistente que "comia a hora que ele queria... fumava demais... não tomava a medicação... o final de semana, apesar de levar".

N3: Considera-se que a situação da TB pode ser revertida: 1) realizando-se busca em locais onde há importante concentração de jovens, a exemplo de baile funk ativa, balada, como forma de prevenção; 2) por meio da divulgação da doença na mídia; 3) busca ativa nas UBS. 


\section{Profissional O}

O1: Considera-se que a cesta básica "anima" o paciente a aderir ao tratamento.

O2: Relata-se caso de paciente o qual "não vinha de jeito nenhum" fazer o tratamento supervisionado, mesmo oferecendo-se a cesta básica "pra ela não mudava nada [...] falava da questão do emprego, que ela não precisava”.

O3: A cesta básica não ajuda na adesão ao tratamento em condições que envolvem dificuldade na dinâmica familiar: situação financeira comprometida e violência por parte do marido "... prejudicava e dificultava ela vir... questão importante de violência que ela sofria pelo marido". 


\section{Profissional P}

P1: Considera-se que a cesta básica é importante para afastar falha no seguimento do tratamento em caso de paciente com TB resistente.

P2: Considera-se que em todos os casos o oferecimento da cesta básica e vale-transporte é positivo para o seguimento do tratamento, mesmo em caso de pacientes que não necessitam desse recurso (pacientes que tem convênio, por exemplo).

P3: Admite-se que o incentivo e o acolhimento apoiam a adesão ao tratamento. 


\section{Profissional Q}

Q1: Considera-se que incentivos como cesta básica, vale transporte são significativos para a cura da doença, devido à "vulnerabilidade social e econômica" dos pacientes, apoiando a corresponsabilidade dos pacientes pelo tratamento.

Q2: Considera-se que a situação da TB pode ser revertida: 1) com política de incentivo: cesta básica, vale-transporte; 2) sensibilizar a população em relação à importância do tratamento; 3 ) busca ativa assertiva por parte dos profissionais das equipes de saúde da família; 4) vínculo.

Q3: Considera-se que o incentivo é uma troca em função do cumprimento do tratamento pelo paciente, criando-se "um vínculo" entre o profissional e o paciente. 


\section{Profissional R}

R1: Considera-se que a cesta básica é importante em caso de paciente “... com condição socioeconômica bem complicada".

R2: Aponta-se satisfação de paciente pelo recebimento da cesta básica.

R3: Incentivos como cesta básica e vale-transporte não são significativos para a adesão em caso de "etilista crônico".

R4: Considera-se que a situação da TB pode ser revertida: 1) "dobrar a atenção" em relação à questão da TB, sensibilizando os profissionais de saúde; 2) realizar busca ativa: “... todas as vezes... em todas as consultas. Até os que parecem que não são nada”; 3 ) município deve prover os incentivos. 


\section{Profissional S}

S1: Considera-se que o incentivo contribui para a adesão ao tratamento.

S2: Em caso de alcoolismo e em “... outras questões psicológicas”, incentivos como cesta básica, vale-transporte e TS no domicílio não apresentam resultado.

S3: Considera-se que a situação da TB pode ser revertida: 1) incrementando-se a divulgação da doença, pois "as pessoas acham que a tuberculose foi erradicada", para diminuir o estigma e o preconceito. 


\section{Profissional T}

T1: Considera-se que a cesta básica e o vale-transporte mantiveram a assiduidade do paciente e ajudam na adesão ao tratamento para a TB, devido ao “... estilo de vida que eles levam aqui no Brasil".

T2: Relata-se o caso de um paciente boliviano para o qual o oferecimento do vale-transporte definiu a sua manutenção no TDO, tendo sido seu chefe "sensibilizado" em relação à necessidade do tratamento.

T3: Relata-se o caso de um paciente boliviano, para o qual o vale-transporte definiu a sua manutenção no TDO, pois tinha dificuldade financeira e de disponibilidade.

T4: Considera-se que, em caso de um paciente boliviano, "se não tivesse nada a oferecer, eu acredito que ele já teria abandonado... eles trocam também muito de lugar [...], é uma possibilidade muito grande de troca de emprego", assim, o bilhete único significou "incentivo para continuar o tratamento dele até o final, independente do lugar onde ele esteja".

T5: A UBS mantém contato constante com o paciente (boliviano) e seu chefe, o que fortalece a confiança no tratamento, aliado ao oferecimento do bilhete único.

T6: Considera-se que o bilhete único, mais do que a cesta básica,é primordial para a continuidade do tratamento do paciente.

T7: Relata-se o caso de paciente para a qual o inventivo não foi significativo para a cura, pois “queria era se livrar da doença... tinha um objetivo... o objetivo dela era concluir... todo o esclarecimento que ela tinha, ajudou a entender a importância do tratamento... esclarecimento de ela saber que é parte da saúde dela... foi primordial pra ela fazer o tratamento até o final... ela compreendeu a necessidade de ter um rigor no tratamento... que, às vezes, não acontece com os outros... ela entendeu que o papel era dela...".

T8: Afirma-se que "os maiores casos de gravidade que a gente tem, são pessoas que tem uma situação precária...”.

T9: A situação da TB poderia ser revertida: 1) “... com ação em relação às situações precárias, as situações de saneamento, as situações de moradia, esclarecimento do que deve ser feito e pode ser feito em relação à prevenção, em relação à diagnóstico e não só incentivos”; 2) atuar “... de maneira melhor" em relação aos imigrantes, "as pessoas que vem de fora": controle da doença e ações educativas; 4) UBS com maior tempo para resolver os problemas de saúde das pessoas, planejar e implantar ações de saúde. 
T10: Profissional pondera que "é muito difícil a gente mudar a mentalidade de algumas pessoas em relação a se comprometer com a própria saúde [...] eles se comprometem com o cartão, com cesta básica, com Bolsa Família”.

T11: Afirma-se que "o Brasil tem uma cultura muito curativa e não preventiva... não adianta só forçar mesmo essas questões de hospitais de ponta, tecnologia... a gente não tem uma boa estrutura de base... se o problema de base, relacionado à prevenção, à promoção de saúde fosse resolvido, se as unidades tivessem o tempo necessário para resolver, para planejar, implantar e implementar essas ações", isso tudo melhoria a situação atual da tuberculose.

T12: Profissional afirma: “... teve uma ascensão de poder aquisitivo das pessoas, mas elas só pensam de suprir necessidades de conquistas materiais... mas a saúde não é cuidada... o próprio cidadão chega... só querendo a troca da receita, querendo resolver o problema, mas a gente tenta fazer ações educativas, não tem aderência e eles acham que não tem necessidade". 


\section{Profissional U}

U1: Considera-se que o incentivo, a cesta básica... "ajuda muito no tratamento porque a pessoas sabe que ela só vai receber a cesta básica se ela fizer o tratamento muito regular... são pacientes com baixa renda..., com uma vulnerabilidade social maior".

U2: Considera-se que o incentivo é desnecessário para os pacientes que apresentam melhor poder aquisitivo ou quando possui "um certo nível de conhecimento ... ele não aceita a cesta básica como um incentivo para o tratamento ... fala que é autossuficiente, que ele sabe tomar a medicação, que ele não precisa disso, é como se fosse uma esmola, o paciente se sente esmolado".

U3: Relata-se o caso de um paciente para o qual, ainda que a UBS insistisse no oferecimento da cesta básica, "não queria receber a cesta básica, não queria fazer o tratamento supervisionado, [...] fez o tratamento pra doar a cesta básica".

U4: Considera-se que a situação da TB poderia ser revertida: 1) por meio da conscientização dos profissionais de saúde: "não são conscientes da importância do papel da atuação deles frente ao paciente com tuberculose"; 2) por meio de divulgação na mídia (em emissora de televisão, na TV minuto do metrô); 3) dispor de política de ação para os usuários de drogas: com locais onde possam tratar-se; 4) informação por meio da TB WEB com acesso para hospitais e UBS (para que a unidade de saúde tenha conhecimento de que o paciente já abandonou o tratamento, por exemplo).

U5: Profissional de saúde afirma ter questionado responsável pelo Programa de Controle da Tuberculose sobre a divulgação da doença no metrô, e que recebeu como resposta “... nós íamos ter um bum muito grande de sintomáticos respiratórios e nós não vamos ter laboratórios preparados com capacidade pra atender esta demanda". 


\section{Profissional V}

V1: Considera-se que a cesta básica, em conjunto com o TDO, foi significativa em caso de paciente que apresenta situação socioeconômica difícil “... quanto mais carente esse paciente for, realmente, a cesta básica faz um diferencial muito grande, porque ele vira como um meio de sustento pra essa família...".

V2: Considera-se que, em caso de pacientes "difíceis", alcoolistas, e em casos de pacientes que tem "melhor situação", o incentivo não apresenta impacto.

O Programa de Controle da TB “... não diferencia se o paciente tem condições sociais ou não”.

V5: Considera-se que a situação da TB poderia ser revertida: 1) por meio do comprometimento “... das políticas que são elaboradas de cima pra baixo, mas, também, do movimento da cadeia daqueles que estão na ponta [...], fazer com que o funcionário compreenda o papel dele na sociedade... como um agente transformador", com responsabilização do trabalhador de saúde para o cumprimento das ações do Programa; 2) busca ativa como uma ação constante e não esporádica; 3) visão mais ampla da saúde pública... "mudar a mentalidade dos profissionais... mudar a cultura brasileira... procuramos saúde quando estamos doente, nós não procuramos saúde pra prevenção", com mudança do modelo de atenção do curativo para a prevenção; 4) fixação de médicos na rede de unidades básicas de saúde, com bons salários.

V6: Profissional afirma: “... estamos vivendo um momento de transferência da responsabilidade... existe aquela responsabilidade do governo", mas o profissional de saúde "não tem responsabilidade, ele cumpre metas... é da responsabilidade do profissional que tem que ter essa visão ampla do que é saúde pública".

V7: Profissional afirma: “... recebemos muitos mais médicos recém-formados”. Porém, não há “comprometimento porque não há realmente uma política capaz de fixar esses médicos com bons salários... todos querem uma especialização em áreas que dão lucro..., precisa desmistificar essa parte".

V8: Profissional afirma: “... o Brasil tá numa fase de mudanças, você não realmente espera que mude em dois, três dias. É um trabalho de formiga, você tem muitas pessoas comprometidas". 


\section{Profissional W}

W1: Considera-se que em caso de condição socioeconômica precária, o recurso financeiro para que o paciente realizasse o raio $\mathrm{X}$ em outro local foi importante para a cura da doença.

W2: Considera-se que, em caso de paciente com condição socioeconômica, que tem disponibilidade para realizar exame e comparecer à Unidade de Saúde, não acamado, que não tem comorbidade, o incentivo não é significativo para a cura da doença.

W3: Considera-se que a situação da TB poderia ser revertida: 1) por meio da continuidade da busca ativa; 2) de recursos econômicos; 3) serviço de referência para o encaminhamento de pacientes com TB resistente e extrapulmonar, pois “... a gente tem um pouco mais de dificuldade no manejo dos casos". 


\section{Profissional X}

X1: Considera-se que a cesta básica é significativa para a cura da doença, em situação de vulnerabilidade social, em áreas de invasão: “... a cesta básica é uma coisa bem legal de troca, é uma coisa que ajuda bastante".

X2: Considera-se que o incentivo não é significativo em caso de pacientes que apresentam melhor condição socioeconômica, mas sim o vínculo estabelecido, que é fortalecido pela necessidade de comparecimento à UBS para o TDO.

X3: Afirma-se que o “... vínculo, de você entregar todo dia o medicamento pra ele... e mostrando a importância do tratamento... é diferente você entregar uma vez por mês,... você acaba nem conhecendo o paciente da área".

X4: Considera-se que a Estratégia de Saúde da Família possibilita “... ir na casa do paciente... conhecer a família dele, ..., explicar pra família porque que é tuberculose, a importância que ele faça o tratamento... conhecer a família... filho, filha, outros parentes envolvidos... acaba-se tendo uma rede familiar que ajuda no tratamento".

X5: Considera-se que a situação da TB pode ser revertida: 1) por meio da busca ativa; 2) monitorar os pacientes e prestar contas sobre os tratamentos realizados; 3) dar continuidade à divulgação da doença.

X6: Considera-se que imigrantes apresentam situação especial: “... haitianos... ficavam por um período de tempo, de repente já mudavam... mesmo que você ofereça todas as coisas, eles se sentem ainda meio vulneráveis..., eles não aderem totalmente..., se eles veem que aconteceu alguma coisa diferente, eles acabam fugindo". 


\section{Profissional Y}

Y1: Considera-se que, em caso de "situação precária, com um grande risco de vulnerabilidade", a cesta básica ajuda na adesão ao tratamento.

Y2: Pondera-se que em caso de multirresistência, usuário e tráfico de droga, mesmo que seja oferecida cesta básica e vale-transporte, a adesão não ocorre.

Y3: Considera-se que a situação da TB pode ser revertida: 1) aumentar o tempo para o atendimento do paciente “... 15 minutos é impossível... para todos os pacientes... você pode tá atendendo um paciente diabético, hipertenso e ele ser um paciente com tuberculose e você talvez não consiga na consulta identificar porque o tempo é curto, você têm vários papeis administrativos que você tem que preencher durante a consulta, eles cobram uma evolução enorme, então você tem que registrar tudo... Seria fundamental pra gente poder fazer uma avaliação clínica melhor do paciente pra poder identificar o paciente sintomático respiratório"; 2) maior motivação dos profissionais para lembrem da TB durante os atendimentos. 


\section{Profissional Z}

Z1: Considera-se que a cesta básica é significativa em caso de situação precária: “... não era só uma pessoa que vivia nessa casa e eles não tinha renda... não tinha benefício nenhum... foi uma adesão muito grande porque ela sabia que podia contar com essa cesta básica,... que podia contar com esse benefício".

Z2: Aponta-se que o incentivo, além do envolvimento da equipe do NASF e da SUVIS, são importantes para a adesão do paciente em casos em que a situação da família é complexa.

Z3: Considera-se que a cesta básica não apresenta impacto em paciente que apresenta envolvimento com tráfico de drogas, e em que a dinâmica familiar é complexa: “... a mãe... era muito relapsa”.

Z4: Considera-se que a situação da TB pode ser revertida: 1) com o envolvimento e comprometimento das equipes: “... entender que a tuberculose é uma saúde coletiva e que nós precisamos fazer um belo trabalho"; envolvimento da comunidade e do Conselho Gestor; 2) rastreamento por equipes e estabelecimento de metas em relação ao número de baciloscopias a serem realizadas; 3) maior proximidade da SUVIS com as UBS, realizando visitas conjuntas nos domicílios dos pacientes; 4) divulgação permanente na mídia.

Z5: Admite-se que "o município, já faz esse trabalho" de busca ativa. Mas, acredita-se que "a SUVIS poderia tá um pouco mais próxima [...] porque a gente tá na ponta, a gente conhece a realidade". Porém, relata-se que "quando precisou dela, ela esteve presente".

Z6: Acredita-se que "a mídia deveria divulgar mais" a tuberculose "porque existe preconceito até hoje... um trabalho de sensibilização [...], não ficar só focando quando tem aquela semana de intensificação, de conscientização, [...] mas que tivesse outros momentos pra gente trabalhar melhor". 